ORNL/TM-2007/044

\title{
ANNUAL TECHNICAL PROGRESS REPORT OF RADIOISOTOPE POWER SYSTEM MATERIALS PRODUCTION AND TECHNOLOGY PROGRAM TASKS FOR OCTOBER 1, 2005 THROUGH SEPTEMBER 30, 2006
}

Prepared for Department of Energy Office of Space and Defense Power Systems Under Budget and Reporting Classification

AF 011010 00, 40041300 , 40041400 , and 400403305

by

Radioisotope Power System Program Materials Science and Technology Division Oak Ridge National Laboratory

Oak Ridge National Laboratory

Oak Ridge, Tennessee 37831-6080

Operated by UT-Battelle, LLC for the

U. S. Department of Energy

Contract DE-AC05-00OR22725 


\section{CONTENTS}

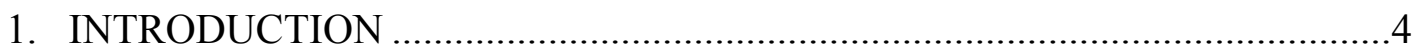

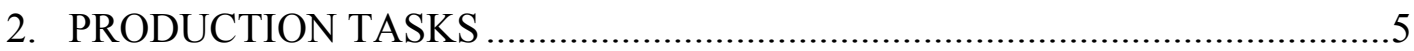

2.1 CARBON-BONDED CARBON FIBER ……………………………......

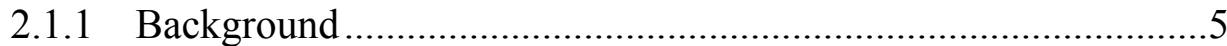

2.1.2 CBCF Production in Fiscal Year 2006 ........................................

2.1.3 CBCF Shipments in Fiscal Year 2006 ..........................................5

2.1.4 Fine Weave Pierced Fabric ...........................................................

2.2 IRIDIUM ALLOY BLANK AND FOIL PRODUCTION …………............

2.2.1 Iridium Powder Procurement......................................................

2.2.2 Blank Production .......................................................................

2.2.2.1 Blank Production from K2 Ingot .....................................

2.2.2.2 Blank Production from GR9 Ingot.....................................

2.2.2.3 Blank Production from K3 Ingot .......................................

2.2.2.4 Blank Production from KR4 Ingot.....................................

2.2.2.5 Blank Production from L1 Ingot........................................

2.2.3 Iridium Alloy Foil Production .....................................................

2.2.4 Iridium Frit Vent Powder...........................................................

2.2.5 Transfers to CVS Task................................................................

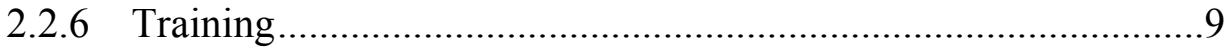

2.2.7 Processing Equipment...........................................................9

2.2.7.1 Qualification of Vacuum Annealing Furnace for Iridium Alloy Production Use.........................................9

2.2.7.1.1 Procedure ...........................................................

2.2.7.1.2 Results and Discussion ......................................10

2.2.7.1.3 Conclusions of Vacuum Annealing Furnace Qualification ..................................................16

2.2.7.2 Installation and Start-Up of 4Hi/2Hi Rolling Mill..........16

2.2.7.3 Control System Upgrades for Vacuum Arc Remelting Furnace and Electron Beam Melting Furnace .................22

2.2.8 Processing of Iridium Scrap Materials.........................................23

2.2.9 Analysis for Iridium Alloy Blank and Foil Production ...............23

2.2.9.1 Introduction.................................................................23

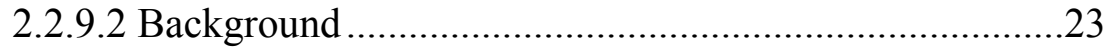

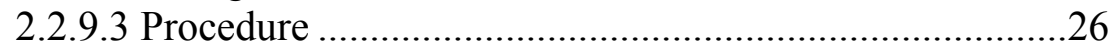

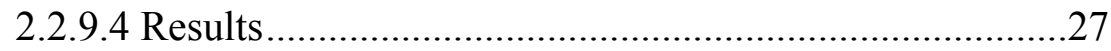

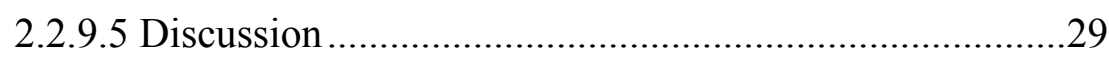

2.2.9.6 Summary - Purification of Iridium Powder Compacts During Electron Beam Melting........................................32

2.2.9.7 Conclusions.....................................................................

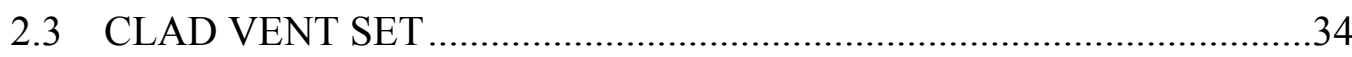

2.3.1 Maintenance Production Summary ................................................34

2.3.2 Nonconformance Report, Deviation Requests, and Special Instruction Deviation Request Summaries......................34

2.3.3 Frit Vent Backing Disc and Frit Vent Cover Disc Piercing Tooling .......................................................................................

2.3.4 Decontamination Cover Blanking Tooling..................................34 
2.3.5 Weld Shield Butt Weld Tooling ...............................................35

2.3.6 Cup Second-Form Die Evaluation ...........................................35

2.3.7 Carbon and Oxygen Back-up Analytical Qualifications .............36

2.3.8 Frit Vent Powder Evaluation .......................................................36

2.4 IRIDIUM POWDER AND INVENTORY MANAGEMENT .................40

2.4.1 Iridium Demand and Supply Schedule ....................................40

2.4.2 Annual Write-Off................................................................41

2.4.3 Iridium Accountability Reviews .............................................41

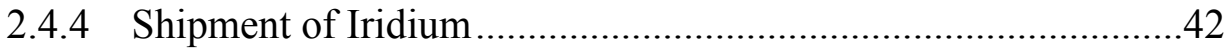

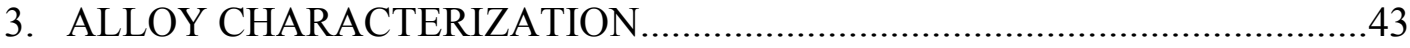

3.1 TENSILE BEHAVIOR OF Ta-10W ..................................................43

3.1.2 "Low Temperature" Tensile Impact Ductility of DOP-26 Iridium ...................................................................43

3.1.3 Effects of Grain Size and Strain Rate on Strength and Ductility of DOP-26 Iridium ............................................43

3.1.4 Effects of Copper on the Tensile Impact Ductility

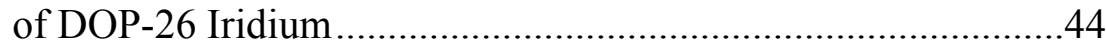

3.1.5 Effects of Oxygen on the Elevated Temperature Tensile Ductility of Ta-10W .................................................................44

3.2 ORNL CHARACTERIZATION OF MIN-K TE-1400 .........................45

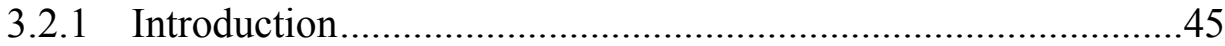

3.2.2 Experimental Procedures .......................................................46

3.2.3 Results.........................................................................47

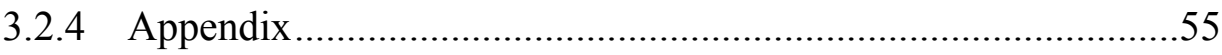




\subsection{INTRODUCTION}

The Office of Space and Defense Power Systems of the Department of Energy (DOE) provides Radioisotope Power Systems (RPS) for applications where conventional power systems are not feasible. For example, radioisotope thermoelectric generators were supplied by the DOE to the National Aeronautics and Space Administration for deep space missions including the Cassini Mission launched in October of 1997 to study the planet Saturn. For the Cassini Mission, ORNL produced carbon-bonded carbon fiber (CBCF) insulator sets, iridium alloy blanks and foil, and clad vent sets (CVS) used in the generators. The Oak Ridge National Laboratory (ORNL) has been involved in developing materials and technology and producing components for the DOE for more than three decades.

This report reflects program guidance from the Office of Space and Defense Power Systems for fiscal year (FY) 2006. Production activities for prime quality (prime) CBCF insulator sets, iridium alloy blanks and foil, and CVS are summarized in this report. Technology activities are also reported that were conducted to improve the manufacturing processes, characterize materials, or to develop information for new radioisotope power systems. 


\subsection{PRODUCTION TASKS}

\subsection{CARBON-BONDED CARBON FIBER}

\subsubsection{Background}

The Carbon Bonded Carbon Fiber (CBCF) production facilities have been operated in a production maintenance mode since the Cassini campaign to produce prime quality insulators. Dedicated facilities for CBCF production remain in the Carbon Materials Technology Laboratory at ORNL. During much of the 1990s CBCF production was directed at making experimental variations of $\mathrm{CBCF}$ that explored the potential for improved insulating attributes at very high temperatures. The effect of brief excursions to reentry temperatures was also explored. Sleeves produced in FY 2000 were the first to be fully characterized as prime in nearly a decade. Resolution of issues related to elevated impurities in CBCF allowed for the continued production of Prime Quality insulators in FY 2003. Prime quality insulator production has continued since that time.

\subsubsection{CBCF Production in Fiscal Year 2006}

More than twenty-four additional prime CBCF insulation sets were produced in FY 2006 to support the MMRTG Program. Numerous Quality Assurance Surveillances were conducted at ORNL including: Instrument Calibration, Inspection of Insulators, Machining of Insulators and Personnel Training. Procedure MET-CER-SOP-37 was revised to better reflect current machining practices. $\mathrm{CBCF}$ Sleeve and Disc Insulator Drawings, as well as Qualification Sampling Diagrams were updated to modern conventions. A Quality Surveillance was also conducted at the Y12 Analytical Chemistry Organization of procedures, instrumentation and personnel involved with chemical analysis of CBCF including: Ash Analysis, Sulfur Analysis and Spark Source Mass Spectroscopy (SSMS) for impurities. Revision of the SSMS procedure was initiated to incorporate the use of new standard reference materials.

Renovation of the CBCF production laboratory was completed. Walls were repaired and painted. Ceiling and floor tile were replaced. New lab furnishings were installed including three new hoods that meet higher standards for ventilating the work area. The more flexible work space could better support future carbon materials work.

\subsubsection{CBCF Shipments in Fiscal Year 2006}

Six Engineering Use Only (EUO) CBCF Sleeves and twelve EUO CBCF Discs were shipped to Idaho National Laboratory (INL) in June to support training for the Multi Mission Radioisotope Thermoelectric Generator (MMRTG) Program. Seventeen Prime Quality CBCF Sleeves and forty-four Prime Quality CBCF Discs were shipped to INL in September for the MMRTG program.

\subsubsection{Fine Weave Pierced Fabric}

A letter report entitled "Securing Long Term Availability of Fine Weave Pierced Fabric (FWPF) was issued. Textron Systems (Wilmington, MA) is producing a reestablished FWPF material to support near-term missions. Although the production of FWPF has been discontinued since 1992, Textron has retained critical elements of the production capability as well as key personnel. Hexcel is producing HMU carbon fiber in their pilot facility using the original fiber precursors to support the restart of FWPF production. The $15 \mathrm{~V}$ coal tar pitch used to densify FWPF billets is still commercially available. Textron's approach to FWPF production makes extensive use of 
outside vendors. Preform production is carried out at Textron and requires significant manual assembly. All other steps are outsourced. This brief report identifies the primary vendors, raw materials and key operations that are required for the production of FWPF. A preliminary assessment was made of the long term availability of key elements of production. It was concluded that the majority of the vendors critical to the production of FWPF are secure for the long term. Two key vulnerabilities include the continued availability of HMU fiber through Hexcel and the continued commitment of Textron to fabricate FWPF preforms and execute overall production management.

Carbon Fiber: Securing the long term availability and affordability of FWPF will require qualifying an alternative, commercially available carbon fiber. Two approaches can be followed to identify a suitable replacement for HMU fiber. The first option is to select a commercially available, polyacrylonitrile (PAN) fiber with a modulus and strength comparable to HMU. Torayca M40 carbon fiber is nearly a perfect match with respect to properties. A comparison of properties is given in Table 1 . The principal vulnerability here is that a low market demand for a specialty fiber could result in supply vulnerability similar to the experience with HMU fiber. A domestic supplier of an HMU equivalent fiber would be desirable for program flexibility. Other issues including fiber twist and surface treatments must be addressed. The suitability of a replacement fiber for producing 8 Harness Satin Weave Fabric should be demonstrated. A second option would be to select a high-volume production PAN fiber, such as T300, and convert it to a high-modulus fiber by an additional high temperature heat treatment. The tensile modulus of carbon fiber increases with final heat treatment temperature.

Table 1. Candidate PAN Carbon Fibers for FWPF

\begin{tabular}{|c|c|c|}
\hline Carbon Fiber & $\begin{array}{c}\text { Tensile Modulus } \\
\text { (GPa) }\end{array}$ & $\begin{array}{c}\text { Tensile Strength } \\
\text { (GPa) }\end{array}$ \\
\hline Hexcel HMU & 379 & 2.76 \\
\hline Torayca M40 & 393 & 2.74 \\
\hline Torayca T300 & 230 & 3.53 \\
\hline Cytek T300 & 231 & 3.65 \\
\hline
\end{tabular}




\subsection{IRIDIUM ALLOY BLANK AND FOIL PRODUCTION}

The goals for this activity are to produce flight-quality blanks and foil under full configuration control, maintain production capability and to supply materials needed for clad vent set demonstration and maintenance activities. During FY 2006 a total of 110 blanks from ingot K2 ingot and 44 blanks from GR9 ingot were boxed and placed in secure storage with approved data packages. A total of $72 \mathrm{~kg}$ of iridium in scrap was shipped for refining to powder. A vacuumannealing furnace was qualified for iridium processing. A new $4 \mathrm{Hi} / 2 \mathrm{Hi}$ rolling mill was installed to replace to obsolete rolling mills. A purchase order was issued for an upgraded control system for the vacuum arc remelting (VAR) furnace and electron beam (EB) melting furnaces.

\subsubsection{Iridium Powder Procurement}

Shipment of iridium scrap for refining was completed. It is anticipated that about $72 \mathrm{~kg}$ of iridium powder will be available by January 2007. The refining cost is paid from the DOE pool account for precious metals. The current market value of the refined iridium to be returned is about $\$ 925,000$.

\subsubsection{Blank Production}

\subsubsection{Blank Production from K2 Ingot}

Ultrasonic inspection of the 111 blanks produced in FY 2005 showed all but one passing this inspection. All blanks also passed dye penetrant inspection. Metallography and chemical analysis of samples from K2 ingot were also completed in 2005. A large majority of the blanks showed indications of inclusions on the surface during visual inspection. These blanks were reworked by sanding, reinspected, and all were found acceptable. All 110 blanks were stored with an approved data package. (72 blanks were stored on November 23, 2005 and 38 blanks on January 30,2006 .)

Later investigation attributed the very large number of blanks with surface inclusions to inadequate cleanliness of the Teflon fixtures used for acid cleaning. The fixtures were all thoroughly cleaned and eventually were all replaced with new fixtures.

\subsubsection{Blank Production from GR9 Ingot}

A total of 114 blanks were electrodischarge machined (EDM) from ingot GR9 and ground. Four blanks failed dimensional inspection. The dimensional nonconformances (NCR-IrB\&F-2162) were attributed to buildup of corrosion products under the grinding fixture. The fixture was reworked and the performance verified by grinding of nine iridium scrap blanks. The 110 remaining blanks were cleaned and sampled. Chemical and metallographic analysis and hardness testing of samples was successfully completed. Ultrasonic inspection of the blanks was completed with 107 blanks passing the inspection and three blanks failing (NCR-IrB\&F-2163, 4). All blanks passed dye penetrant inspection. A total of 69 blanks passed visual inspection. An additional 38 blanks showed indications of inclusions during visual inspection. These blanks were reworked by sanding and reinspected. All of these blanks subsequently passed visual inspection.

Data packages were prepared for 44 FQ blanks from ingot GR9 sheets 1 through 12 . These blanks with approved data packages were boxed and placed in secure storage on April 13, 2006. The remaining 63 blanks are stored but data packages for these have not yet been prepared. 


\subsubsection{Blank Production from K3 Ingot}

Rolling of 17 sheets from ingot K3 was completed. A traveler document was issued for processing of one of the sheets, K3-14, into rectangular blanks, from which tensile specimens were machined. A total of 5 rectangular blanks were machined by wire EDM, ground, cleaned, heat treated, and sampled. Samples were submitted for chemical and metallographic analysis. All chemical and metallographic analyses were successfully completed. Four of the blanks showed small regions which failed to clean up during grinding or which had thickness outside the range of specified values. Theses regions were marked to assist in layout for later machining of tensile specimens. Ultrasonic inspection of rectangular blanks from sheet K3-14 was completed. No indications of internal defects were found on any of the five blanks. Dye penetrant inspection was performed on 5 rectangular blanks from sheet K3-14. No indications of defects were found. A data package was prepared and was approved by the QA representative. The 5 rectangular blanks were transferred to the materials testing task with the approved data package on August 3.

\subsubsection{Blank Production from KR4 Ingot}

A traveler document was initiated for recycle ingot KR4. The melt stock consists of $13.8 \mathrm{~kg}$ of recycle material from ingots $\mathrm{K} 1$ and $\mathrm{K} 2$. The recycled materials from ingots $\mathrm{K} 1$ and $\mathrm{K} 2$ were cleaned. Melting and drop casting of electrode segments for the KR4 electrode was completed. Electron-beam welding of the segments was also completed. Melting of the electrode by VAR is planned for early in FY2007.

\subsubsection{Blank Production from L1 Ingot}

Powder processing of iridium for the L-batch was begun in FY 2005 and continued in FY 2006. Powder blending of $18 \mathrm{~kg}$ of iridium powder for L1 ingot was completed. This powder was then compacted, sintered and outgassed. The compacts were then electron beam melted. This was completed for about $3 \mathrm{~kg}$ of the powder. The EB-melted buttons were melted with aluminum and thorium master alloy to produce the DOP-26 alloy. The melted alloy was drop-cast to produce segments for the L1 electrode. The electrode segments were EB-welded to produce the L1 electrode. The electrode was successfully vacuum arc remelted to produce the L1 ingot. The ingot was machined and placed in a molybdenum can. The L1 ingot was successfully extruded on June 7, 2006. Blanks from this extrusion will be processed during FY 2007.

\subsubsection{Iridium Alloy Foil Production}

Melting and drop-casting of rectangular ingots for foil production was initiated. The melt stock consists of recycle material from the ER10 ingot and EB-melted buttons remaining from the Kbatch of iridium powder. One drop-casting was completed and another four buttons have been melted. Processing of these materials to foil is scheduled for FY 2007.

\subsubsection{Iridium Frit Vent Powder}

Additional iridium powder was qualified for use in frit vent manufacture. Powder was screened to obtain the $-325 /+400$ mesh fraction. Chemical analysis of two lots of samples from two lots (Lot 12800 jar A and Lot $92-0035$ jar 6) by glow discharge mass spectrographic analysis and by combustion analysis for carbon showed that both lots meet the specification for frit vent powder. Oxygen analysis for "information only" was also completed with normal results. The two jars of iridium powder for frit vent use were transferred to the CVS task with an approved data package. The total of more than 250 grams is sufficient for several hundred clad vent sets. 


\subsubsection{Transfers to CVS Task}

A total of 25 pieces of foil from ingots GFR 245 and GFR 246 were removed from storage and transferred, with an approved data package, to the CVS task on June 28, 2006. This material, weighing 490 grams with an area of 0.19 square meters, is the last of the foil that was in storage. A total of 250 grams of frit vent powder was transferred, with an approved data package, to the CVS task on May 8, 2006.

\subsubsection{Training}

Training of a second machinist in the procedure for electrodischarge machining of iridium alloy blanks was completed. The training included the machining of 24 blanks from iridium alloy scrap sheets. A technician was trained in button arc melting and drop casting of iridium alloys. Another technician was trained in operation of the VAR furnace.

\subsubsection{Processing Equipment}

\subsubsection{Qualification of Vacuum Annealing Furnace for Iridium Alloy Production Use}

During FY 2005, a vacuum annealing furnace manufactured by Brew Division of Thermal Technologies, Inc. was relocated from the Oak Ridge K-25 site to Oak Ridge National Laboratory for use in the Radioisotope Power Systems Program. The furnace was originally purchased in1998 and was used for heat treating a wide variety of materials at the K-25 site. The original hot zone was removed and the interior of the furnace thoroughly cleaned. A new hot zone installed with all components of commercially pure tungsten. The new hot zone consists of tungsten mesh heating elements, tungsten heat shield, tungsten hearth plates, and tungsten rail hearth supports. The hot zone supports constructed of stainless steel were also replaced as were all 7 thermocouples. This following study provides the justification for the qualification of this furnace for vacuum heat treatment of iridium alloy production materials.

\subsection{Procedure}

The production process for iridium alloy production requires vacuum annealing of iridium alloy blanks and foil and also annealing of several intermediate products. The most critical anneals occur on the final blank and foil products. The iridium blanks receive a stress relief anneal at $900^{\circ} \mathrm{C}$. Metallographic examination is performed on samples to meet specification requirements for fibrous condition and microhardness. The foil receives a final recrystallization anneal at $1250^{\circ} \mathrm{C}$. Metallographic examination is performed on samples to meet specification requirements for grain size and fully recrystallized structure. Qualification runs were performed in the furnace using non-prime blank and foil samples at $900^{\circ} \mathrm{C}$ and $1250^{\circ} \mathrm{C}$ respectively. The samples were then analyzed metallographically using the same procedure as for prime materials. In addition the surface cleanliness of the samples was characterized by scanning electron microscopy (SEM) and energy dispersive $\mathrm{x}$-ray analysis (EDX).

Various intermediate products in the iridium alloy production process receive vacuum heat treatment at temperatures in the range of 900 to $1500^{\circ} \mathrm{C}$. The intermediate products do not have requirements for microstructure, grain size, or hardness. The intermediate products are not typically characterized following heat treatment. It is considered adequate for heat treatment of these intermediate products to demonstrate only that the specified temperature and vacuum levels are achieved. This is accomplished by zone calibration of the furnace using calibrated thermocouples and calibration of the furnace chamber vacuum gauge. 


\subsubsection{Results and Discussion}

A zone calibration of the furnace was performed on February 13, 2006. Three of the seven Type $\mathrm{C}$ thermocouples were removed and replaced with calibrated Type $\mathrm{S}$ thermocouples. The calibrated thermocouples were located at positions about $10 \mathrm{~cm}$ above the hearth plates in locations near the center and about $20 \mathrm{~cm}$ from each end of the furnace hot zone. The calibration run consisted of 30 minutes holds at 900,1200 , and $1400^{\circ} \mathrm{C}$. (Type $\mathrm{S}$ thermocouples used for calibration are limited to $1400^{\circ} \mathrm{C}$ maximum temperature.) All calibration thermocouples were within $+/-10^{\circ} \mathrm{C}$ of the furnace set point after 30 minute hold at temperature. This compares with procedural requirements for temperature variation of $+/-25^{\circ} \mathrm{C}$ maximum. Vacuum pressure levels, as measured by a calibrated gauge, were $3 \times 10^{-5}$ torr or less for all calibration and qualification runs as compared to a specified maximum value of $10^{-4}$ torr.

Metallographic and microhardness testing was performed on samples of blank material (from blank RS15-1-2) heated at $900^{\circ} \mathrm{C}$ for 1 hour at three positions in the furnace, identified as front, middle, and rear. All of the samples passed the normal metallographic and microhardness inspection. Average Vickers microhardness (1000 gram load) was in the range of 446 to 458, as compared to the specification of 400 to 550. The samples all exhibited little if any evidence of localized recrystallization and met the specification requirement. A representative micrograph of the stress relieved blank material is shown in Figure 1.

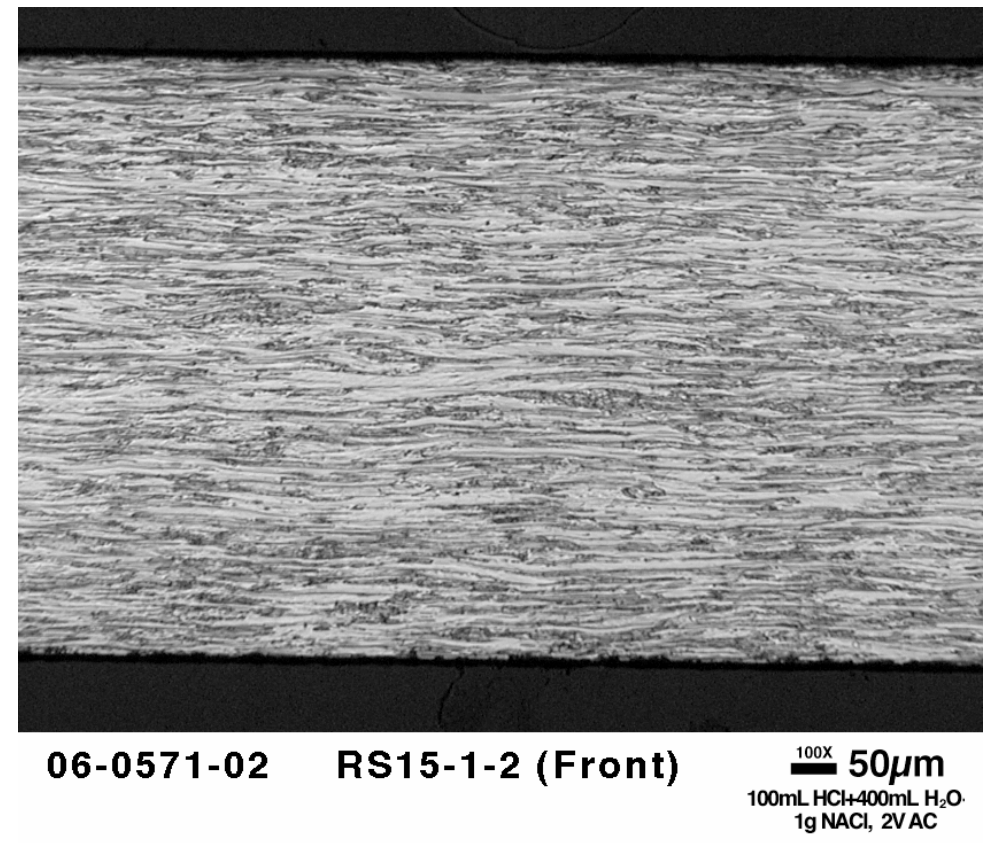

Figure 1. Optical micrograph of blank sample following stress relief heat treatment of 1 hour at $900^{\circ} \mathrm{C}$ meets requirements for fibrous structure with minimal recrystallization.

Metallographic examination was performed on a sample of foil heated at $1250^{\circ} \mathrm{C}$ for 1 hour. The grain size was measured at ASTM \# 7.5 as compared to a specified grain size number of 5 or higher. (The larger grain size number corresponds to a smaller grain size.) The microstructure was fully recrystallized. A representative micrograph of the recrystallized foil is shown in Figure 2. 


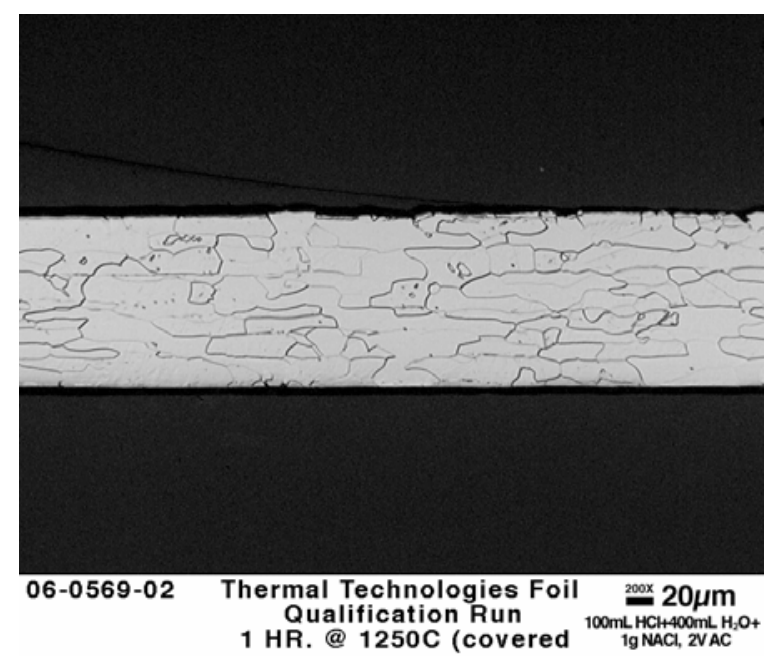

Figure 2. Optical micrograph of foil sample Following Recrystallization heat treat of 1 hour at $1250^{\circ} \mathrm{C}$ meets requirements for grain size and full recrystallization.

The SEM evaluation of the stress relieved blank sample showed a clean surface with no evidence of surface deposits. A representative area at low magnification is shown in Figure 3a. At higher magnification (Figure $3 \mathrm{~b}$ ) both striations from the surface grinding of the blanks and individual grains are visible. In addition a few small localized surface tears are seen associated with grinding striations are visible as dark areas.

Chemical microanalysis by EDX was performed in the dark areas of the surface. The x-ray spectra showed only iridium peaks and a small peak indicating the presence of carbon. There is no indication that the stress relief treatment in the Thermal Technologies furnace added any chemical impurity to the surface of the stress relieved blank. Similar surface characterization was performed on the recrystallized foil sample. A typical area of the as-rolled surface of the foil, following chemical cleaning, is shown in Figure 4. Another area showing surface marks and local tearing is shown in Figure 5. This is likely associated with the use of non-prime foil, which was not rolled under optimal conditions.

During recrystallization of iridium foil in production, the foil pieces are covered with iridium cover foils to minimize surface contamination. The foil used for this furnace qualification study was heated with one portion of the foil covered with clean iridium and another portion of the foil exposed directly to the residual atmosphere of the vacuum furnace. An SEM micrograph typical of the uncovered surface of the recrystallized foil is shown in Figure 6. There surface appears clean, while the grains and grain boundaries are clearly visible. Another region shown if Figure 7 has a distribution of dark areas associated with the grain boundaries visible on the surface. Similar SEM micrographs of the surface of the foil recrystallized under iridium cover materials are shown in Figures 8 and 9. The foil surface with the cover appears qualitatively similar to that without a cover, and possibly shows more prevalent dark areas. It is believed that these dark areas at grain boundaries are small cavities associated with pits or other defects on the rolled surface. During recrystallization these cavities could serve to pin the grain boundaries. Chemical microanalysis by EDX was performed in the dark areas of the foil surfaces. Again, the x-ray spectra showed only iridium peaks and a small peak indicating the presence of carbon. There is no indication that the heat treatment in the Thermal Technologies furnace added any chemical impurity to the surface of the recrystallized foil. 


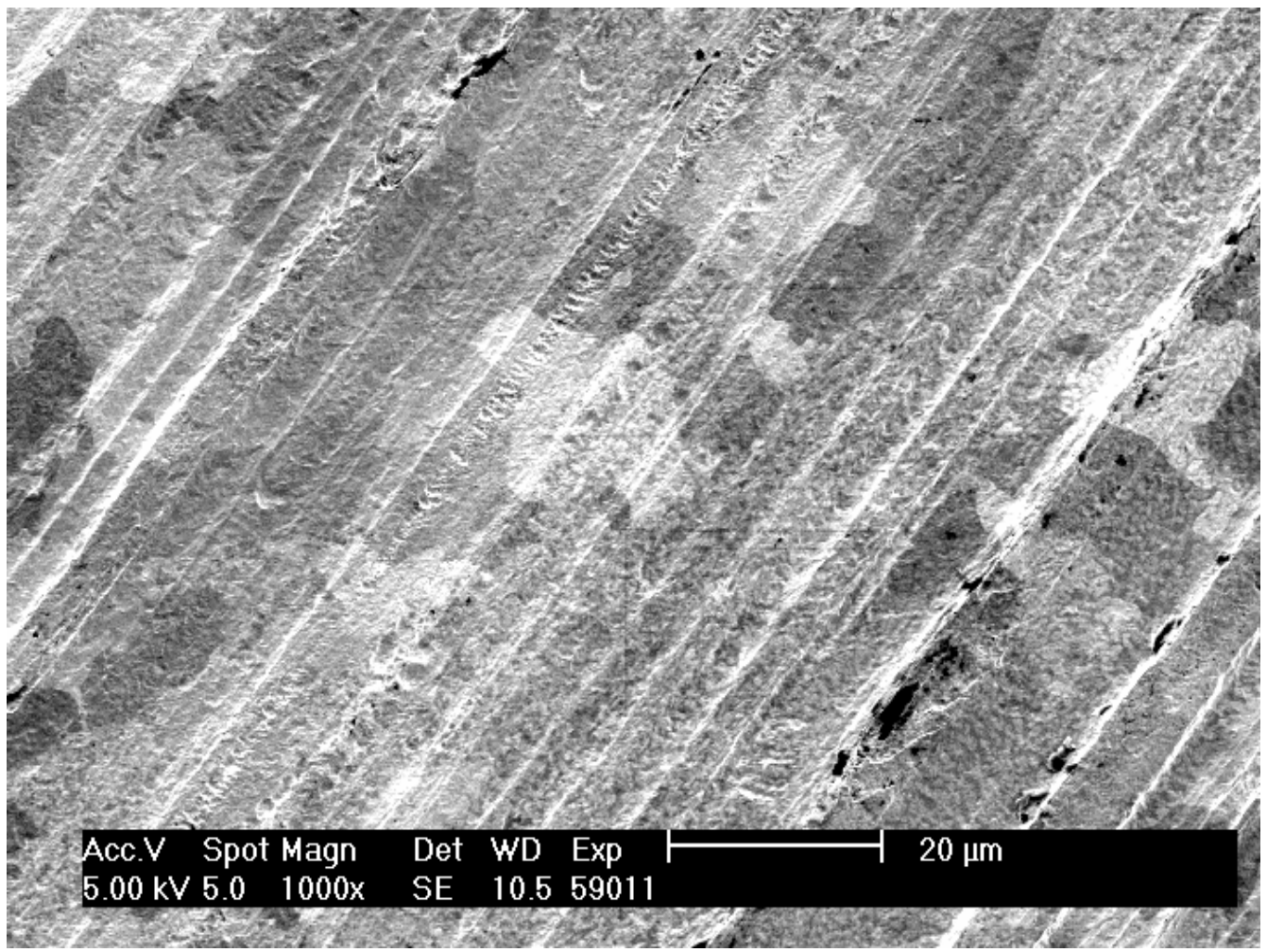

(a)

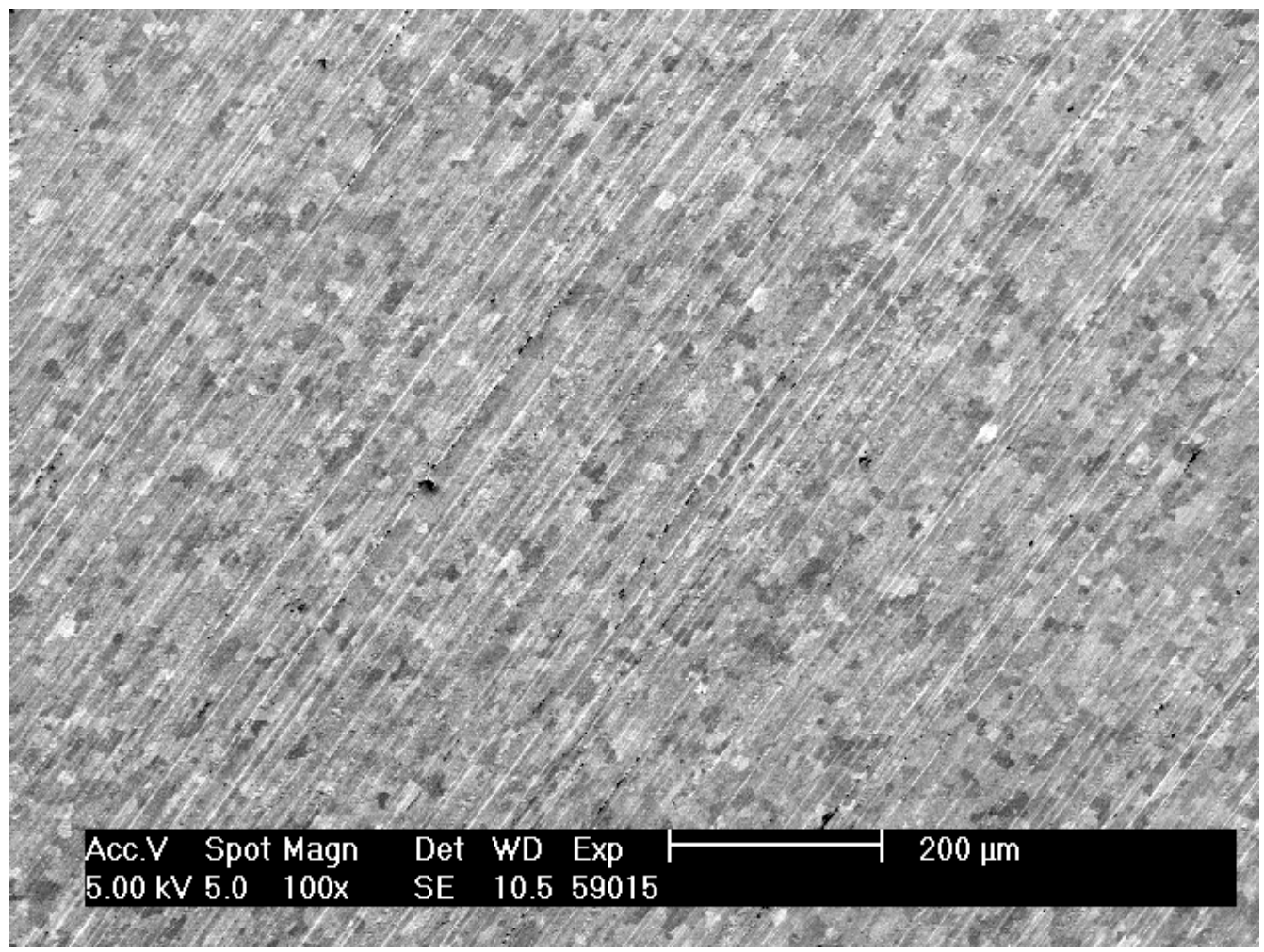

(b)

Figure 3. Secondary electron image of stress relieved iridium alloy blank shows clean surface at low magnification (a) and occasional minor surface tears associated with grinding marks at high magnification, (b). 


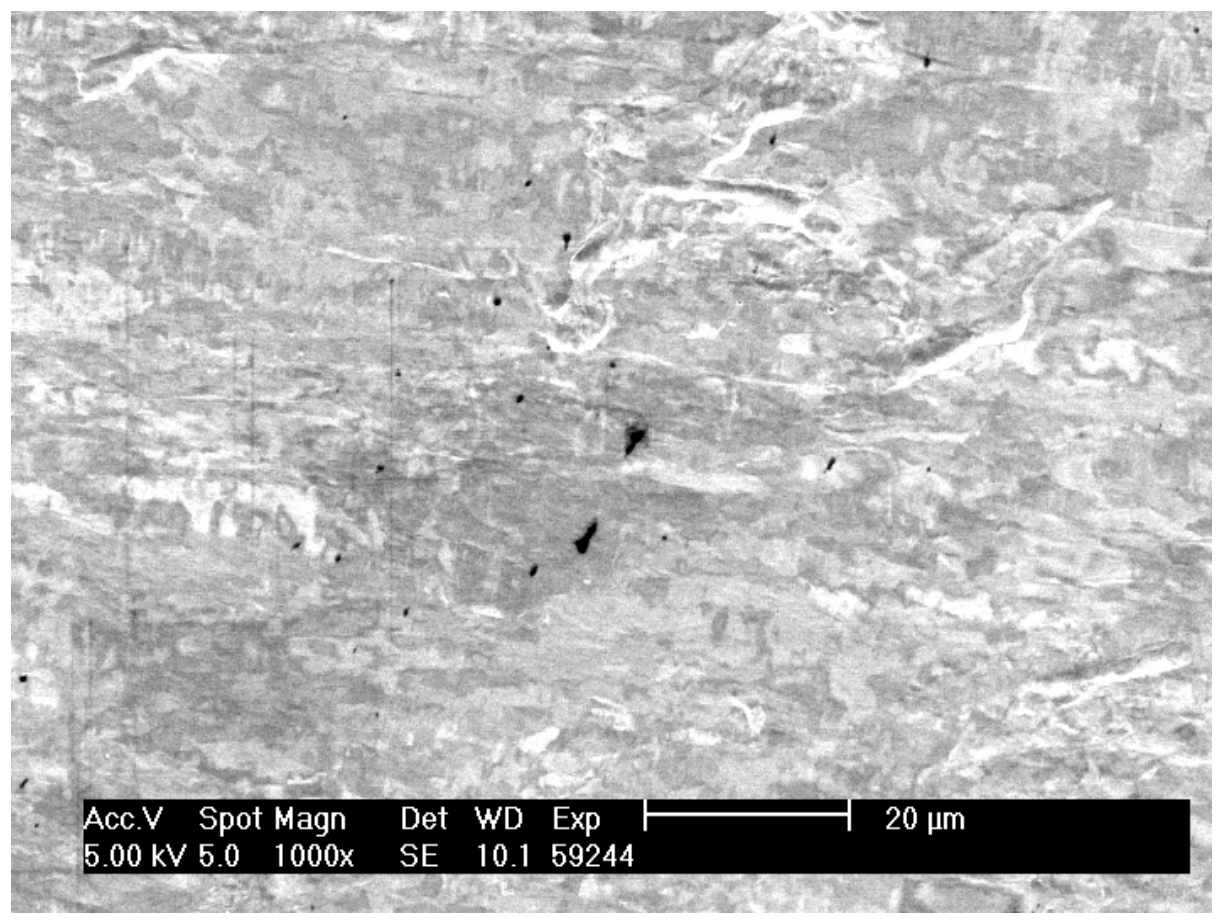

Figure 4. Secondary electron image of as rolled iridium alloy foil.

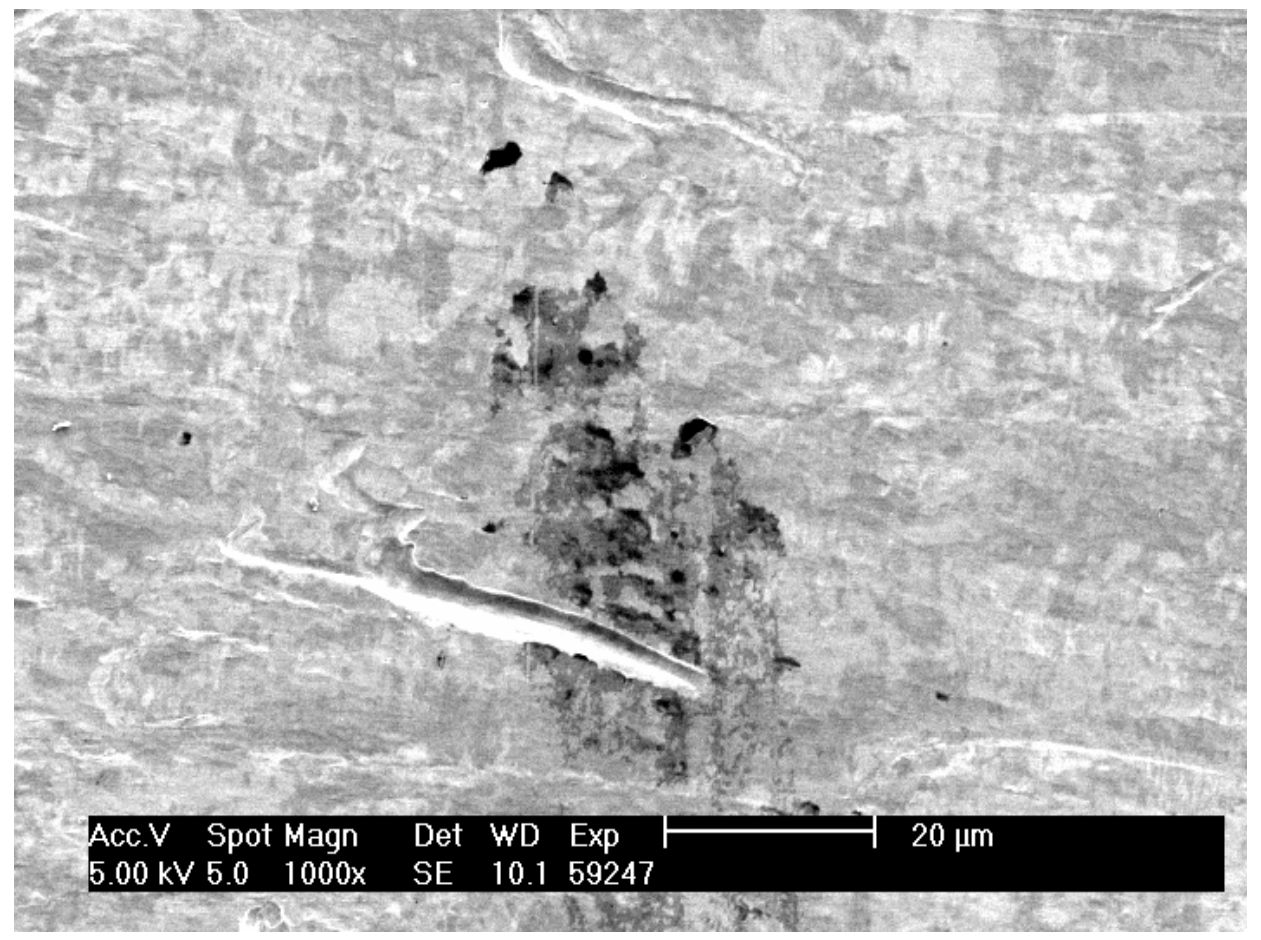

Figure 5. Secondary electron image of as rolled iridium alloy foil (defect region). 


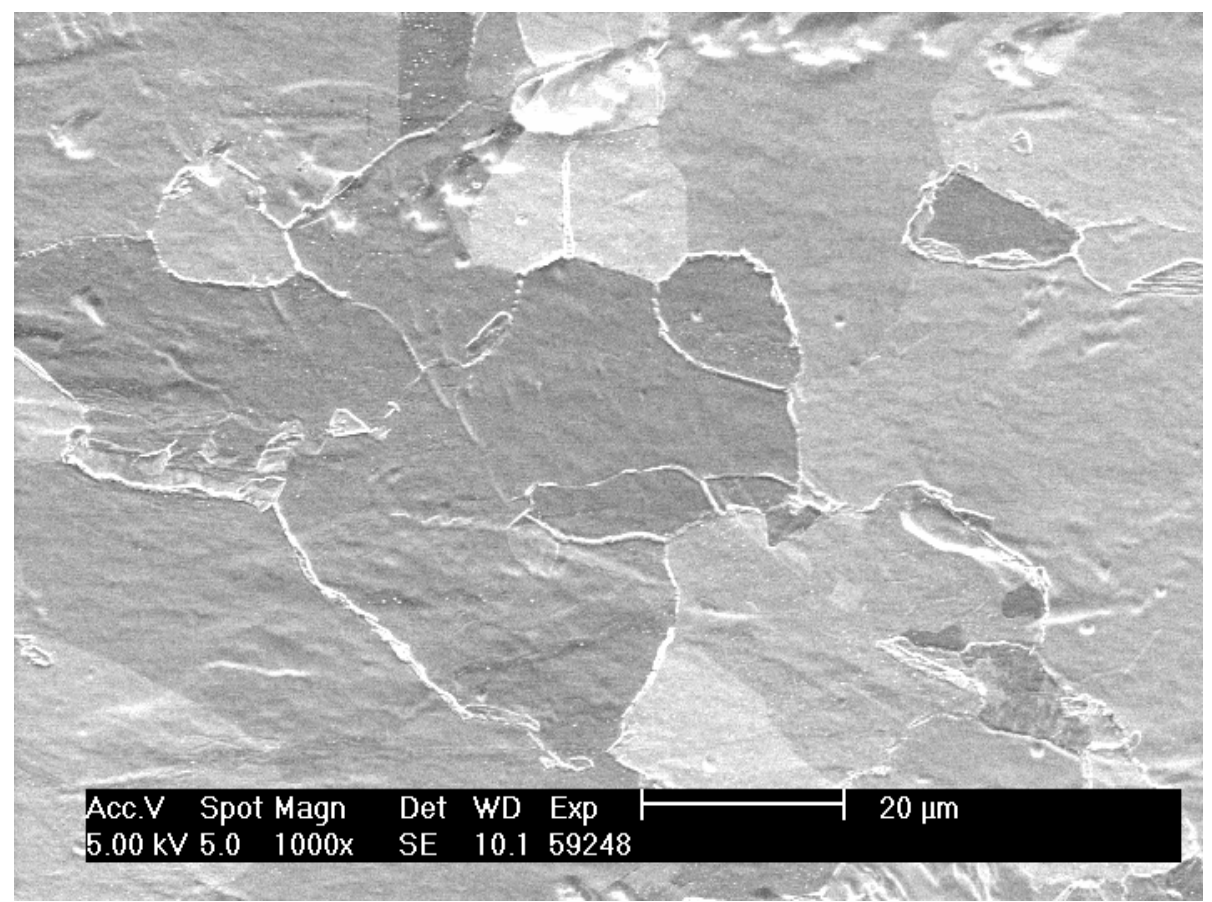

Figure 6. Secondary electron image of recrystallized (uncovered) iridium alloy foil.

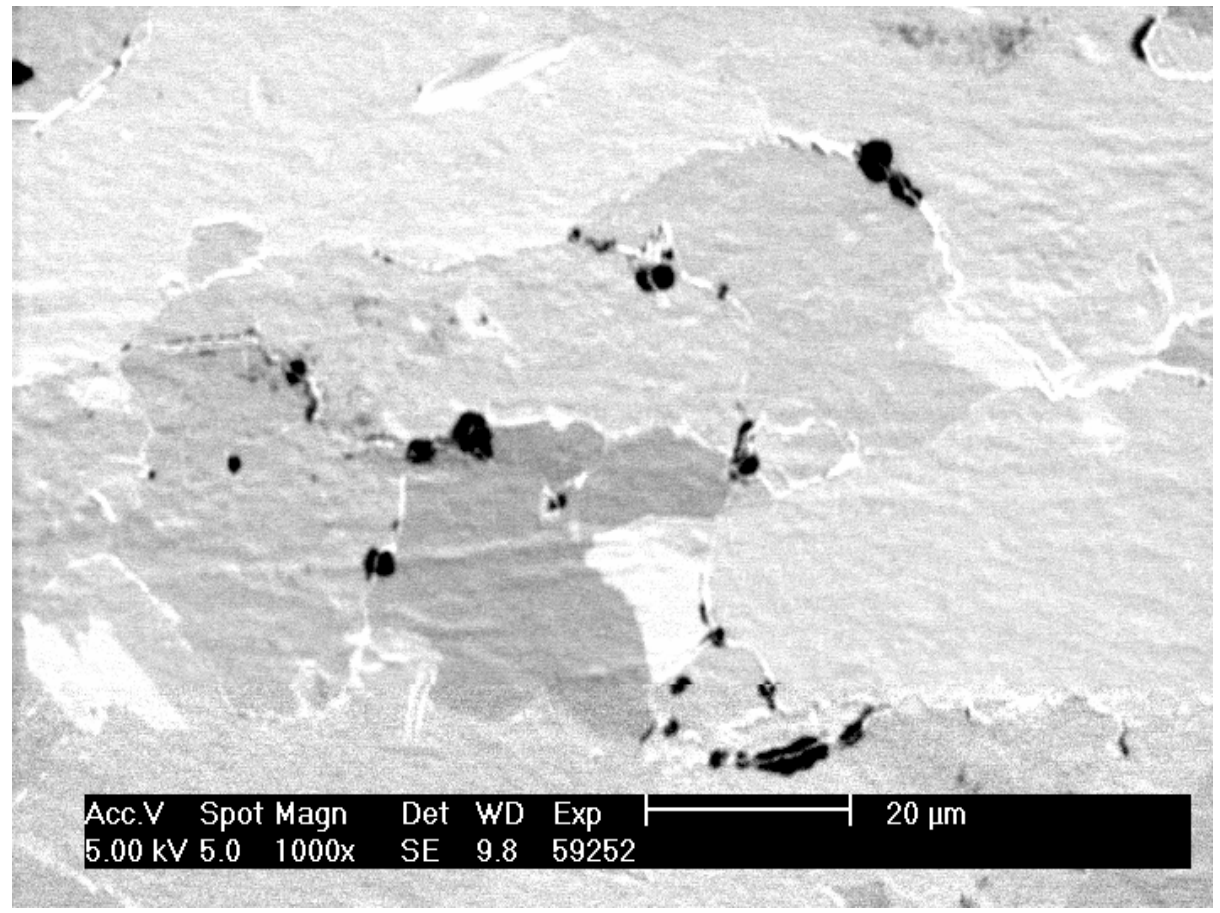

Figure 7. Secondary electron image of recrystallized (covered) iridium alloy foil. 


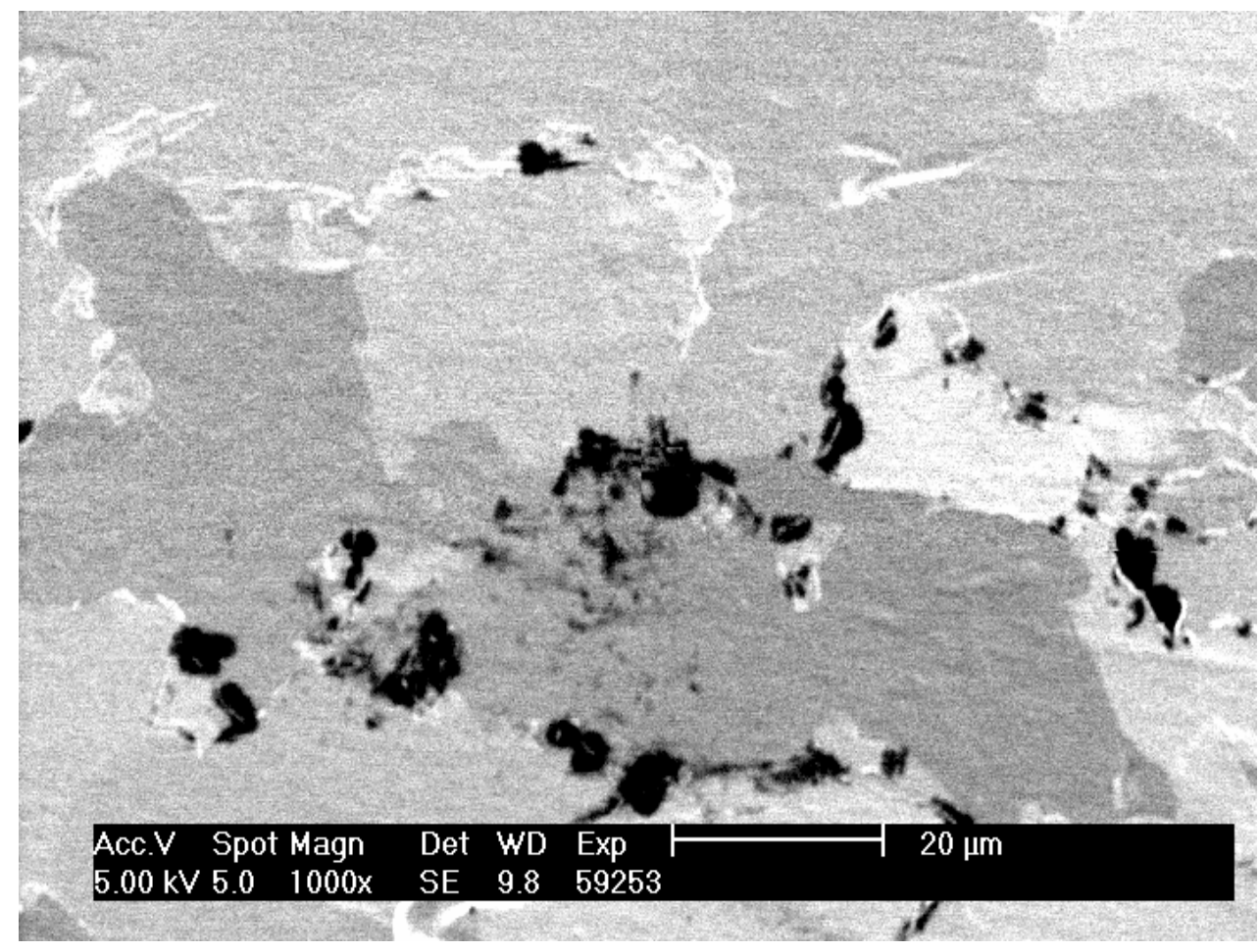

Figure 8. Secondary electron image of recrystallized (covered) iridium alloy foil.

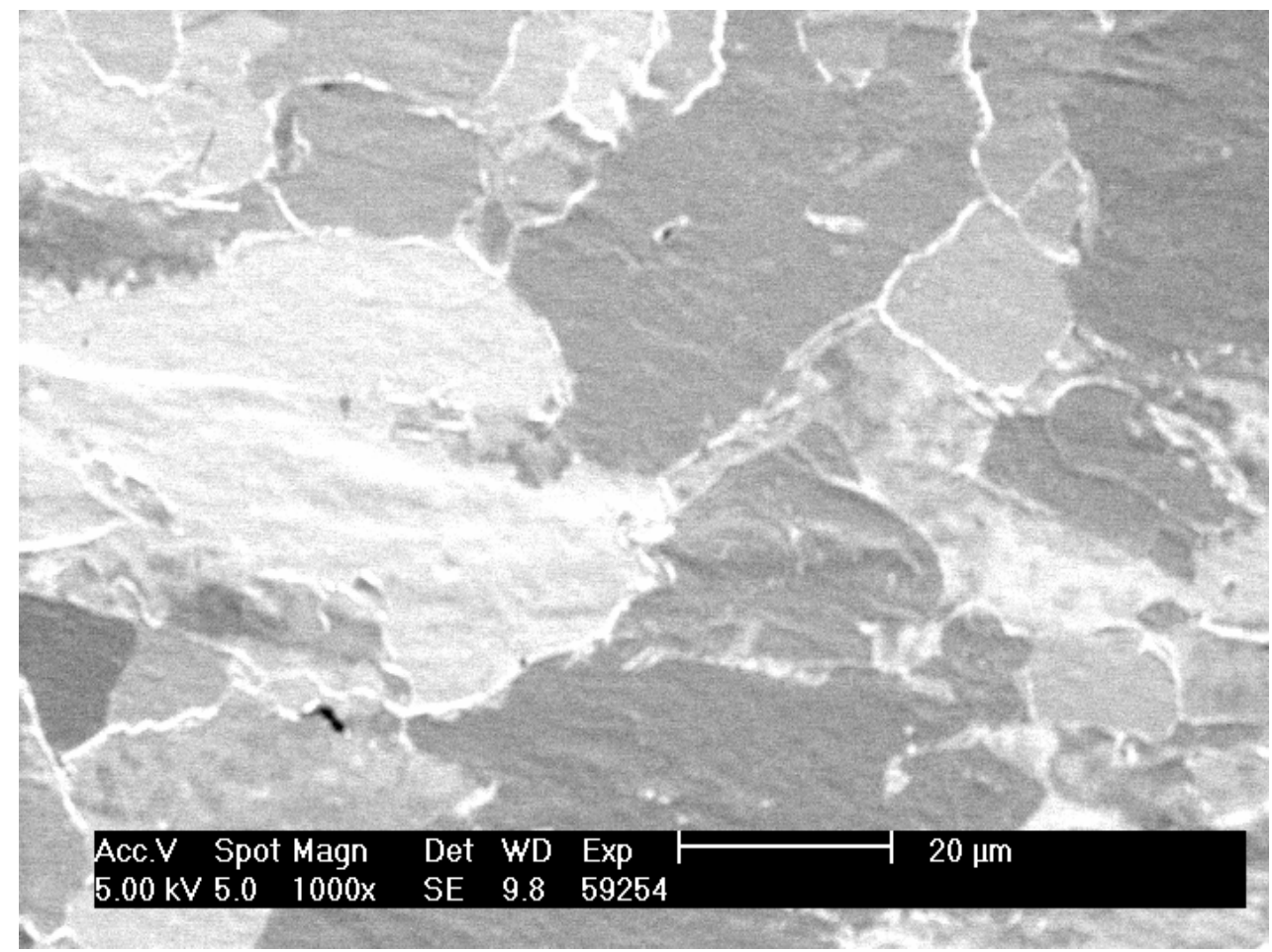

Figure 9. Secondary electron image of recrystallized (covered) iridium alloy foil. 


\subsection{Conclusions of Vacuum Annealing Furnace Qualification}

1. The recently installed vacuum furnace (Thermal Technologies) with a new tungsten hot zone has been calibrated and shows acceptable temperature uniformity and vacuum levels.

2. The furnace has been shown to produce heat treated blank and foil products with the normal microstructures and microhardness and meeting the applicable specification requirements.

3. Examination of the surfaces of heat treated blank and foil products by SEM and EDX shows no evidence of surface contamination from the furnace.

4. The furnace is qualified for heat treatment of iridium alloy blanks and may be designated as such by the task leader in accordance with procedures MET-MatP-SOP-101 and METMatP-SOP-104.

5. A deviation request will be issued to revise procedures MET-MatP-SOP-87 and METMatP-SOP-88 to permit the use of this furnace for heat treatment of foil.

\subsubsection{Installation and Start-Up of $4 \mathrm{Hi} / 2 \mathrm{Hi}$ Rolling Mill}

A purchase order for the $4 \mathrm{Hi} / 2 \mathrm{Hi}$ rolling mill was issued in FY 2005. This mill replaces two rolling mills used for the production of iridium alloy blanks and foil at Oak Ridge National Laboratory. The Bliss 4-Hi mill, purchased as a used mill and installed at Oak Ridge in the 1940's, was used for warm and cold rolling of iridium alloy sheets for blank production and cold rolling of iridium alloy foil. The Mesta 2-Hi mill, was originally sold to the Ford Motor Company in 1919 and moved to the Oak Ridge site in 1943, was used for flattening of iridium alloy sheets and foil. The building housing both of these rolling mills is scheduled for demolition. Due to chemical contamination of the equipment and marginal capability of the equipment for maintaining needed tolerances neither of the two rolling mills used for iridium alloy rolling could be relocated. The mill was designed to use the existing carbide sets of carbide work rolls. One of the two sets of carbide work rolls was shipped to the vendor's facility for use in acceptance testing.

An acceptance test of the $4 \mathrm{Hi} / 2 \mathrm{Hi}$ rolling was conducted at Fenn's manufacturing site in Newington, CT on May 24 and May 25, 2006. The acceptance test was performed in accordance with the requirements of the purchase specification MET-MP-13 rev. 0. Rolling was performed by an ORNL technician trained in rolling of iridium alloy materials under the supervision of Fenn's mill design engineer and the ORNL task leader.

Testing was first performed in the 4-Hi configuration using one set of the carbide work rolls normally used for rolling of iridium materials. The back-up rolls were of cast steel previously used as back-up rolls with old 4-Hi mill at ORNL, which were modified to accommodate the currently available roller bearings. The cast rolls did reveal some minor defect during machining. The specified acceptance testing in the 4-Hi configuration consisted of:

1) Leveling of the rolls and demonstration by rolling of aluminum alloy sheet of approximately $0.75 \mathrm{~mm}(0.030$ inch) thickness in $10 \%$ passes to obtain uniformity of length of equivalent to $0.0075 \mathrm{~mm}$ (0.0003 inch).

2) Demonstration of all controls, pressure transducer readouts, and safety stop. 
3) Rolling of nickel aluminide sheet of $10 \mathrm{~mm}$ (4 inch) width and approximately $0.25 \mathrm{~mm}$ (0.010 inch) thickness at $10 \%$ per pass.

4) Rolling of iridium alloy foil of $5 \mathrm{~cm}$ (2 inch) width from a thickness of $0.2 \mathrm{~mm}(0.008)$ inch to $0.13 \mathrm{~mm}(0.005 \mathrm{inch})$ with reductions of 0.001 inch per pass, with two passes at each roll gap setting. Thickness of final foil shall be $0.127 \pm 0.008 \mathrm{~mm}(0.005 \pm 0.0003$ inch).

5) Upon completion of these tests the mill shall be converted back to 2-Hi rolling. The change time shall not be greater than about 8 hours and preferably 4 hours or less.

Annealed aluminum of about $3 \mathrm{~mm}$ thickness was rolled to thickness values of about 2 to $0.7 \mathrm{~mm}$ in order to level the mill. Afterwards nickel aluminide sheet of $10 \mathrm{~mm}$ width was rolled to 0.75 $\mathrm{mm}$ thickness and then in multiple passes of $10 \%$ further rolled to $0.5 \mathrm{~mm}$ thickness. Iridium foil was rolled to $0.127 \mathrm{~mm}$ thickness from a starting thickness of $0.20 \mathrm{~mm}$ for foil GFR236-1 and $0.17 \mathrm{~mm}$ for foil GFR236-2. Thickness measurements were made at a minimum of 9 locations, including near the center and edges of each sheet of foil, by the ORNL technician using calibrated digital deep throat micrometers. The minimum and maximum of the measurements are listed in Table 1 for the two iridium alloy foils and one of the nickel aluminide sheets. The thickness measurements show that the specification requirements for the rolling mill were met.

The emergency stop was demonstrated. All controls functioned properly. The pressure transducer readouts exhibited considerable noise in the display readings. Fenn attributed this to the temporary wiring used for this test leading to interference in the low voltage DC signals. The permanent installation will require shielded cables to avoid electrical interference from the power cables.

Mill loads reached about 160,000 lbs for the rolling of iridium foil and 140,000 lbs for the nickel aluminide. Loads during aluminum rolling were about 20,000 lbs or less. The mill is rated to 300,000 lbs.

The mill was then converted to the 2-Hi configuration by two millwrights in a time of about 4 hours. Testing was performed in the 2-Hi configuration using the back-up rolls described above. The acceptance testing requirements for the 2-Hi configuration consisted of:

1) Leveling of the rolls and demonstration by rolling of aluminum alloy sheet of approximately $0.75 \mathrm{~mm}(0.030 \mathrm{inch})$ thickness in $10 \%$ passes to obtain uniformity of length of equivalent to $0.0075 \mathrm{~mm}$ (0.0003 inch).

2) Demonstration of all controls, pressure transducer readouts, and safety stop.

3) Flattening of iridium alloy sheet of about $1 \mathrm{~mm}(0.040 \mathrm{inch})$ thickness. 
Table 1. Thickness Measurements of Rolled Nickel Aluminide Sheet and Iridium Alloy Foil

\begin{tabular}{llllll}
\hline Material & Pass & Minimum & Maximum & Range & Variation \\
\hline \multirow{2}{*}{ GFR236-1 } & initial & 0.193 & 0.211 & 0.018 & $8 \%$ \\
& 1 & 0.163 & 0.173 & 0.010 & $6 \%$ \\
& 2 & 0.142 & 0.150 & 0.008 & $5 \%$ \\
& 3 & 0.132 & 0.142 & 0.010 & $7 \%$ \\
& final & 0.119 & 0.130 & 0.010 & $8 \%$ \\
GFR236-2 & & & & & \\
& initial & 0.170 & 0.175 & 0.005 & $3 \%$ \\
nickel & final & 0.122 & 0.130 & 0.008 & $6 \%$ \\
aluminide & & & & & \\
& & & & & \\
& initial & 0.739 & 0.762 & 0.022 & $3 \%$ \\
& 1 & 0.683 & 0.719 & 0.036 & $5 \%$ \\
& 2 & 0.676 & 0.701 & 0.025 & $4 \%$ \\
& 3 & 0.648 & 0.655 & 0.008 & $1 \%$ \\
& 4 & 0.605 & 0.607 & 0.003 & $0 \%$ \\
& 5 & 0.572 & 0.579 & 0.008 & $1 \%$ \\
& final & 0.518 & 0.523 & 0.005 & $1 \%$ \\
\hline
\end{tabular}

These tests were performed satisfactorily. The cast rolls did reveal some minor defect during machining and there was some impressions left on the rolls from the flattening of the iridium sheet. The rolls, while adequate for back-up rolls are not suited for cold rolling of high hardness materials such as iridium. Fenn will provide a quotation for a set of new 2-Hi rolls for cold and warm rolling from heat-treated $\mathrm{H}-13$ tool steel. There are no plans to pursue modification to the remaining sets of back-up rolls from the old 4-Hi mill. Following the successful conclusion of these tests the mill was packaged for shipment.

The 4Hi/2Hi Rolling Mill was received at ORNL on June 2, 2006, following acceptance testing in May conducted at the manufacturer's site. Installation was completed in August 2006. The startup of the mill was conducted under the supervision of the vendor's engineers. Training was conducted in mill operations and maintenance. The acceptance testing performed at the vendor's site, described above was successfully repeated and all performance requirements of the purchase specification were met. One piece of iridium alloy foil was rolled to final thickness with excellent thickness uniformity, in the range of 0.127 to $0.135 \mathrm{~mm}$. A photograph on the rolling mill installed at ORNL is shown in Figure 10.

Three sheets of DOP-26 iridium alloy scrap from the extruded bar MS3 were rolled to produce foil for purposes of both further characterizing the performance of the mill and also to make foil for corrugation. The corrugated foil is for use as furnace liner during air burn-off of iridium alloy CVS components. The method of producing this foil differs from current foil production in both the composition of the material, $60 \mathrm{ppm}$ Th vs. a nominal $30 \mathrm{ppm}$ Th for production, as well as the use of extruded bar as a starting material rather than drop-cast ingots for current foil production. The sheets were rolled from extruded segments of the MS3 ingot using a discontinued archived procedure for foil production. The procedure was discontinued due to the higher product yields found for the drop-cast process. The sheets were rolled to a sheet thickness 
of about $0.75 \mathrm{~mm}$ and then recrystallized. The sheets were cut and then warm rolled to an intermediate foil thickness of about $0.2 \mathrm{~mm}$ thickness. The foils were trimmed, cleaned, and then rolled to final thickness on the new $4 \mathrm{Hi} / 2 \mathrm{Hi}$ mill in the $4 \mathrm{Hi}$ configuration. The intermediate reductions by warm rolling were performed on the old 4Hi mill for operational reasons of cost and schedule. A total of three sheets were rolled to produce 26 pieces of foil. As part of this effort the thickness uniformity of foil rolled with the new $4 \mathrm{Hi} / 2 \mathrm{Hi}$ rolling mill will be further characterized. During rolling of four of the foils an alternative lubricant, Spindura 10, was used on the rolls in place of the Stoddard's solvent normally used.

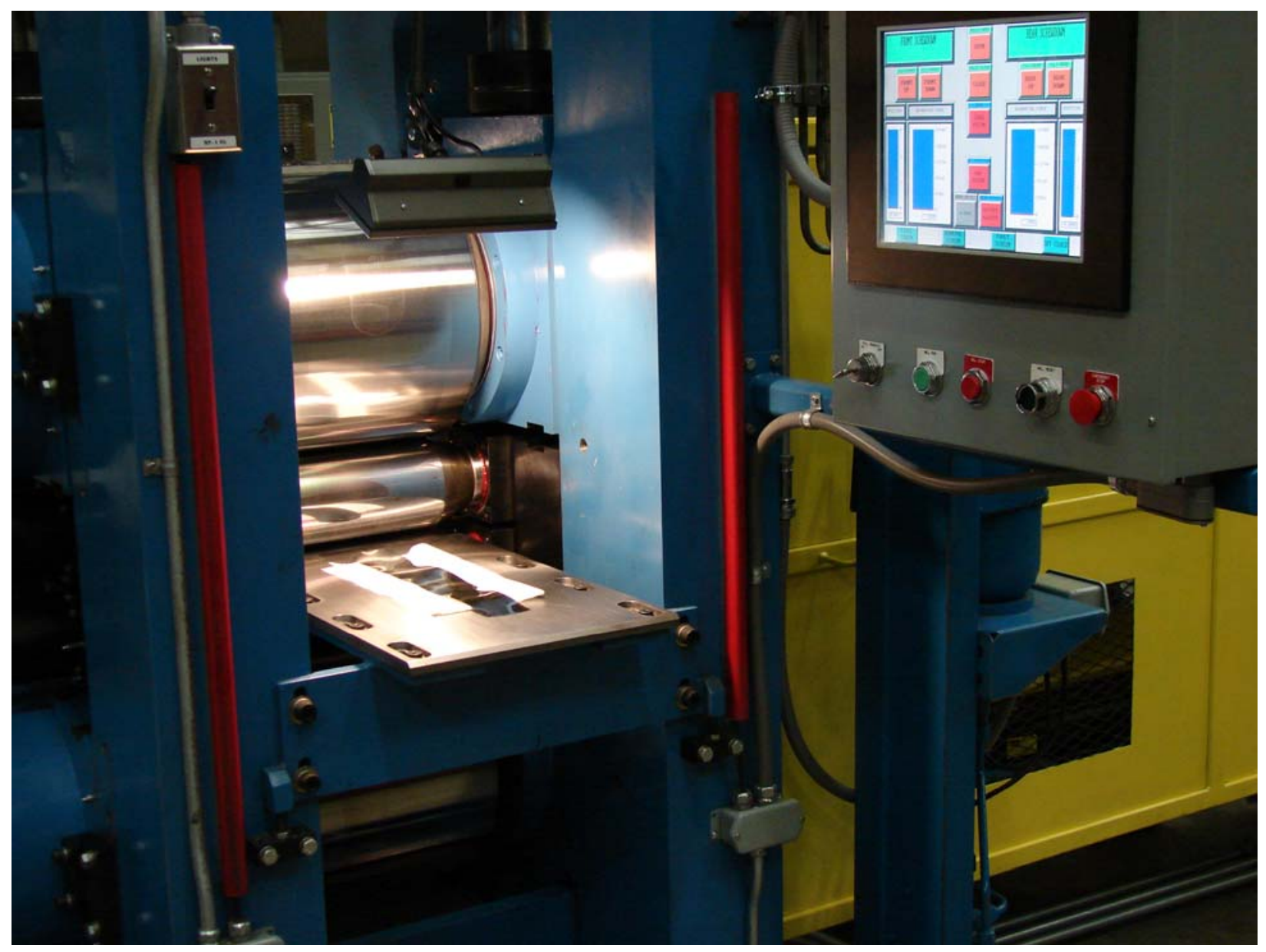

Figure 10. View of roll gap area of new $4 \mathrm{Hi} / 2 \mathrm{Hi}$ rolling mill in the $4 \mathrm{Hi}$ configuration. The touch screen control station can be seen along with iridium foil rolled onto the run out table.

Since the dimensional variability of the materials used for final rolling on the $4 \mathrm{Hi} / 2 \mathrm{Hi}$ mill was not entirely characteristic of production materials, the effect of starting thickness variation on final thickness variation was evaluated. These results are plotted in Figure 11. A linear curve fit indicates that the expected average variation in finished thickness of a foil is $0.005 \mathrm{~mm}$ for a starting foil with zero initial thickness variation. This is considered to be the lower limit of thickness variation obtainable with the mill. 


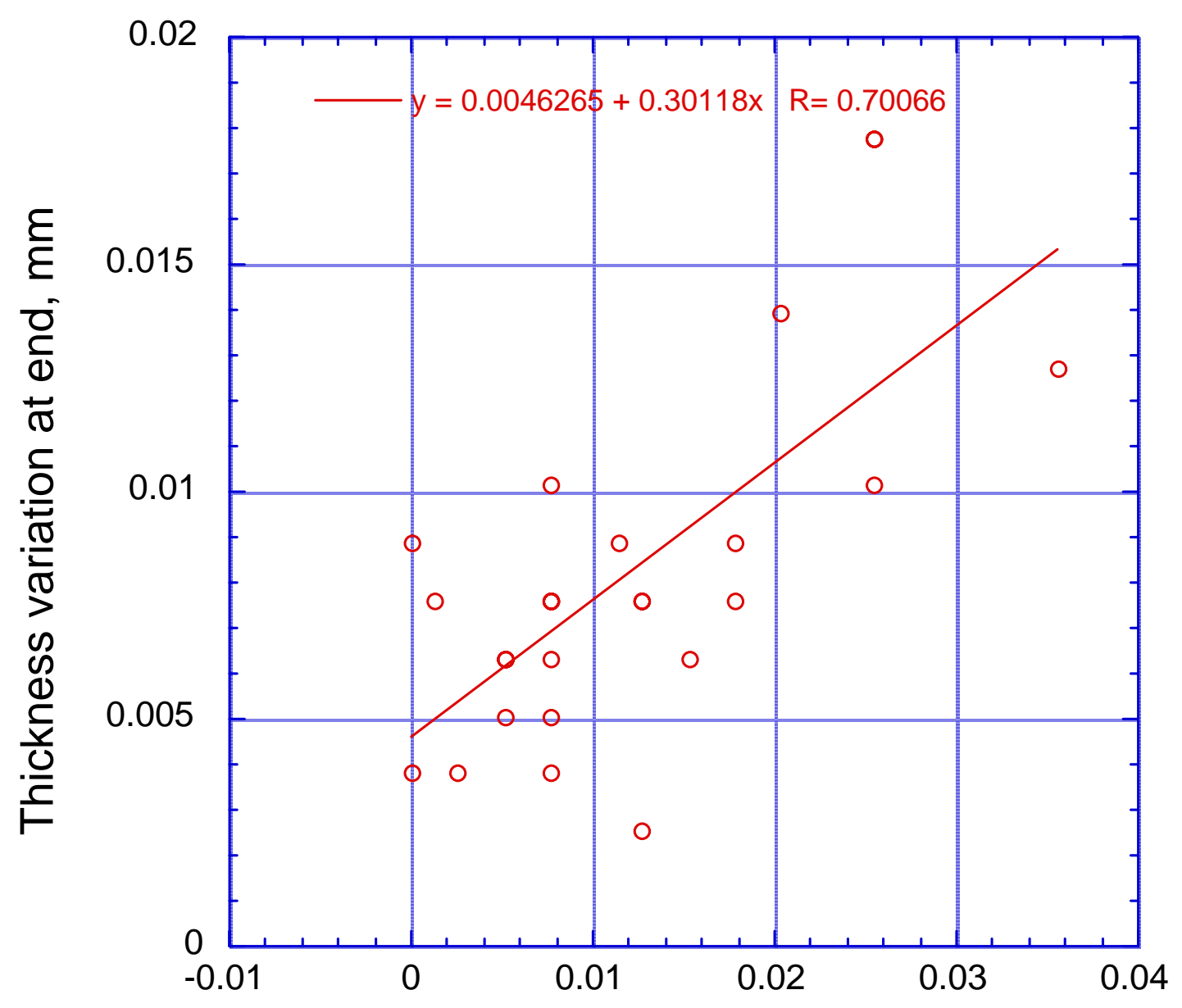

\section{Thickness variation at start, $\mathrm{mm}$}

Figure 11. The variation in thickness of the finished $0.13-\mathrm{mm}$ thick cold rolled foil increases with increased variation in thickness of the starting $0.02-\mathrm{mm}$ thick warm rolled foil.

The large variability in starting thickness for several of the foils would not be characteristic of foils processed under production conditions. Since all of the foils had variations in final thickness of less than $0.02 \mathrm{~mm}$, it is reasonable to expect that variations in starting thickness can be routinely achieved. The four foils with variations in starting thickness of $0.02 \mathrm{~mm}$ or greater are therefore excluded from this analysis of equipment capability for uniformity of finished foil.

The minimum and maximum values of the final thickness are listed in Table 2 together with the variation, or difference between the maximum and minimum, for twenty foils of MS3 iridium scrap. All of the thickness values fall in the range of $0.123 \mathrm{~mm}$ to $0.136 \mathrm{~mm}$. The range of foil 
thickness values is $0.013 \mathrm{~mm}$. This can be expressed as $0.130 \pm 0.007 \mathrm{~mm}$ as compared to the foil specification range of $0.130 \pm 0.030 \mathrm{~mm}$. The average variation in thickness within an individual foil is $0.006 \mathrm{~mm}$ for this study. This is anticipated to be the limit of capability for this mill for the iridium foil rolling process.

The measured thickness variations for several production lots, with similar numbers of foils in each lot that were rolled to final thickness on the old Bliss 4Hi mill are listed in Table 3. These similar sized lots of foil exhibit a typical foil thickness range of $0.03 \mathrm{~mm}$. A comparison can be made to the thickness range of $0.018 \mathrm{~mm}$ for all 24 foils rolled to final thickness on the Fenn mill. A comparison can be also be made to the thickness range of $0.013 \mathrm{~mm}$ for the 20 foils with starting thickness variations of less than $0.02 \mathrm{~mm}$. This lesser degree of variation is expected to be typical of foil which is both warm rolled and cold rolled on the Fenn mill. It can be concluded that the variation in foil thickness obtained with the new $4 \mathrm{Hi} / 2 \mathrm{Hi}$ mill is about one half of that for recent production lots rolled with the old Bliss $4 \mathrm{Hi}$ mill.

Table 2. Final Thickness of Foil Rolled on the New 4Hi/2Hi Mill

\begin{tabular}{|c|c|c|c|}
\hline \multirow[b]{2}{*}{ Foil } & \multicolumn{2}{|c|}{ Final Thickness, mm } & \multirow{2}{*}{$\begin{array}{l}\text { Thickness } \\
\text { variation, } \mathrm{mm}\end{array}$} \\
\hline & $\underline{\text { minimum }}$ & $\underline{\text { maximum }}$ & \\
\hline$\overline{\mathrm{MS}} 3-1-\mathrm{A}$ & 0.127 & 0.135 & 0.008 \\
\hline MS3-1-C & 0.130 & 0.132 & 0.003 \\
\hline MS3-1-D1 & 0.127 & 0.135 & 0.008 \\
\hline MS3-1-E & 0.123 & 0.132 & 0.009 \\
\hline MS3-1-F & 0.128 & 0.132 & 0.004 \\
\hline MS3-1-H & 0.126 & 0.133 & 0.008 \\
\hline MS3-1-I & 0.130 & 0.135 & 0.005 \\
\hline MS3-2-A & 0.126 & 0.132 & 0.006 \\
\hline MS3-2-B & 0.131 & 0.135 & 0.004 \\
\hline MS3-2-E & 0.127 & 0.132 & 0.005 \\
\hline MS3-2-F & 0.127 & 0.135 & 0.008 \\
\hline MS3-2G & 0.124 & 0.132 & 0.008 \\
\hline MS3-2-H & 0.124 & 0.131 & 0.006 \\
\hline MS3-2-I & 0.130 & 0.133 & 0.004 \\
\hline MS3-3-A & 0.124 & 0.133 & 0.009 \\
\hline MS3-3-B & 0.127 & 0.136 & 0.009 \\
\hline MS3-3-C & 0.124 & 0.132 & 0.008 \\
\hline MS3-3-D1 & 0.127 & 0.135 & 0.008 \\
\hline MS3-3-E & 0.126 & 0.132 & 0.006 \\
\hline MS3-3-F & 0.126 & 0.132 & 0.006 \\
\hline overall measured & 0.123 & 0.136 & 0.013 \\
\hline specification limit & 0.100 & 0.160 & 0.060 \\
\hline measured foil vari & avg. & & 0.006 \\
\hline
\end{tabular}


Table 3. Comparison of Foil Thickness Variation Shows Significantly Greater Uniformity for Foil Rolled to Final Thickness on the New Fenn 4Hi/2Hi Mill.

\begin{tabular}{|c|c|c|c|c|c|}
\hline $\begin{array}{l}\text { Mill for } \\
\text { Final } \\
\text { Rolling }\end{array}$ & Material Lot & $\begin{array}{c}\text { Thickness } \\
\text { range for lot, } \\
\mathrm{mm}\end{array}$ & $\begin{array}{l}\text { Avg. thickness } \\
\text { variation, mm }\end{array}$ & $\begin{array}{l}\text { No. of } \\
\text { foils in } \\
\text { lot }\end{array}$ & Comments \\
\hline \multirow[t]{2}{*}{ Fenn } & MS3 $-1,-2,-3$ & 0.018 & 0.008 & 24 & all foils \\
\hline & MS3 $-1,-2,-3$ & 0.013 & 0.006 & 20 & initial variation $<0.02 \mathrm{~mm}$ \\
\hline \multirow[t]{3}{*}{ Bliss } & GFR240, 241 & 0.030 & 0.012 & 24 & \multirow[t]{3}{*}{2004 production } \\
\hline & GFR242, 243 & 0.030 & 0.011 & 24 & \\
\hline & GFR244, 245 & 0.040 & 0.009 & 25 & \\
\hline \multirow[t]{3}{*}{ Bliss } & GFR220, 221 & 0.030 & 0.007 & 20 & \multirow[t]{3}{*}{1997 production } \\
\hline & GFR222, 223 & 0.020 & 0.007 & 23 & \\
\hline & GFR224, 225 & 0.050 & 0.009 & 20 & \\
\hline \multirow[t]{5}{*}{ Bliss } & FF901,902 & 0.043 & 0.010 & 32 & \multirow[t]{5}{*}{1993 production } \\
\hline & FF903, 904 & 0.040 & 0.012 & 32 & \\
\hline & FF905, 906 & 0.037 & 0.012 & 31 & \\
\hline & FF907, 908 & 0.010 & 0.007 & 21 & \\
\hline & FF909, 910 & 0.030 & 0.009 & 28 & \\
\hline Bliss & $\begin{array}{l}\text { average } \\
\text { production }\end{array}$ & 0.033 & 0.010 & & \\
\hline
\end{tabular}

The trial use as a roll lubricant of Spindura 10, refined oil produced by Texaco, was judged not successful. Small particles of iridium frequently come detached and foil edges or ends and are continuously removed from the roll surfaces by felt wipers pressed against each of the rolls. The substitute lubricant tended to decrease the efficiency of particle removal from the roll surfaces resulting in some minor but observable pitting of the foil surfaces.

\subsubsection{Control System Upgrades for Vacuum Arc Remelting Furnace and Electron Beam Melting Furnace}

A specification for upgrade of the Electron Beam Melting Furnace Beam Deflection Control System was approved. The existing control system has become difficult to maintain due to component obsolescence and is no longer fully functional. Installation of the upgraded system is expected in the first quarter of FY 2007.

A purchase order was released for upgrade of the control system on the vacuum arc remelt (VAR) furnace. The new system will provide greater reliability and maintainability. Installation of the upgraded system is expected in the second quarter of FY 2007.

A purchase order for the control system upgrade to the EB melting furnace was issued. Shipment of the system is expected in FY 2007. 


\subsubsection{Processing of Iridium Scrap Materials}

Samples from several sheets of non-prime DOP-26 iridium alloy (MS3 ingot) were submitted for chemical and metallographic analysis. The material is being characterized to permit its use in a program to obtain test data of the alloy's high-strain rate mechanical properties.

Samples from several sheets of non-prime DOP-26 iridium alloy (MS3 ingot) were analyzed for potential use as material for high strain rate tensile testing. The sheets were found to contain platinum levels of 750 to $1100 \mathrm{ppm}$, which exceeds a specified maximum level of $300 \mathrm{ppm}$. The material was produced by melting of scrap material received from Mound Plant. It is believed that some platinum material was mixed with the scrap at Mound. Processing of the scrap material was terminated and a sheet of production DOP-26 alloy, K3-14, was designated for use in tensile testing.

\subsubsection{Analysis for Iridium Alloy Blank and Foil Production}

\subsubsection{Introduction}

Iridium powder used for production of iridium alloy blanks and foil is purchased from commercial sources or refined by commercial refiners. Recently it has become more difficult to obtain iridium powder that meets the program's specification. There are several reasons for this. There is no commercial process that routinely produces powder of the purity that meets the specification. Rather vendors have selected particular lots of commercial grade powder to supply for program use. The impurity levels in iridium powder vary considerably, depending on the particular mine or refinery from which it is produced. Since all iridium powder is a byproduct of platinum or nickel production, the production of iridium is all in relatively small lots with varying impurity contents. Some iridium powder is produced by refining of iridium-containing scrap materials. However in the past five years the two major refiners of iridium in the USA have discontinued iridium refining in this country. Iridium refining is now performed primarily in the EU.

In addition to issues of iridium powder supply there are also issues associated with analysis of the powder. The methods used by the industry for analysis of impurity elements in the iridium powder are not adequate to assure compliance to the program specification. Chemical analysis for acceptance testing is performed by glow discharge mass spectrographic analysis (GDMS). The chemical analysis performed by the vendors of iridium powder is typically done by optical atomic absorption methods which are not as sensitive. Consequently a substantial fraction of iridium powder that is received is determined to be nonconforming after receipt and acceptance testing. In some instances this powder has been returned for replacement and in some cases the powder has been approved for use as-is. The justifications for use of non-conforming powder include that the powder is blended with other powder lots to produce a master blend which does conform to the powder specification and that reduction of the impurity levels occurs during processing of the material, particularly during electron beam melting. This report contains the first systematic quantitative study of the changes in impurity contents that occur when powder is processed to finished alloy sheet products, such as blanks or foil.

\subsubsection{Background}

Iridium powder is the raw material for the production of iridium alloy blanks and foil. The specification for iridium powder MET-MatP-TS- 1 rev. 5 states requirements for chemical purity of the iridium powder. The maximum level of elemental impurities is listed in Table 1. The 
maximum impurity levels specified for sheet products of blanks and foil are also listed in Table 1 . Many of the impurity elements have maximum allowable levels of $50 \mu \mathrm{g} / \mathrm{g}$ in both the powder specification and the specification for blanks and foil and are listed as "other" in Table 1.

The specification for the powder is much the same as that originally used in the 1970's for blank and foil production and was determined primarily by the typical chemistry of the highest purity iridium powder available. It was recognized that electron beam melting is effective in reducing the quantity of many of the impurity elements, due to vaporization of the impurities during repeated melting in vacuum. This is particularly true for the elements with very high vapor pressures, $\mathrm{Cl}, \mathrm{Ca}, \mathrm{K}$, and $\mathrm{Na}$. The maximum impurity levels for these elements in the starting powder are higher than those for the finished sheet product. This is also the case for the elements $\mathrm{Cr}$ and $\mathrm{C}$ which do not have such high vapor pressures.

Historically it has been recognized that due to the purification that occurs during melting, the specified levels of impurities in the powder may be unnecessarily low. A number of nonconformance reports have been accepted for use of powder with higher levels of impurities than that specified for the powder. The justification for the use of this powder was based on both the effects of dilution when blended with other conforming powder and also on the purification that occurs during melting. A summary of relevant nonconformance reports for iridium powder for the past 25 years is listed in Table 2. A number of revisions to the original specification for iridium powder were made over the years to increase the permitted level of some impurities. The maximum contents of $\mathrm{Na}$ and $\mathrm{K}$ were increased from $70 \mu \mathrm{g} / \mathrm{g}$ in the original specification of 1977 to a maximum value of $100 \mu \mathrm{g} / \mathrm{g}$ in 1982. The maximum contents $\mathrm{C}$ was increased from 25

Table 1. Specified Limits for Impurity Elements in Iridium Powder and Iridium Alloy Sheet Products

$\begin{array}{ccc}\text { Element } & \begin{array}{c}\text { Powder } \\ \text { maximum } \mu \mathrm{g} / \mathrm{g}\end{array} & \begin{array}{c}\text { Sheet } \\ \text { maximum } \mu \mathrm{g} / \mathrm{g}\end{array} \\ \mathrm{Al} & 40 & 20-80 \\ \mathrm{C} & 50 & 35 \\ \mathrm{Ca} & 70 & 50 \\ \mathrm{Cl} & 600 & 50 \\ \mathrm{Co} & 20 & 50 \\ \mathrm{Cr} & 50 & 25 \\ \mathrm{Fe} & 100 & 150 \\ \mathrm{~K} & 100 & 50 \\ \mathrm{Mn} & 20 & 50 \\ \mathrm{Mo} & 40 & 50 \\ \mathrm{Na} & 100 & 50 \\ \mathrm{Ni} & 20 & 50 \\ \mathrm{P} & 20 & 50 \\ \mathrm{~Pb} & 20 & 50 \\ \mathrm{Pt} & 100 & 50 \\ \mathrm{Rh} & 70 & 150 \\ \mathrm{Sb} & 20 & 50 \\ \mathrm{Si} & 70 & 50 \\ \mathrm{Others} & 50 & 50 \\ \mathrm{Ir} & \text { Remainder } & \end{array}$


Table 2. Summary of Nonconformance Reports Issued for Purchased Iridium Powder

\begin{tabular}{|c|c|c|c|c|c|c|}
\hline Batch & Lot No. & NCR & Element & $\mu \mathrm{g} / \mathrm{g}$ & Qty, kg & Disposition \\
\hline $\mathrm{K}$ & 570 & 2145 & $\mathrm{Na}$ & 320 & 12 & reject \\
\hline $\mathrm{K}$ & Feb-03 & 2145 & $\mathrm{Si}$ & 120 & 12 & reject \\
\hline $\mathrm{K}$ & OIR03/4A2 & 2146 & $\mathrm{C}$ & 100 & 8 & reject \\
\hline $\mathrm{K}$ & & & $\mathrm{Na}$ & 330 & & reject \\
\hline $\mathrm{K}$ & OIR03/01 & 2147 & $\mathrm{Rh}$ & 72 & 1.5 & use as-is \\
\hline $\mathrm{L}$ & 11 & 2151 & $\mathrm{Na}$ & 280 & 11 & reject \\
\hline $\mathrm{L}$ & 128 & 2151 & $\mathrm{Ru}$ & 90 & 5 & reject \\
\hline $\mathrm{L}$ & 84 & 2150 & $\mathrm{Ru}$ & 62 & 3 & use as-is \\
\hline $\mathrm{L}$ & 11 & 2153 & $\mathrm{Rh}$ & 137 & 1.5 & use as-is \\
\hline $\mathrm{L}$ & 2003/31A1 & 2152 & $\mathrm{Rh}$ & 78 & 3 & use as-is \\
\hline $\mathrm{L}$ & 19852 & 2152 & $\mathrm{Ru}$ & 55 & 3 & use as-is \\
\hline $\mathrm{L}$ & 19852 & 2152 & $\mathrm{Na}$ & 110 & 3 & use as-is \\
\hline $\mathrm{G}$ & 52 & 1769 & $\mathrm{~S}$ & 240 & 24 & reiect \\
\hline $\mathrm{G}$ & & 2015 & $\mathrm{~S}$ & 600 & & use as-is \\
\hline $\mathrm{F}$ & & 1669 & $\mathrm{C}$ & 59 & 3 & use as-is \\
\hline & & & & & & \\
\hline B & $8369-10$ & 940 & $\mathrm{P}$ & 200 & & use as-is \\
\hline & & & $\mathrm{C}$ & 110 & & use as-is \\
\hline Z & $5301-11$ & 444 & $\mathrm{~S}$ & 100 & & use as-is \\
\hline $\mathrm{X}$ & & 152 & $\mathrm{Cl}$ & 1000 & & use as-is \\
\hline & & & & & & \\
\hline $\mathrm{S}$ & various & 61 & $\mathrm{C}$ & 90 & & use as-is \\
\hline & & 61 & $\mathrm{Cl}$ & 600 & & use as-is \\
\hline & & 61 & S & 300 & & use as-is \\
\hline
\end{tabular}

to $50 \mu \mathrm{g} / \mathrm{g}$ in 1983 . The maximum contents of $\mathrm{Cl}$ were increased from an original value of 50 $\mu \mathrm{g} / \mathrm{g}$ to $200 \mu \mathrm{g} / \mathrm{g}$ in 1982 and to $600 \mu \mathrm{g} / \mathrm{g}$ in 1983 . The impurity limits for the DOP-26 iridium alloy sheet products listed in Table 1 have not changed since the original issue in 1979. They differ from an earlier 1973 specification for the undoped $\mathrm{Ir}-0.3 \% \mathrm{~W}$ alloy in that maximum contents of $\mathrm{Fe}$ and $\mathrm{Rh}$ are increased from 50 to $150 \mu \mathrm{g} / \mathrm{g}$.

Chemical analysis of iridium materials both before and after electron-beam melting has been performed in the past. However quantitative analysis of the results was limited by the imprecision of the spark source mass spectroscope (SSMS) method in use for analytical chemistry at the time. Typically the objective was to demonstrate that an iridium powder with one or more elements above the specified level did produce a melted material which conformed to the chemical specification for the final product. The results of electron-beam melting on material purity was reported for five electron-beam melted buttons produced from a single batch of iridium powder, [Huxford, T. J., and E. K Ohriner, in Proceedings Electron Beam Melting and 
Refining - State of the Art 1992, R. Bakish ed. (1992) 219-232.] These results were also only semi-quantitative due to the limited precision of the SSMS technique used for impurity analysis.

\subsubsection{Procedure}

This is the first systematic report on the effects of electron beam melting on material impurity using glow discharge mass spectrographic (GDMS) analysis of both starting powder and finished sheet products. The materials used for this study consisted of a blend of iridium powder lots containing $54 \mathrm{~kg}$ of iridium powder and designated as "K-batch" powder. The powder was received and chemically analyzed during the period August 2003 to May 2004. The powder was from 12 different lots produced at various locations throughout the world. Each lot was placed into one or more jars so that no single jar contained more than $4 \mathrm{~kg}$ of powder. This produced 20 jars, each from a single lot, containing from 1.5 to $3.7 \mathrm{~kg}$ of powder. Each jar was blended for 2 hours and sampled in accordance with the standard procedure. The samples were analyzed by GDMS in accordance with the standard procedure for analysis of iridium materials at Shiva Technologies, Syracuse, NY. Additional samples were analyzed for carbon and oxygen contents at Oak Ridge Y-12 Plant. The 20 jars of powder were each then weighed and dispensed in equal amounts into 18 new containers to produce batch blends. A quantity of tungsten powder equivalent to $0.3 \%$ by weight was added to each of the 18 containers. The containers were then blended for four hours each to a homogeneous mix across all 18 batch blends.

The 18 batch blends were processed to make iridium alloy blanks using the standard procedures. The first six batch blends were processed to produce blanks from ingot K1. The next six batch blends were processed to produce blanks from ingot K2. Processing of the remaining batch blends to produce blanks from ingot $\mathrm{K} 3$ is not yet completed. The batch blends of powder were compacted, sintered, and then electron beam melted a total of eight times each in a vacuum chamber at a pressure of about 1 x 10-5 torr. The electron-beam melted buttons of about $500 \mathrm{~g}$ each were then further alloyed with thorium and aluminum by button arc melting in argon gas. These buttons were drop cast to produce electrode segments, which were electron beam welded to produce an electrode. The electrode was vacuum arc melted to produce an ingot, which was then hot extruded and hot and warm rolled to produce sheet products. A total of 17 or 18 sheets were produced from each ingot. A sample for chemical analysis by GDMS was taken from each pair of adjacent sheets, for a total of 9 samples per ingot. Duplicate samples for carbon and oxygen analysis are taken from each group of six adjacent sheets for a total of six of each per ingot.

Since the most important process in purification of the iridium is electron beam melting the details of this process are significant. Prior to melting the compacts are vacuum degassed at 1873 $\mathrm{K}$ for 4 hours. They are subsequently heated with the electron beam for 5 minutes at a temperature below the melting point to further degas the powder compacts. The buttons are melted in a water cooled hearth with spherical radius cavities eight times and turned after each melting. Each of the eight melt cycles extends for $270 \mathrm{~s}$ with $60 \mathrm{~s}$ at maximum power. The power is ramped up over a $180 \mathrm{~s}$ and ramped down over $30 \mathrm{~s}$. The maximum power is $19 \mathrm{~kW}$ at $35 \mathrm{kV}$ for those buttons in hearth locations closest to the electron beam gun. The maximum power level is $26 \mathrm{~kW}$ for hearth locations furthest from the electron beam gun. During the initial melting the weight loss is typically $5 \%$ of the initial weight, in part due to splatter particles ejected from the melt pool. About one fifth of the lost material is recovered as large splatter particles which can be remelted. Typically the recovered splatter is added to the button in the first cavity of the hearth and this button therefore generally shows higher than average weight losses during subsequent melting. In order to estimate the quantity of material that is evaporated, rather than ejected from the melt as a liquid, the average weight loss is obtained for the buttons in cavities 2 through 5. This is then averaged for melts 2 through 8 . The average weight loss for 
four buttons is $0.75 \%$ per melt with a standard deviation of $0.3 \%$ over melts 2 through 8 . The calculated weight loss due to evaporation over the entire cycle of 8 melts is estimated at $6 \%$, nearly all of which is iridium. This estimate is likely higher than the actual value since it likely also includes the weight loss of some ejected liquid particles.

\subsubsection{Results}

The results of chemical analysis of the K-batch starting powder and the sheet products produced from that powder are listed in Table 3. The average composition of the powder was obtained by calculation of the weighted average composition of the 20 jars of powder used to produce the master blends. The average sheet composition was calculated for the 18 GDMS analyses of samples from ingots $\mathrm{K} 1$ and $\mathrm{K} 2$. In the case of carbon the average sheet composition was calculated for the 12 combustion analyses of samples from ingots $\mathrm{K} 1$ and $\mathrm{K} 2$. The impurity level in the sheet product is below the detectable limit for many of the impurity elements as indicated by the " $<$ " symbol in the table. In addition, the ratio of the average impurity level of each element in the powder to the average impurity level in the sheet, or purification ratio for each element, is listed in column 5 of Table 3 . This purification ratio is an indication of the effectiveness of the processing, in particular electron beam melting, in purifying the iridium. In those cases where the average impurity level in the sheet product is below the detectable limit only a minimum value of the purification ratio can be calculated.

The various impurity elements can be sorted into five distinct groups on the basis of the effect of processing on the impurity level and purification ratio. In group 1 are elements, $\mathrm{Cl}, \mathrm{S}, \mathrm{K}, \mathrm{Mg}, \mathrm{Bi}$, $\mathrm{Pd}, \mathrm{Ca}, \mathrm{Zn}, \mathrm{Tl}, \mathrm{Na}, \mathrm{Pb}, \mathrm{Ba}, \mathrm{B}, \mathrm{P}, \mathrm{Li}$, and As for which purification by processing is extremely effective. These elements are characterized by impurity contents in the sheet product of 0.05 $\mu \mathrm{g} / \mathrm{g}$ or less and purification ratios of 16 or greater. In group 2 are elements $\mathrm{Sn}, \mathrm{Sb}$, and $\mathrm{Te}$ for which purification is at least

\begin{tabular}{|c|c|c|c|c|c|}
\hline \multicolumn{6}{|c|}{$\begin{array}{l}\text { Table 3. Comparison of Impurity Contents in K-Batch Iridium } \\
\text { Powder With Sheet Products From the Powder }\end{array}$} \\
\hline & & powder & sheet & measured ratio & calculated ratio \\
\hline & Element & avg. $\mu \mathrm{g} / \mathrm{g}$ & avg. $\mu \mathrm{g} / \mathrm{g}$ & powder/sheet & (ideal solution) \\
\hline \multirow[t]{16}{*}{ GROUP 1} & $\mathrm{Cl}$ & 36.6 & $<0.05$ & $>731$ & $>10000$ \\
\hline & $\mathrm{S}$ & 3.3 & 0.001 & 312 & $>10000$ \\
\hline & $\mathrm{K}$ & 10.0 & $<0.05$ & $>199$ & $>10000$ \\
\hline & $\mathrm{Mg}$ & 1.9 & $<0.01$ & $>191$ & $>10000$ \\
\hline & $\mathrm{Bi}$ & 2.9 & 0.02 & 145 & $>10000$ \\
\hline & $\mathrm{Pd}$ & 1.2 & $<0.01$ & $>116$ & $>10000$ \\
\hline & $\mathrm{Ca}$ & 5.0 & $<0.05$ & $>100$ & $>10000$ \\
\hline & $\mathrm{Zn}$ & 1.3 & 0.01 & 99 & $>10000$ \\
\hline & $\mathrm{Tl}$ & 1.4 & 0.01 & 84 & $>10000$ \\
\hline & $\mathrm{Na}$ & 3.2 & 0.04 & 74 & $>10000$ \\
\hline & $\mathrm{Pb}$ & 0.7 & $<0.01$ & $>67$ & $>10000$ \\
\hline & $\mathrm{Ba}$ & 0.5 & $<0.01$ & $>46$ & $>10000$ \\
\hline & $\mathrm{B}$ & 0.7 & 0.01 & 45 & 20 \\
\hline & $\mathrm{P}$ & 0.3 & $<0.01$ & $>32$ & $>10000$ \\
\hline & $\mathrm{Li}$ & 0.2 & $<0.01$ & $>17$ & $>10000$ \\
\hline & As & 0.2 & $<0.01$ & $>16$ & $>10000$ \\
\hline
\end{tabular}




\begin{tabular}{|c|c|c|c|c|c|}
\hline \multicolumn{6}{|c|}{$\begin{array}{l}\text { Table } 3 \text { (continued). Comparison of Impurity Contents in K-Batch } \\
\text { Iridium Powder With Sheet Products From the Powder }\end{array}$} \\
\hline \multirow[t]{3}{*}{ GROUP 2} & $\mathrm{Sn}$ & 0.5 & $<0.05$ & $>10$ & $>10000$ \\
\hline & $\mathrm{Sb}$ & 0.2 & $<0.05$ & $>4$ & $>10000$ \\
\hline & $\mathrm{Te}$ & 0.02 & $<0.01$ & $>2$ & $>10000$ \\
\hline \multirow[t]{10}{*}{ GROUP 3} & $\mathrm{Rh}$ & 34.8 & 2.12 & 16 & 13 \\
\hline & $\mathrm{Fe}$ & 6.4 & 0.58 & 11 & $>10000$ \\
\hline & $\mathrm{Mn}$ & 0.3 & 0.03 & 9 & $>10000$ \\
\hline & $\mathrm{Pt}$ & 12.0 & 1.33 & 9 & 2 \\
\hline & Co & 0.03 & 0.001 & 5 & $>10000$ \\
\hline & $\mathrm{Cr}$ & 0.8 & 0.15 & 5 & $>10000$ \\
\hline & $\mathrm{Cu}$ & 1.0 & 0.21 & 4 & $>10000$ \\
\hline & $\mathrm{Si}$ & 7.0 & 1.82 & 3 & $>10000$ \\
\hline & $\mathrm{C}$ & 23 & 7 & 3 & 3 \\
\hline & $\mathrm{Ni}$ & 0.6 & 0.2 & 2 & $>10000$ \\
\hline \multirow[t]{8}{*}{ GROUP 4} & $\mathrm{Ru}$ & 10.0 & 8.0 & 1 & 1 \\
\hline & $\mathrm{Y}$ & 0.004 & 0.004 & \begin{tabular}{|l|l|}
1 \\
\end{tabular} & $>10000$ \\
\hline & $\mathrm{Re}$ & 0.19 & 0.25 & 1.0 & 1 \\
\hline & $\mathrm{Ti}$ & 1.18 & 1.29 & \begin{tabular}{|l|}
0.9 \\
\end{tabular} & $>10000$ \\
\hline & $\mathrm{Zr}$ & 0.12 & 0.15 & 0.8 & 1 \\
\hline & $\mathrm{V}$ & 0.02 & 0.03 & \begin{tabular}{|l|l|}
0.7 \\
\end{tabular} & $>10000$ \\
\hline & $\mathrm{Nb}$ & 0.07 & 0.14 & \begin{tabular}{|l|}
0.6 \\
\end{tabular} & 1 \\
\hline & Mo & 0.16 & 0.98 & \begin{tabular}{|l|}
0.2 \\
\end{tabular} & 1 \\
\hline \multirow[t]{9}{*}{ GROUP 5} & $\mathrm{Rb}$ & 0.01 & $<0.01$ & N/A & $>10000$ \\
\hline & Cs & 0.01 & $<0.01$ & N/A & $>10000$ \\
\hline & $\mathrm{Ag}$ & 0.05 & $<0.05$ & N/A & $>10000$ \\
\hline & $\mathrm{Hf}$ & 0.01 & $<0.01$ & N/A & 1 \\
\hline & $\mathrm{Br}$ & 0.02 & $<0.05$ & N/A & $>10000$ \\
\hline & $\mathrm{Au}$ & 0.24 & $<0.5$ & N/A & $>10000$ \\
\hline & $\mathrm{Cd}$ & 0.02 & $<0.05$ & N/A & $>10000$ \\
\hline & Os & 0.06 & $<0.2$ & N/A & 1 \\
\hline & $\mathrm{Se}$ & 0.01 & $<0.1$ & N/A & $>10000$ \\
\hline
\end{tabular}

somewhat effective but for which the initial impurity levels are not much above the detectable limit of the analysis. The purification ratios vary from $>2$ to $>10$ but without additional data can not be determined more precisely. In group 3 are elements $\mathrm{Rh}, \mathrm{Fe}, \mathrm{Mn}, \mathrm{Pt}, \mathrm{Co}, \mathrm{Cr}, \mathrm{Cu}, \mathrm{Si}, \mathrm{C}$, and $\mathrm{Ni}$ which have purification ratios in the range of 2 to 16 . The processing is somewhat effective in reducing the levels of these impurities. In group 4 are elements $\mathrm{Ru}, \mathrm{Y}, \mathrm{Re}, \mathrm{Ti}, \mathrm{Zr}, \mathrm{V}, \mathrm{Nb}, \mathrm{Mo}$ with purification ratios of 1 or less. The processing has no capability to remove these impurities. In group 5 are elements with very low levels of impurities in the starting powder and impurity levels below the detectable limit in the sheet products. It is not possible to make any statements about the purification behavior during processing without additional data. 


\subsubsection{Discussion}

The removal of impurities during melting in vacuum is caused by vaporization of elements with relatively high vapor pressures. The rate of ideal vaporization into a vacuum is given by Langmuir's equation

$$
J_{i}=\frac{P_{v i}}{\sqrt{2 \pi M_{i} R_{g} T}}
$$

in which $\quad J_{i}$ is the evaporative flux of species i, in $\mathrm{mol} / \mathrm{m}^{2} \mathrm{~s}$

$P_{v i}$ is the vapor pressure of species $\mathrm{i}$, in $\mathrm{Pa}$

$M_{i}$ is the molar mass of species i, in $\mathrm{kg} / \mathrm{mol}$

$R_{g} \quad$ is the ideal gas constant, in $\mathrm{J} /(\mathrm{mol} \mathrm{K})$

and $\mathrm{T}$ is the absolute temperature, in $\mathrm{K}$.

Assuming a cylindrical button with evaporation only from the top circular surface, the relative weight loss by ideal evaporation of an iridium button of can be calculated as

$$
\frac{\Delta W}{W}=\frac{J_{I r} M_{I r} t}{h \rho_{I r}}
$$

in which $\quad \Delta W$ is the change in weight, in $\mathrm{kg}$

$\mathrm{W}$ is the initial $\mathrm{wt}$, in $\mathrm{kg}$

$\rho_{\text {Ir }}$ is the density of $\mathrm{Ir}$, in $\mathrm{kg} / \mathrm{m} 3$

$\mathrm{t}$ is time, in seconds

and $h \quad$ is the height of the button, in $\mathrm{m}$.

Using approximate button height of $0.01 \mathrm{~m}$, a time of $480 \mathrm{~s}$, and an estimated temperature of $3000 \mathrm{~K}$, which is $10 \%$ above the iridium melting point of $2716 \mathrm{~K}$, the calculated relative weight loss is $4 \%$. This compares favorably with the experimentally determined relative weight loss from evaporation of $6 \%$ or less.

The evaporation rate of impurity elements can be calculated by substituting for $P_{v i}$ in Equation 1

$$
p_{v i}=x_{i} \gamma_{i} \overline{p_{v i}}
$$

in which $\quad x_{i} \quad$ is the atom fraction of element $\mathrm{i}$

$\frac{\gamma_{i}}{p_{v i}} \quad$ is the chemical activity coefficient of element $i$ 
Assuming that the evaporation step is the rate-limiting step in the removal of impurities and that the evaporation of iridium is negligible in comparison to evaporation of the impurity, then the evaporative flux controls the rate of change of composition as

$$
J_{i} A=-\frac{V \rho_{I r}}{M_{I r}} \frac{d x_{i}}{d t}
$$

in which A is the area of the melt subject to evaporation

$\mathrm{V} \quad$ is the volume of the melt.

Again assuming a cylindrical melt with evaporation from the top surface only and substituting into Equation (4) yields

$$
\frac{d x_{i}}{x_{i}}=-\frac{\gamma_{i} \overline{p_{v i}}}{\sqrt{2 \pi M_{i} R_{g} T}} \frac{M_{I r} d t}{h \rho_{I r}}
$$

The solution to Equation (5) is given by

$$
x_{i}=x_{i o} \exp \left(-\frac{\gamma_{i} \overline{p_{v i}}}{\sqrt{2 \pi M_{i} R_{g} T}} \frac{M_{I r} t}{h \rho_{I r}}\right)
$$

in which $\quad x_{i o} \quad$ is the mole fraction at time $t=0$.

In the case of the low initial levels of impurities in the starting powder and assuming that all changes in chemical composition occur only during electron beam melting, then the ratio of impurities in the final sheet product to those in the initial powder shown in Table 1 is numerically equivalent to the calculated value of $X_{i} / X_{i o}$. The vapor pressures of pure elements are taken from CRC Handbook of Chemistry and Physics, 84th Edition. CRC Press. Boca Raton, Florida, 2003. Since there are no available data for the activity coefficient of the impurity elements in iridium, it is only possible to assume an ideal solution $\left(\gamma_{i}=1\right)$ to calculate the impurity ratios which are tabulated in the far right column of Table 3. The button dimensions, melting time, and melting temperature are the same as described above.

The experimentally determined values of the purification ratio of impurity content in the powder to that in melted sheet product are generally in good agreement with the values of the ratio calculated for an ideal solution. In the cases of three of the impurity elements, $\mathrm{Pt}, \mathrm{Rh}$, and $\mathrm{B}$, the measured ratio is somewhat greater than that calculated for an ideal solution. The most likely explanation for the cases of $\mathrm{Pt}$ and $\mathrm{Rh}$ is that the thermodynamic activity coefficient is greater than. The binary phase diagrams for Ir-Pt and Ir-Rh both show a miscibility gap in the solid phase, which is consistent with an activity coefficient, is greater than 1 . In order to obtain agreement of experimental and calculated purification ratios, the activity coefficients would be 1.1 and 2.5 for $\mathrm{Rh}$ and $\mathrm{Pt}$ respectively. In order to obtain agreement of experimental and calculated purification ratios for boron, the activity coefficients would be 1.3. In the case of carbon the measured and calculated purification ratios are essentially the same. In this case some carbon removal may also be due to reaction of carbon with residual oxygen in the sintered powder compact or in the vacuum chamber to form $\mathrm{CO}$ gas. While boron does form volatile oxides, thermodynamic data indicates these oxides are not sufficiently stable to remove 
significant quantities of boron during electron beam melting. (LinkPankratz, L. B., Thermodynamic properties of elements and oxides, Bureau of Mines, 1982)

There are several elements, listed in Group 3 of Table 3 for which the measured purification ratio is less than 12 as compared to much higher calculated ratios. In the cases of $\mathrm{Fe}, \mathrm{Ni}, \mathrm{Cr}, \mathrm{Cu}, \mathrm{Mn}$, and Co it is most likely that these elements are removed with greater efficiency during electron beam melting than indicated by the analysis of the finished rolled sheet product. These elements are present in the stainless steel and copper components of the processing equipment, including that used for subsequent melting and alloying. It is likely that iridium alloy material picks up these impurities in the processing following the purification step of electron beam melting. Analysis is not normally performed on the material immediately following electron beam melting and no data is available for K-batch material. However data for electron beam melted button from G-batch material show levels of $\mathrm{Fe}, \mathrm{Ni}, \mathrm{Cr}$, and $\mathrm{Cu}$ significantly lower than those for the $\mathrm{K}$ batch sheet materials. The data from the electron beam melted button G-19 (29-35) is shown in Table 4. The levels of impurities in the button are considerably lower than in Table 3 and the resulting purification ratios are consistent with the calculated ratios.

There are four elements, which appear in groups 3 and 4 of Table 3 for which the measured purification ratio is far lower than the calculated ratio. These are $\mathrm{Si}$, with a measured ratio of 3 , and $\mathrm{Y}, \mathrm{Ti}$, and $\mathrm{V}$, with ratios of 1 or less. The levels of these impurities reported in Table 3 for the sheet products are not substantially different from those found in the electron beam melted buttons from the G-batch material. It must be concluded that the electron beam melting is not nearly as effective as expected from calculations of an ideal solution of these impurities in molten iridium. The impurity activity coefficients that would produce agreement of the calculated and measured purification ratios are 0.02 for $\mathrm{Si}$ and $\mathrm{V}$, and 0.01 for Ti and $\mathrm{Y}$. While these elements do form intermetallic compounds in the solid state, an indication of strong bonding which is associated with values of activity coefficients less than 1 , it is not clear whether the low efficiency of removal of these impurities is due to such low activity coefficients or some other phenomenon.

The impurity elements with low vapor pressures, $\mathrm{Ru}, \mathrm{Re}, \mathrm{Zr}, \mathrm{Nb}$, and $\mathrm{Mo}$, are not removed by electron beam melting. Generally the concentration of these elements is higher in the sheet product than in the starting powder, although concentrations remain below about $1 \mu \mathrm{g} / \mathrm{g}$. No data are reported for tantalum because sensitivity for tantalum in iridium powder is limited to about $5 \mu \mathrm{g} / \mathrm{g}$ due to the use of a tantalum sample holder. Solid iridium samples are analyzed using a special iridium alloy holder.

Table 4. Comparison of Impurity Contents in K-Batch Iridium Powder With Those of G-19 (29-35) Electron Beam Melted Button.

$\begin{array}{lllll}\text { Element } & \begin{array}{l}\text { K-batch powder } \\ \text { avg. } \mu \mathrm{g} / \mathrm{g}\end{array} & \begin{array}{l}\text { EB button } \\ \text { avg. } \mu \mathrm{g} / \mathrm{g}\end{array} & \begin{array}{l}\text { measured ratio } \\ \text { powder/sheet }\end{array} & \begin{array}{l}\text { calculated ratio } \\ \text { (ideal solution) }\end{array} \\ \mathrm{Fe} & 6.4 & 0.026 & 246 & >10000 \\ \mathrm{Mn} & 0.3 & <0.01 & >30 & >10000 \\ \mathrm{Co} & 0.03 & <0.005 & >6 & >10000 \\ \mathrm{Cr} & 0.8 & 0.0072 & 110 & >10000 \\ \mathrm{Cu} & 1.0 & <0.05 & >20 & >10000 \\ \mathrm{Ni} & 0.6 & <0.01 & >60 & >10000\end{array}$




\subsubsection{Summary-Purification of Iridium Powder Compacts During Electron Beam Melting}

The effectiveness of the purification of iridium during the electron beam melting of iridium powder compacts has been characterized for 37 impurity elements. The average impurity contents of a blend of $54 \mathrm{~kg}$ of iridium powder was compared with average impurity contents of the DOP-26 iridium alloy sheet products produced from that powder. Chemical analysis was performed by glow discharge mass spectrographic (GDMS) analysis for all elements except carbon, which was analyzed by combustion. The impurity levels in the starting powder vary from $37 \mu \mathrm{g} / \mathrm{g}$ to $0.02 \mu \mathrm{g} / \mathrm{g}$. The impurity elements $\mathrm{Cl}, \mathrm{S}, \mathrm{K}, \mathrm{Mg}, \mathrm{Bi}, \mathrm{Pd}, \mathrm{Ca}, \mathrm{Zn}, \mathrm{Tl}, \mathrm{Na}, \mathrm{Pb}, \mathrm{Ba}, \mathrm{B}, \mathrm{P}$, $\mathrm{Li}$, and As are very effectively removed by vaporization during electron beam melting, with measured ratios of initial impurity levels to those after processing of at least 16 to more than 700 . The impurity elements $\mathrm{Sn}, \mathrm{Sb}$, and Te are removed, although quantitative measurement was limited by the very low initial impurity levels in the powder. The levels of the impurity elements $\mathrm{Rh}, \mathrm{Pt}, \mathrm{Cu}, \mathrm{Si}$, and $\mathrm{C}$ are reduced to a lesser degree during processing, with measured ratios of initial impurity levels to those after processing in the range of 2 to 16. Direct comparison with impurity levels in electron beam melted material indicates that the elements $\mathrm{Fe}, \mathrm{Ni}, \mathrm{Cr}, \mathrm{Cu}, \mathrm{Mn}$, and Co are removed during electron beam melting but are picked up at levels of about $5 \mu \mathrm{g} / \mathrm{g}$ or less during subsequent processing. The elements $\mathrm{Ru}, \mathrm{Y}, \mathrm{Re}, \mathrm{Ti}, \mathrm{Zr}, \mathrm{V}, \mathrm{Nb}$, and Mo are not removed during processing. Calculations of expected purification were made using Langmuir's equation for ideal vaporization into a vacuum and an ideal solution model for each impurity in iridium. The calculated values are generally in good agreement with measured values. The impurity elements $\mathrm{Pt}, \mathrm{Rh}$, and $\mathrm{B}$ exhibit somewhat greater reduction in impurity levels than predicted by the ideal solution model, while $\mathrm{Si}$, Ti, and $\mathrm{V}$ show far less reduction in impurity levels than predicted. These results should be relevant to future technical decisions involving acceptance criteria for iridium powder starting materials.

\subsubsection{Conclusions}

The following conclusions can be drawn from this study of the purification of iridium by electron beam melting:

1. The impurity elements $\mathrm{Cl}, \mathrm{S}, \mathrm{K}, \mathrm{Mg}, \mathrm{Bi}, \mathrm{Pd}, \mathrm{Ca}, \mathrm{Zn}, \mathrm{Tl}, \mathrm{Na}, \mathrm{Pb}, \mathrm{Ba}, \mathrm{B}, \mathrm{P}, \mathrm{Li}$, and As are very effectively removed by vaporization during electron beam melting, with purification ratios of at least 16 to more than 700 .

2. The impurity elements $\mathrm{Sn}, \mathrm{Sb}$, and Te are removed, although quantitative characterization was limited by the low initial impurity levels in the powder.

3. The levels of the impurity elements $\mathrm{Rh}, \mathrm{Pt}, \mathrm{Cu}, \mathrm{Si}$, and $\mathrm{C}$ are reduced to a lesser degree during processing, with purification ratios of 2 to 16 .

4. Direct comparison with impurity levels in electron beam melted material indicates that the elements $\mathrm{Fe}, \mathrm{Ni}, \mathrm{Cr}, \mathrm{Cu}, \mathrm{Mn}$, and $\mathrm{Co}$ are removed during electron beam melting but are picked up at levels of about $5 \mu \mathrm{g} / \mathrm{g}$ or less during subsequent processing.

5. The elements $\mathrm{Ru}, \mathrm{Y}, \mathrm{Re}, \mathrm{Ti}, \mathrm{Zr}, \mathrm{V}, \mathrm{Nb}$, and Mo are not removed during processing. 
6. Calculations of expected purification using Langmuir's equation for ideal vaporization into a vacuum and an ideal solution model are generally in good agreement with measured values. The impurity elements $\mathrm{Pt}, \mathrm{Rh}$, and $\mathrm{B}$ exhibit somewhat greater reduction in impurity levels than predicted by the ideal solution model, while $\mathrm{Si}$, Ti, and $\mathrm{V}$ show far less reduction in impurity levels than predicted. 


\subsection{CLAD VENT SET}

\subsubsection{Maintenance Production Summary}

Ten prime Clad Vent Sets (CVS) were shipped in August 2006 to Los Alamos National Laboratory as part of the DOE CVS Production Maintenance program. CVS production facility operability was maintained throughout the year. Training of personnel was maintained for all CVS operations during FY06. Trend analyses were maintained for all part types. No adverse trends were noted at the end of the year. Twelve surveillances, listed below, were successfully completed during the year.

Welding Equipment (Laser and Electron Beam)

Destructive Test of Frit Vent Subassembly

Air burn-off/Vacuum Outgas Witness Specimen SEM Evaluation

SEM of Weld Zone on CVS Production Sample

Reinspection (twice)

Tooling Identification and Control

Measuring and Test Equipment Identification and Calibration (twice)

Independent Assessments

QA Programs

Personnel Training Documentation

\subsubsection{Nonconformance Report, Deviation Requests, and Special Instruction Deviation Request Summaries}

One nonconformance report, NCR-CVS-069, was submitted and accepted for five vent cup assemblies that were processed without a courtesy leak test. Two deviation requests were generated and accepted. The first one, DR-CVS-059, primarily eliminated one leak test by changing the vent cup assembly courtesy leak test to the certification leak test operation. The second deviation request, DR-CVS-060, incorporated revised piercing tooling drawings and limited foil/component thicknesses for both frit vent backing and cover disc fabrication procedures, GPHS-XF-3621 and -3622, respectively. One special instruction deviation request, SIDR-CVS-006, was prepared (and work will continue in FY07) to reduce the incidence of weld burnback during the weld shield electron beam butt weld operation.

\subsubsection{Frit Vent Backing Disc and Frit Vent Cover Disc Piercing Tooling}

Back-up frit vent backing disc and frit vent cover disc piercing tooling sets were fabricated and successfully evaluated. After approval of deviation request DR-CVS-060 (for changes to the frit vent backing and cover disc fabrication procedures, GPHS-XF-3621 and -3622, respectively) the approved procedures and the electronic and hardcopy tooling drawings were put into the configuration control system, the tooling sets were scribed with the correct drawing and revision numbers, and the follow sheets were modified to show the correct fabrication procedure revisions.

\subsubsection{Decontamination Cover Blanking Tooling}

The decontamination cover outer diameters were trending toward the lower specification limit. The first replacement decontamination cover blanking punches and dies did not increase the finished outer diameters. A second die and punch set was installed. Twelve parts were fabricated. A courtesy inspection of the outer diameters indicated this punch and die set was 
producing diameters around the nominal of the specification limits. No additional tooling adjustments were needed.

\subsubsection{Weld Shield Butt Weld Tooling}

The weld shield butt weld process was reviewed for data trends with regard to rewelds and burnback. Higher incidences of rewelds and burnback were found with fixtures 1-3 versus fixtures 4-6. Sixteen new clamps and 8 specimen holders were fabricated and inspected. The clamps were found to be acceptable for prime production use. Unfortunately, using $10 \mathrm{X}-20 \mathrm{X}$ magnification, the specimen holders were found to have insufficient edge quality. The original specimen holders were retained for production use. Unfortunately, the incidence of rewelds and/or burnback remained high.

A special instruction deviation request, SIDR-CVS-006, was written to conduct a study intended to reduce the incidence of weld burnback. The initial results indicated that new specimen holders were needed. Eight standard nickel-plated copper specimen holders are being fabricated along with three stainless steel specimen holders and six stainless steel clamps. The stainless steel items are ready for welding evaluation. Once fabrication of the nickel-plated copper specimen holders is complete they will be dimensionally inspected prior to use, then the SIDR-CVS-006 study will resume.

\subsubsection{Cup Second-Form Die Evaluation}

An evaluation was conducted to determine the effect(s), if any, of the $2^{\text {nd }}$-form die entrant radius and forming surface length on cup dimensions, in particular cup weld zone wall thickness. The majority of formed cups require hand working of one or two locations in the weld zone because of wall thicknesses above the $0.73 \mathrm{~mm}(0.0287 ")$ maximum limit.

Twelve test cups ( 4 sets of 3 each) were $2^{\text {nd }}$-formed with four dies of different entrant radii and forming surface lengths using non-prime blanks. The same $2^{\text {nd }}$-form punch was used to form all 12 cups. The dies had the entrant radius, forming surface length, and forming diameter combinations shown in Table 1. Also shown in Table 1 are the current $2^{\text {nd }}$-form die requirements per ORNL drawing T2E-140186, Rev. F plus the requirements for Galileo and Ulysses production per Monsanto drawing AYD790402, Issue D. The wall thicknesses listed for these drawings are actually the cup weld zone specification limits.

Table 1. Second-Form Die Evaluation (Dimensions are inches)

\begin{tabular}{|l|c|c|c|c|c|}
\hline $\begin{array}{c}\text { Cup Identities } \\
\text { (TC) }\end{array}$ & $\begin{array}{c}\text { Entrant } \\
\text { Radius }\end{array}$ & $\begin{array}{c}\text { Forming } \\
\text { Surface } \\
\text { Length }\end{array}$ & $\begin{array}{c}\text { Forming } \\
\text { Diameter }\end{array}$ & $\begin{array}{c}\text { Minimum } \\
\text { Weld Zone } \\
\text { Wall } \\
\text { Thickness }\end{array}$ & $\begin{array}{c}\text { Maximum } \\
\text { Weld Zone } \\
\text { Wall } \\
\text { Thickness }\end{array}$ \\
\hline $145-147$ & 0.090 & 0.288 & 1.244 & 0.0248 & 0.0280 \\
\hline 151,152, and 162 & 0.180 & 0.190 & 1.244 & 0.0255 & 0.0289 \\
\hline $142-144$ & 0.318 & 0.285 & 1.245 & 0.0255 & 0.0290 \\
\hline $148-150$ & 0.360 & 0.410 & 1.247 & 0.0267 & 0.0290 \\
\hline T2E-140186, Rev. F & $0.30 \pm$ & $0.38 \pm$ & $1.244 \pm$ & 0.0248 & 0.0287 \\
& 0.01 & 0.01 & 0.001 & & \\
\hline AYD790402, Issue D & $0.12 \pm$ & $0.38 \pm$ & $1.250 \pm$ & 0.0248 & 0.0287 \\
& 0.02 & 0.01 & 0.001 & & \\
\hline
\end{tabular}


All 12 cups were formed and fabricated to finished acceptable cups. Cups TC145 - TC147, formed with the sharpest entrant radius (0.090"), had rounded bottoms in the as-formed condition. Table 1 indicates these cups tended to have slightly thinner as-formed weld zone wall thicknesses. Cups TC148 - TC150, formed with the largest entrant radius (0.360") and the longest forming surface $(0.410 ")$, tended to have slightly thicker weld zone wall thicknesses. This probably had as much or more to do with the larger forming die diameter than the entrant radius and/or forming surface length.

The fact that all cups were acceptable with only slight changes in thickness indicates that the $2^{\text {nd }}-$ form process can accommodate a wide range of entrant radii and forming surface lengths without deleteriously affecting the finished cup dimensions. Possible future work will involve reducing the $2^{\text {nd }}$-form punch-to-die clearance. This will be done by making a smaller diameter die so that it can be reworked later to make a back-up production die.

\subsubsection{Carbon and Oxygen Back-up Analytical Qualifications}

Efforts were started in FY06 to qualify a back-up source for carbon and oxygen analytical testing. The current source for carbon and oxygen in iridium analyses is the Oak Ridge Y-12 Plant. The instruments qualified for RPS Program use at Y-12 are a LECO Corporation (St. Joseph, MI) CS400 and a TC436 for carbon and oxygen, respectively.

The first back-up testing source evaluated was Laboratory A which currently uses a Horiba EMIA 820V Carbon/Sulfur Analyzer and a Horiba EMGA 820W Oxygen/Nitrogen Analyzer. Cup segments, sheet samples, foil samples, and powder samples were tested on both instruments with the most extensive efforts made for carbon testing. These efforts were not successful in qualifying either of these instruments.

The next back-up testing source evaluated was Laboratory B which utilizes a LECO CS400 for carbon and a LECO TC500 for oxygen. Unfortunately, lack of attention-to-detail derailed their initial evaluation.

Additional back-up testing sources will be evaluated in FY07 including possibly a LECO CS600 and a LECO TCH600 at the Oak Ridge Y-12 Plant.

\subsubsection{Frit Vent Powder Evaluation}

Seven candidate frit vent powders were evaluated for production use along with the original production powder. These are listed in Table 2. This was done because the supply of the original frit vent production powder, lot 91-0087-jar 4C, had dwindled below $40 \mathrm{~g}$. First new graphite tooling was procured to minimize "powder sticking" with smooth surface finishes $(16 \mu$-inch $\left.V_{\mathrm{rms}}\right)$. Then appropriate foil was selected so that part thicknesses were close to the nominal thickness requirement of $0.13 \mathrm{~mm}(0.005 ")$. This was needed because it had been shown that frit vent backing and cover discs near the maximum thickness requirement of $0.16 \mathrm{~mm}(0.006 ")$ tend to make it very difficult to produce frit vent assemblies with the combined correct flow rate (4.5 $7.5 \mathrm{std} . \mathrm{cc} / \mathrm{min})$ and thickness $(0.41 \mathrm{~mm} \max )$. The evaluations started with SEM/EDS analyses (photos at 500X magnification are shown in Figures 1-3 for the selected production powders) and specific surface area measurements (by the gas adsorption BET technique - results are in Table 2) of the as-received powders screened to the required (per Frit Vent Iridium Powder specification GPHS-M-187, Rev. C) -325/+400 mesh (-45/+38 $\mu \mathrm{m})$. 
Next, frit vent assemblies were made using the standard vacuum sintering $\left(1500^{\circ} \mathrm{C} / 1 \mathrm{~h}\right)$ and vacuum diffusion bonding $\left(1900^{\circ} \mathrm{C} / 2 \mathrm{~h}\right)$ processes. Some as-sintered frits (powder on backing disc only) were examined by SEM/EDS. The remaining frits were completed by diffusion bonding with cover discs on top of the powder, then compressing and testing for flow rate and thickness. The cover discs were manually removed from selected representative frit vent assemblies to qualitatively verify the bond strength. The exposed powder was analyzed by SEM/EDS to assess the diffusion bonded/compressed condition. Primarily based on the processing results two powders, lot 92-0035-jar 6 and lot 21-012800-jar A were selected for likely frit vent assembly production use.

The two selected powders, lot 92-0035-jar 6 and lot 21-012800-jar A, plus the original production powder, lot 91-0087-jar 4C, were evaluated using minimum, nominal, and maximum production diffusion bonding temperatures of $1875^{\circ} \mathrm{C}, 1900^{\circ} \mathrm{C}$, and $1925^{\circ} \mathrm{C}$, respectively. Metallographic evaluations were performed after compressing/testing for flow rate and thickness. SEM/EDS analyses were performed after the cover discs were manually removed and the bond strength was qualitatively verified. Subsequently, these powders were processed (screened, water washed, re-screened, blended, and sampled) and tested (carbon, oxygen, and glow discharge mass spectrometry analyses) under full configuration control per procedure MET-MatP-SOP-109, Rev. 2. The data packages and powders were received for frit vent assembly production use. Eighteen (six from each of the two new production powder lots plus the original production powder lot 910087-jar 4C) prime frit vent assemblies were produced successfully. The quantities of powder available for production use are: $141 \mathrm{~g}$ of Lot 92-0035-Jar 6, $117 \mathrm{~g}$ of batch 21-lot 012800-jar A, and $34 \mathrm{~g}$ of the original lot 91-0087-jar 4C.

It should be noted that the powder specific surface area measurements by the gas adsorption BET technique were made with the hope that this technique would be helpful in discerning "good" and "bad" frit vent powder. The only requirements for frit vent powder are particle size by screening and chemistry, but meeting these requirements does not ensure that acceptable frit vent assemblies can be made. Thus, a time-consuming and expensive trial and error process of preparing candidate powders and then making and testing (flow rate and thickness) frit vent assemblies must be performed. Unfortunately, the gas adsorption BET technique does not seem to be useful as an upfront discriminator for determining what powders will make good frit vent production powders. The results, shown in Table 2, ranged from 0.35 to $0.82 \mathrm{~m}^{2} / \mathrm{g}$ using nitrogen as the adsorbate gas for the 8 powders tested. Additionally, a specific surface area measurement for the original production powder was made using krypton as the adsorbate gas since it reportedly improves the accuracy of low surface area measurements (ASM Handbook, Volume 7, Powder Metal Technologies and Applications, 1998, p. 276).

Table 2. Frit Vent Powders Evaluated

\begin{tabular}{|l|l|c|c|}
\hline $\begin{array}{l}\text { Powder Lot } \\
\text { Identity }\end{array}$ & Jar Identity & $\begin{array}{c}\text { BET Specific } \\
\text { Surface Area } \\
\left(\mathrm{m}^{2} / \mathrm{g}\right)\end{array}$ & Outcome of Powder \\
\hline $91-0087$ & $4 \mathrm{C}$ & $\begin{array}{c}0.23(\mathrm{Kr}) \\
0.48(\mathrm{~N})\end{array}$ & Elevated sodium and chlorine \\
\hline $91-0087$ & 4B & 0.42 & Insufficient quantity \\
\hline $92-0032$ & $5 \mathrm{~A}$ & 0.82 & New production - good \\
\hline $92-0032$ & $5 \mathrm{~A}, \mathrm{~B}, \mathrm{C}$ & 0.55 & Some excess fines, sticking to tooling, FVA low flow/thick \\
\hline $92-0035$ & 6 & 0.38 & Some excess fines, sticking to tooling \\
\hline 6 & 2A & 0.35 & Extreme excess fines, poor flowability - clumping \\
\hline $02 \mathrm{ROO} / 34 \mathrm{~A} 2$ & 2A & 0.58 & New production - good \\
\hline 21,012800 & A & 0.35 & \\
\hline
\end{tabular}


Additional work may be done on these same eight powders to see if in-process compact density measurements can be used to discern "good" from "bad" frit vent powder.

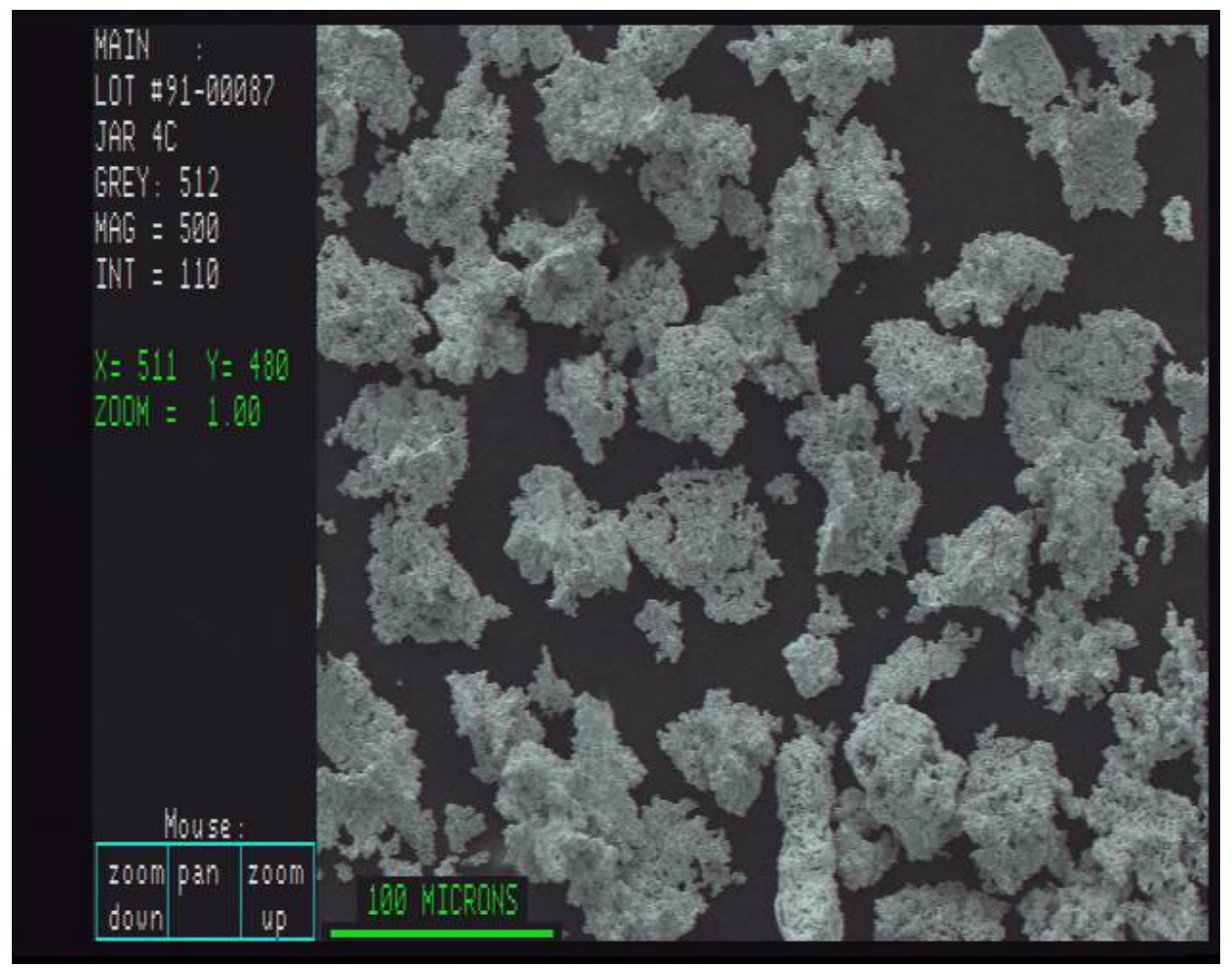

Figure 1. Original production frit vent powder, lot 91-0087-jar 4C, at 500X magnification.

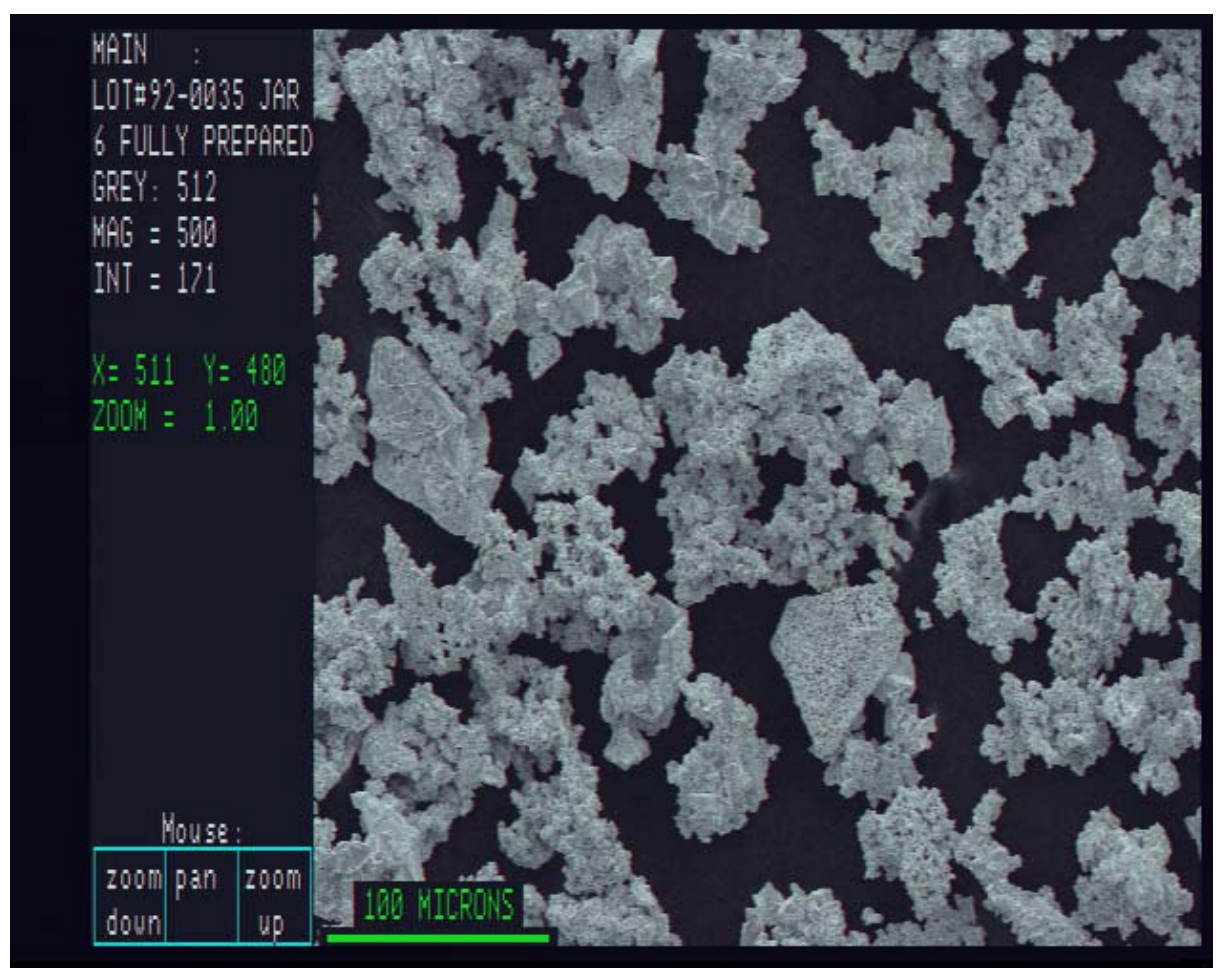

Figure 2. New production frit vent powder, lot 92-0035-jar 6, at 500X magnification. 


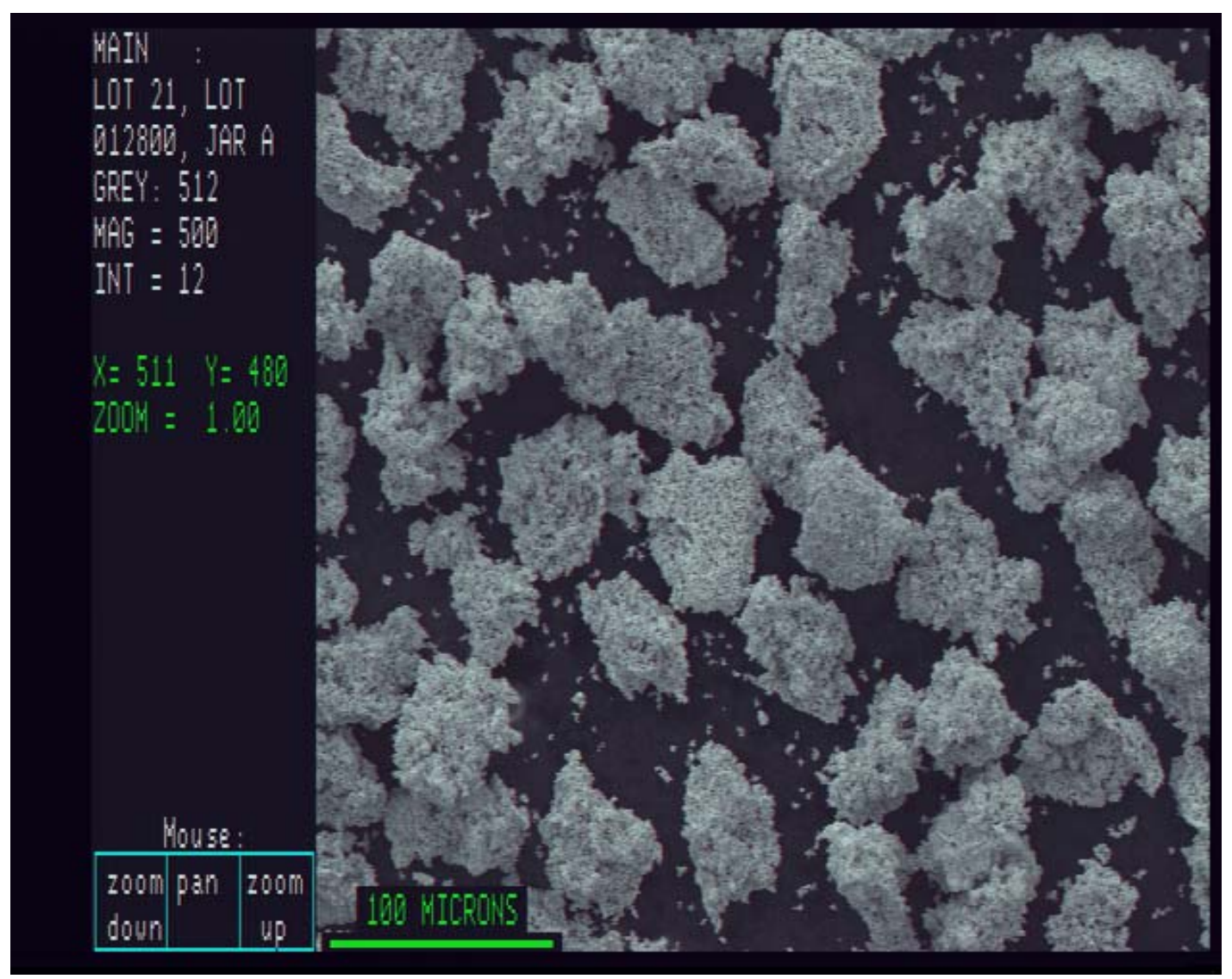

Figure 3. New production frit vent powder, lot 21-012800-jar A, at 500X magnification. 


\subsection{IRIDIUM POWDER AND INVENTORY MANAGEMENT}

The purpose of this work is to manage an iridium inventory for all heat source contractors with emphasis on the significant quantities of iridium located at Los Alamos National Laboratory, Idaho National Laboratory, and Oak Ridge National Laboratory and to maintain a no-change iridium inventory through an annual write-off of inventory and processing losses.

\subsubsection{Iridium Demand and Supply Schedule}

The demand and supply schedule, prepared for contingent planning purposes, presents a strategy to assess the availability of iridium for all improving and producing activities by projecting future demands. An adequate inventory needs to be maintained to meet the needs of the MMRTG, Stirling Radioisotope Generator, and defense missions. The following table indicates that enough iridium will be available for these missions.

The first part of the table shows the estimated production demand factors for prime blanks and foil. The schedule of produced blanks and foil represents the quantity and timing for delivery or storage at Oak Ridge National Laboratory (ORNL). The ingots from new material represent the quantity produced from new iridium powder to make either blanks or foil. These ingots must be produced on a timely basis to meet the lead-time requirement to produce and deliver or store the blanks and foil.

The production of blanks and foil produces recyclable iridium material that can be placed back into the production process at ORNL. A greater economic benefit is realized by using recycled material, since the need to purchase powder from an outside vendor is reduced.

Refinable iridium scrap is also generated from the production of blanks and foil. This scrap is sent to a commercial refinery when a sufficient accumulation occurs at ORNL, funding is available for the refining, and it makes economic sense based on a comparison of refining costs to that of new material.

Process losses of iridium occur during the working of the material at ORNL, Los Alamos National Laboratory, and Idaho National Laboratory. Losses also occur during the refining process. These inventory losses are written-off annually.

The information contained within the table can be summarized as follows. With the completion of the refining contract in FY 2007, there will be an adequate supply of iridium powder to produce the hardware for NASA space and defense missions and $41 \mathrm{~kg}$ will remain at the beginning of FY 2010. 


\section{Demand and Supply Schedule Shows Factors and Provides Strategy to Ensure an Adequate Supply of Iridium Powder for MMRTG, Stirling Generator Program, and Defense Missions}

\begin{tabular}{lcccc}
\hline & \multicolumn{4}{c}{ U. S. Government fiscal years } \\
\cline { 2 - 5 } \multicolumn{1}{c}{ Factors and strategy } & FY 2006 & FY 2007 & FY 2008 & FY 2009 \\
\hline & Production-demand factors & & \\
Produced blanks ${ }^{1}$ & 130 & 30 & 180 & 180 \\
Ingots from new material & 1 & 0 & 1 & 2 \\
Ingots from recyclable material & 1 & 0 & 1 & 0 \\
Produced foil (m ${ }^{2}$ ) & 0 & 0 & 0 & 0.4 \\
& Refining and process losses (kg) & & \\
Refining loss & 0 & 8.0 & 0 & 0 \\
Processing losses & 3.6 & 3.6 & 7.8 & 7.8 \\
& Supply strategy (kg) & & \\
Beginning balance of powder & 43 & 26 & 59 & 75 \\
Receipt of refined powder & 0 & 33 & 33 & 0 \\
Receipt of purchased powder & 0 & 0 & 0 & 0 \\
\hline
\end{tabular}

${ }^{1}$ Estimate of maximum number of blanks

${ }^{2} \mathrm{FY} 2010$ beginning balance of powder is estimated to be $41 \mathrm{~kg}$.

\subsubsection{Annual Write-Off}

The annual fiscal year 2006 write-off of iridium inventory was completed in May. A total of 3.6 $\mathrm{kg}$ of iridium was written off as a normal operating loss. The write-off appropriately reduced the non-fund iridium inventory. This $3.6 \mathrm{~kg}$ loss was considered a normal operating loss compared to the history of iridium losses during the past several years.

\subsubsection{Iridium Accountability Reviews}

The review at ORNL was conduced in March. The purpose of this review was to evaluate the accountability, physical inventory, and security of iridium at ORNL. It was concluded that the accountability, physical inventory, and security for the iridium was in place and operating in a proper manner. One recommendation was proposed to enhance the present accountability and inventory systems.

The review at LANL was conduced in July. The purpose of this review was to evaluate the accountability, physical inventory, and security of iridium at LANL. It was concluded that the accountability, physical inventory, and security for the iridium was in place and operating in a proper manner. No recommendations were necessary. 
The review at INL was conducted in August. The purpose of this review was to evaluate the accountability, physical inventory, and security of iridium at INL. INL personnel will be furnishing additional information to determine if the accountability, physical inventory, and security of iridium were in place and operating in a proper manner.

\subsubsection{Shipment of Iridium}

The shipment of ten (10) iridium alloy clad vent sets to LANL departed ORNL on August 15 and arrived at LANL on August 16. The security seals on the shipping container were intact upon arriving at LANL. U. S. Department of Energy Transfer Voucher No. 100-OR4-NS4-127 dated August 23 was issued to properly account for this shipment. 


\subsection{ALLOY CHARACTERIZATION}

\subsection{TENSILE BEHAVIOR OF Ta-10W}

The objective of this task is to characterize the mechanical and metallurgical properties of metallic materials that are of interest to the Radioisotope Power Systems Program. Current materials of interest include DOP-26 iridium, Ta-10W, and T-111. Summarized below are the results of our activities during FY 2006.

\subsection{2 “Low-Temperature” Tensile Impact Ductility of DOP-26 Iridium}

DOP-26 iridium has been used successfully as a fuel-cladding material in radioisotope thermoelectric generators (RTGs) aboard many interplanetary spacecraft. New RTGs being designed for future missions may have operating temperatures that are lower than in previous designs. The purpose of this study is to extend the database of the tensile impact ductility of DOP-26 iridium down to lower temperatures $\left(500-900^{\circ} \mathrm{C}\right)$. Tensile impact tests were performed on DOP-26 iridium having grain sizes of $23-35 \mu \mathrm{m}$ at temperatures of $500-900^{\circ} \mathrm{C}$ and a bullet velocity of $61 \mathrm{~m} / \mathrm{s}$ (which corresponds to an engineering strain rate of $\sim 10^{3} \mathrm{~s}^{-1}$ ). Ductility increased with increasing test temperature for all three grain sizes. Associated with this increase in ductility with increasing temperature is a change in the fracture mode from intergranular to transgranular. Additional tests are planned, depending on the availability of DOP-26 blanks, which will allow us eventually to test 4 specimens at each test condition (over the grain size and temperature range of $30 \pm 5 \mu \mathrm{m}$ and $700 \pm 200^{\circ} \mathrm{C}$ ).

\subsubsection{Effects of Grain Size and Strain Rate on Strength and Ductility of DOP-26 Iridium}

The DOP-26 iridium alloy is used as cladding material for the plutonia fuel in radioisotope thermoelectric generators. We recently initiated a study to determine the mechanical properties of new-process DOP-26 as a function of temperature, strain rate, and grain size. This year we investigated one grain size and three strain rates. Over time, we plan to generate a complete mechanical properties data-set for the different grain sizes, strain rates, and temperatures of interest to the Radioisotope Power Systems Program. The yield strength, ultimate strength, and ductility (\% elongation) of DOP-26 iridium were found to be relatively insensitive to strain rate at strain rates of $\sim 10^{-3}$ to $10^{-1} \mathrm{~s}^{-1}$. Over this strain-rate range, yield strength was moderately temperature dependent, decreasing from $\sim 130$ to $\sim 60 \mathrm{MPa}$ as the temperature increased from 77 to $1273 \mathrm{~K}$. Ultimate tensile strength was roughly temperature-independent up to $\sim 673 \mathrm{~K}$, beyond which it decreased from 500-600 MPa to $230 \mathrm{MPa}$ at $1473 \mathrm{~K}$. Tensile ductilities (\% elongations) increased from $\sim 5 \%$ at $77 \mathrm{~K}$ to $\sim 40 \%$ at $1473 \mathrm{~K}$. Correspondingly, the fracture mode changed from mostly intergranular at low temperatures, to mixed intergranular plus transgranular at intermediate temperatures, to fully transgranular with significant local reduction in area (necking) at elevated temperatures. Upon comparing these results with those obtained in tensile impact tests performed at a much higher strain rate of $10^{3} \mathrm{~s}^{-1}$, it is found that although the ductility of DOP-26 iridium is not strain rate sensitive at the lower strain rates, it does become strain rate sensitive at the higher strain rate. Additional tests are needed to determine the exact range of strain rates where ductility does become strain rate sensitive. Similarly, additional tests are needed to determine whether the yield and ultimate strength of DOP-26 iridium are strain rate sensitive and, if so, the strain rates over which this happens. Experiments are planned to bridge at least part of this gap (up to a strain rate of $\sim 50 \mathrm{~s}^{-1}$ ) during the next year. 


\subsubsection{Effects of Copper on the Tensile Impact Ductility of DOP-26 Iridium}

Over the years, researchers at Oak Ridge National Laboratory have investigated the effects of various trace elements and impurities on the metallurgical properties and mechanical behavior of DOP-26 iridium. These include Th and $\mathrm{Ce}$, which are beneficial; $\mathrm{Ni}, \mathrm{Fe}, \mathrm{Cr}$, and $\mathrm{Al}$, which are benign; and $\mathrm{Si}$, which is harmful. Recently, we began an investigation of the effects of $\mathrm{Cu}$ because, during melting and casting, the DOP-26 alloy comes into contact with copper. Therefore, it is of interest to determine whether accidental contamination with $\mathrm{Cu}$ can have any deleterious effects. The effects of $\mathrm{Cu}$ concentrations in the range 7-42 wppm on the tensile impact ductility of DOP-26 iridium were investigated. Our preliminary results indicate a possible embrittling effect of $\mathrm{Cu}$ even at relatively low levels. The $\mathrm{Cu}$-containing alloys had both lower ductilities and greater amounts of intergranular fracture compared to DOP-26 iridium containing no added copper. Auger analyses are planned to identify the underlying physical mechanism for the $\mathrm{Cu}$-induced embrittlement. Additionally, some of the tensile impact tests will be repeated during FY 2007 to get better statistics.

\subsubsection{Effects of Oxygen on the Elevated Temperature Tensile Ductility of Ta-10W}

Ta-10W is being considered as a pressure-vessel material to contain the He gas that is released when the plutonia pellets in the radioisotope thermoelectric generators (RTGs) decay during service. One of the potential problems associated with such an application is oxygen-induced embrittlement from long-term exposure to the plutonia fuel. Another concern is whether it will absorb interstitial elements (especially oxygen) during processing. In tensile tests performed at conventional (quasi-static) strain rates, it was previously shown that oxygen severely embrittled $\mathrm{T}-111$. In this work, the effects of oxygen on Ta-10W, at quasi-static and impact strain rates, are being investigated at temperatures to $1100^{\circ} \mathrm{C}$ for subsequent comparison with $\mathrm{T}-111$ at impact strain rates. At all temperatures, the general trend is that ductility decreases with increasing oxygen concentration. Associated with this drop in ductility is a change in the fracture mode from ductile transgranular to brittle intergranular. The oxygen concentration at which ductility decreases sharply (the ductile-brittle transition) depends on the test temperature: the data obtained so far indicates that impact ductility is relatively insensitive to test temperatures in the range $300-1100^{\circ} \mathrm{C}$, with the embrittling effect of oxygen similar at all these temperatures. At room temperature, however, oxygen has a more severe embrittling effect. This behavior is opposite to that observed at slow strain rates $\left(\sim 10^{-3} \mathrm{~s}^{-1}\right)$ where the embrittling effect of oxygen is more severe at elevated temperatures than at room temperature. We think this difference is related to the kinetics of oxygen transport to crack tips and additional experiments are planned to better understand the mechanism of oxygen-induced embrittlement. 


\subsection{ORNL CHARACTERIZATION OF MIN-K TE-1400}

\subsubsection{Introduction}

Oak Ridge National Laboratory (ORNL) was requested to characterize the thermomechanical properties of Thermal Ceramics Min-K 1400TE material, hereafter referred to as Min-K, in support of its Multi-Mission Radioisotope Thermoelectric Generator (MMRTG) Program. In particular, ORNL was tasked with the determination of the high temperature compressive strength and stress relaxation behavior of Min-K up to $900^{\circ} \mathrm{C}$ in helium along with the formulation of a general model for the mechanical behavior exhibited by Min-K. Testing was to consist of general high temperature compressive mechanical testing, isothermal stress relaxation testing, and stress relaxation testing of samples exposed to a thermal gradient.

A previous report written last year, "ORNL Characterization of Min-K TE-1400 FY'05", describes the initial compression testing performed at room temperature and under various loading rates to determine the required sample sizes and geometries for compressive test specimens. The results from these initial tests indicated that there was no effect of sample geometry on the monotonic compressive strength of Min-K leading to subsequent testing being performed on cylindrical specimens. Additionally, compression tests were carried out to determine the loading rates that would be used for subsequent stress relaxation tests.

Isothermal and gradient stress relaxation testing performed last year is also described in the previous report. Isothermal stress relaxation testing was carried out on 6" diameter, 2" long cylindrical samples at temperatures of $850,813,650,550,382$, and $190^{\circ} \mathrm{C}$ and initial loads of 100 or 200 psi. Gradient stress relaxation testing was carried out on 6" diameter, 3" long cylindrical samples under gradients of $850 / 275^{\circ} \mathrm{C}$ and $400 / 190^{\circ} \mathrm{C}$ with initial loads of 100 or 200 psi. Analysis of test results was supported by SEM/EDS analysis of Min-K fractured surfaces, evaluation of elastic modulus changes due to densification, and thermal conductivity measurements.

Stress relaxation results were used to formulate several finite element and mathematical models, also described in the previous report. Mathematical model formulation was initially performed with all collected isothermal data being fit to determine constants with respect to temperature and time. Data from isothermal stress relaxation testing was also incorporated into the finite element program ANSYS with it being found that the data at each test temperature could be modeled by using the time hardening creep equation. Analyses were performed for several isothermal cases to verify this creep model. The material model in ANSYS was applied to a finite element model with the results of this analysis showing good agreement with test data. After the applicability of the creep model was verified for the isothermal case at different temperatures, the model was used to analyze the gradient temperature condition. Initial analyses were performed for the case of a uniform gradient along the main axis of the model, but the results of this analysis predicted much more stress relaxation than what had been determined experimentally. A temperature gradient more closely matching the actual test temperature distribution during testing was then used to repeat the analysis ANSYS and it was found to fit the experimental results much more closely. Additionally, a closed form solution was found to describe the stress relaxation behavior.

Work was continued this fiscal year to further characterize the elevated temperature mechanical behavior of Min-K TE-1400. Additional gradient stress relaxation testing was performed and test equipment was redesigned to facilitate longer-term testing. Additionally, modeling efforts were refined to predict the long-term mechanical behavior of the Min-K material when subjected to a temperature gradient condition. 


\subsubsection{Experimental Procedures}

An effort was undertaken to convert the two current isothermal stress relaxation frames to gradient stress relaxation frames and to improve the robustness of the gradient stress relaxation testing in an effort to complete tests of six-month to one-year duration. To facilitate this, the test frames were retrofitted with new heater platens, improved thermal insulation, improved electrical connections, and a back-up power supply system to run all four retrofitted test frames. The backup power supply system is shown in Figure 1.

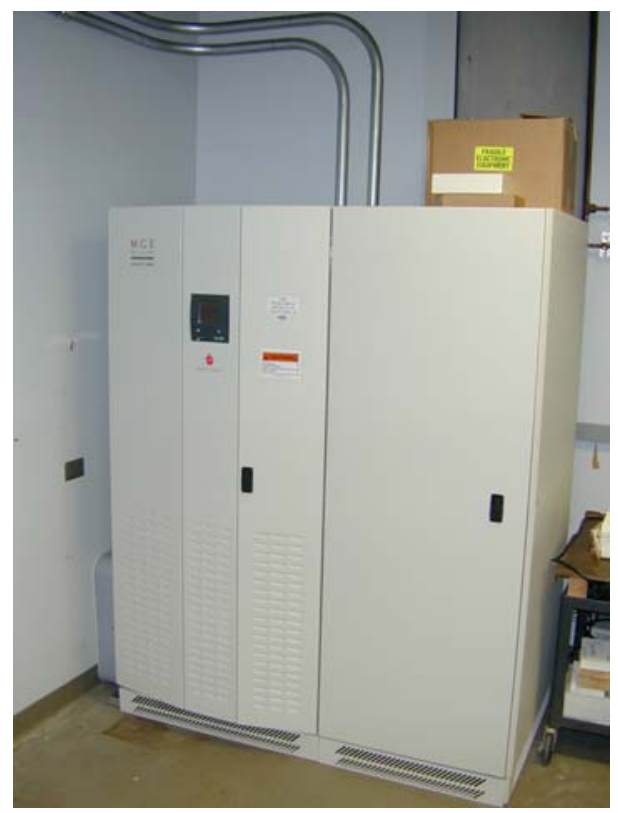

Figure 1. Installed Back-Up Power Supply System for gradient Test Systems

Gradient stress relaxation testing was again performed using 6-inches diameter by 3 -inches long cylindrical samples. Temperature gradients for new testing consisted of $700 / 100^{\circ} \mathrm{C}$ (5 tests) and $800 / 190^{\circ} \mathrm{C}$ ( 1 test) with initial loads of $200 \mathrm{psi}$. A modified test procedure was written, based on the previous gradient stress relaxation test procedure and testing was performed using a set-up similar to the one shown in Figure 2. This set-up consists of an electromechanical testing machine (Instron Model 1380) equipped with load and displacement digital controllers, a $35 \mathrm{kN}$ load cell, a heated Inconel platen above and below the sample, and a single zone furnace. An aluminum environmental chamber with helium flow is used for controlling the environment. 

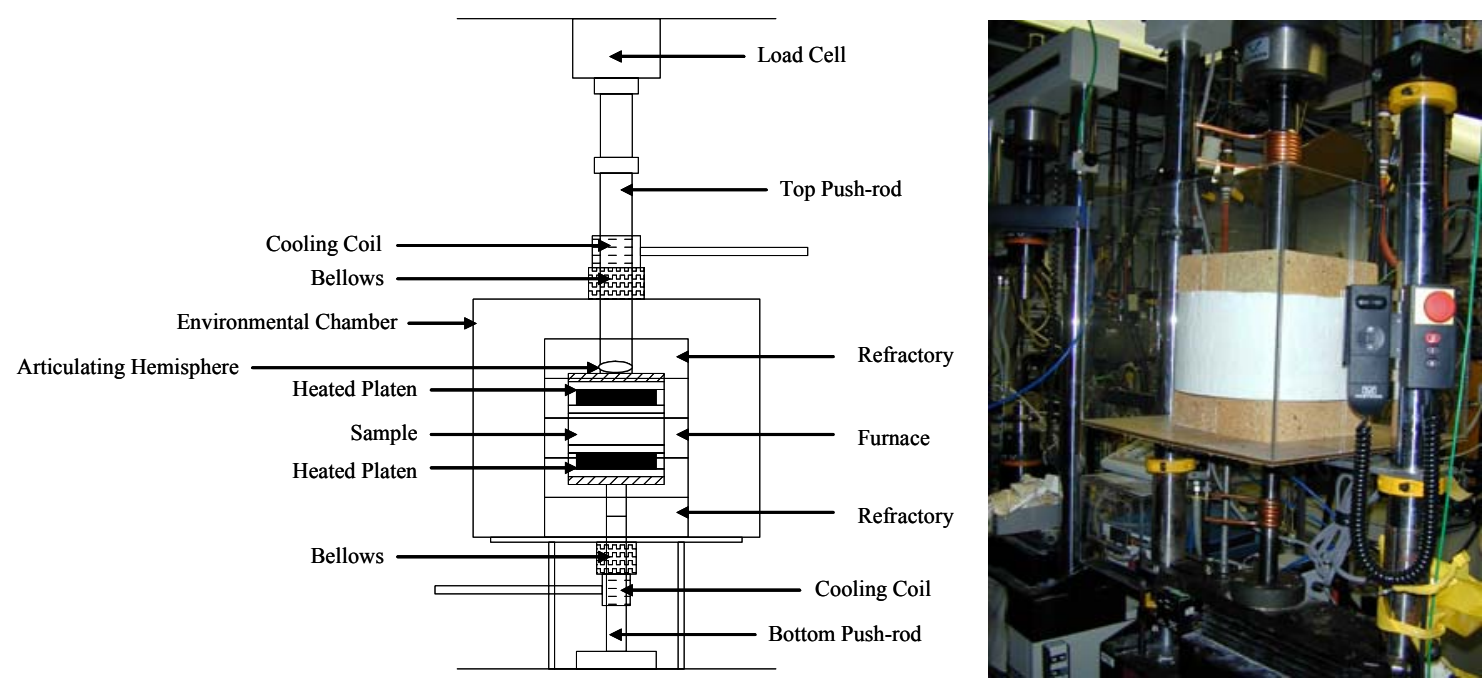

Figure 2. Gradient Stress Relaxation Test Frame

Loading was performed in strain control utilizing a 12 step loading scheme with loading every half hour at a rate of $5.56 \%$ strain/hour. Loading was followed by stress relaxation in strain control with testing scheduled to be carried out for six-months (4400 hours) and possibly extended to one-year. Efforts were attempted on tests that had met or nearly met the 4400 hour time frame to simulate the EDL/MSL Transient Strain Events. These efforts involved four phases of testing. During Phase I of this testing, the strain was raised under displacement control to simulate housing cooling. The test was then allowed to sit for approximately four days under fixed displacement. After sitting, Phase II was initiated by decreasing the strain under displacement control to simulate the EDL expansion event. The sample was then held again under fixed displacement for thirty minutes. Phase III consisted of switching to load control and holding the existing stress level for one hour to collect data on the creep rate of the material given the post EDL stress level. Following the hold, the system was switched back to displacement control and Phase IV was started. For this phase, the strain was returned back to the original strain level. Following Phase IV, the test was put back in hold under fixed displacement.

Additional test specimens for gradient testing were obtained and an effort was made to trace current and previous test specimens to specific batches supplied by Thermal Ceramics. An effort was also made to correlate specimen densities to specific test results. As far as could be determined, the corresponding sample densities, batch designations and test numbers are shown in Table A1 of the Appendix.

\subsubsection{Results}

The initial $700 / 100^{\circ} \mathrm{C}$ gradient test (Gradient Test \#9) was ended after running for only $\approx 300$ hours and relaxing to $138 \mathrm{psi}$ due to noise in the data. At the conclusion of this test, an unloading study was performed by removing $1.3 \%$ strain over a one hour period. This was followed by a 2 hour hold under constant displacement. The unloading event resulted in a reduction in stress of $\approx 62 \mathrm{psi}$ and the hold period resulted in a recovery of $\approx 2 \mathrm{psi}$. The results of this test are shown in Figure 3. Following the retuning of the displacement controller, a new $700 / 100^{\circ} \mathrm{C}$ gradient test (Gradient Test \#10) was started on the frame. 


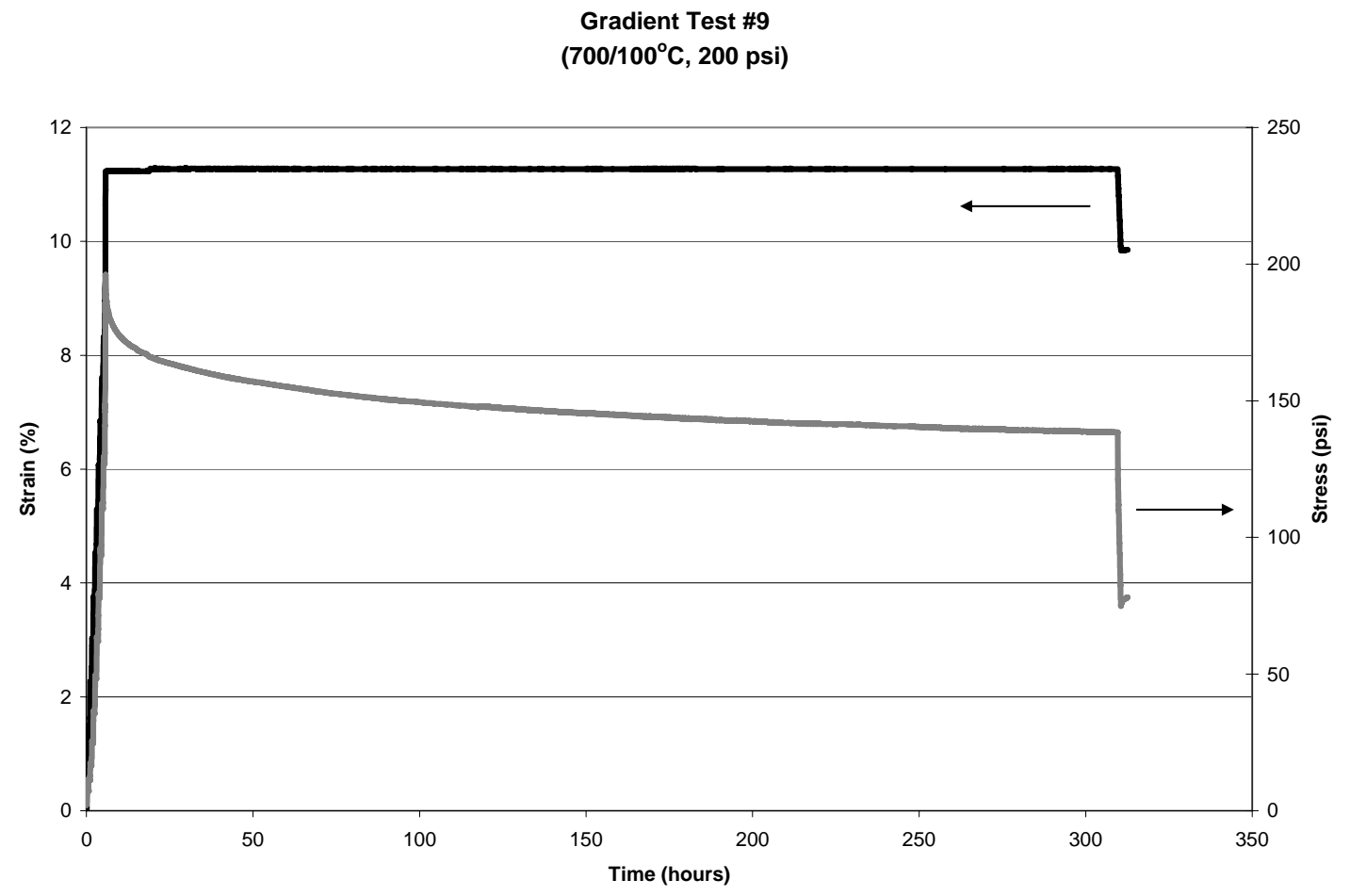

Figure 3. Results from Initial $700 / 100^{\circ} \mathrm{C}$ Gradient Stress

Relaxation Test with Unloading Study at Conclusion of Test

The test run with a $800 / 190^{\circ} \mathrm{C}$ gradient (Test \#8) was ended after nearly 2150 hours due to a failure of the top heater platen. An unloading study could not be run on this test due to the loss of temperature and corresponding stress on the sample. At the time the test lost temperature, the stress had relaxed to $108 \mathrm{psi}$. Upon cooling, the stress relaxed to $65 \mathrm{psi}$. The results of this test are shown in Figure 4. Following replacement of the top platen, a new $700 / 100^{\circ} \mathrm{C}$ gradient test (Gradient Test \#13) was started on the frame. 


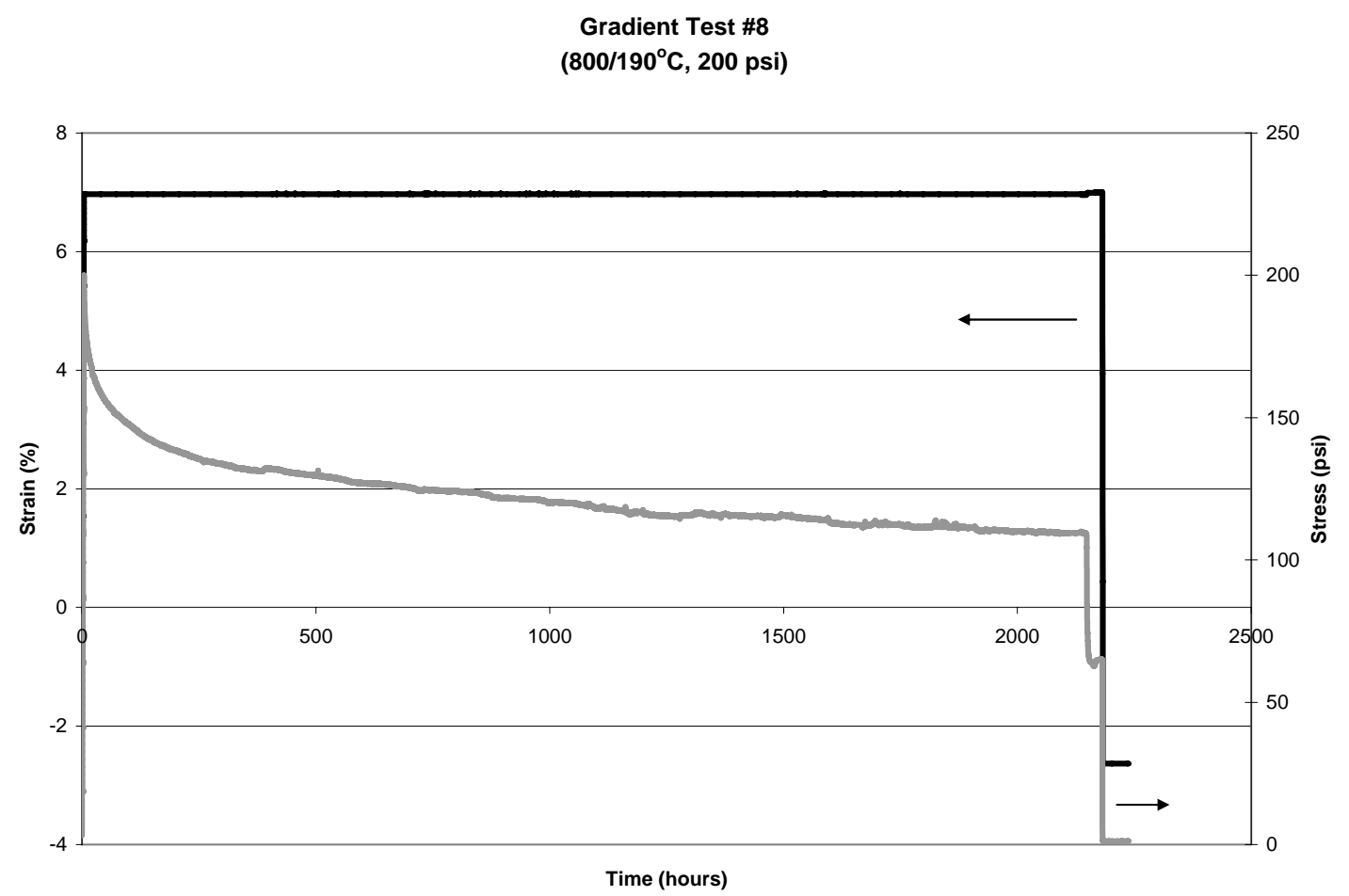

Figure 4. Results from $800 / 190^{\circ} \mathrm{C}$ Gradient Stress

Relaxation Test Ended Due to Loss of Top Platen

Upon completion of the conversion of the two isothermal test frames to gradient test frames and the connecting of these frames to the back-up power supply, testing was initiated on these frames. On the first frame, a $700 / 100^{\circ} \mathrm{C}$ gradient test was started (Gradient Test \#11). On the second frame, a short-term loading test was performed over a one week period to evaluate the effects of preloading a specimen to $180 \mathrm{psi}$ and then heating it to a gradient condition of $700 / 100^{\circ} \mathrm{C}$ to mimic the actual loading conditions of the Min-K material in service. Following the heating over a twenty-four hour period, the sample was allowed to sit at temperature for thirteen hours while stress relaxation occurred. The sample was then cooled over a six and a half hour period, after which the stress was removed by removing the accumulated strain over a two hour period. Results of this testing are shown in Figure 5. Following completion of the short-term loading test, a $700 / 100^{\circ} \mathrm{C}$ gradient test (Gradient Test \#15) was started on the second frame. 
Short-Term Loading Test

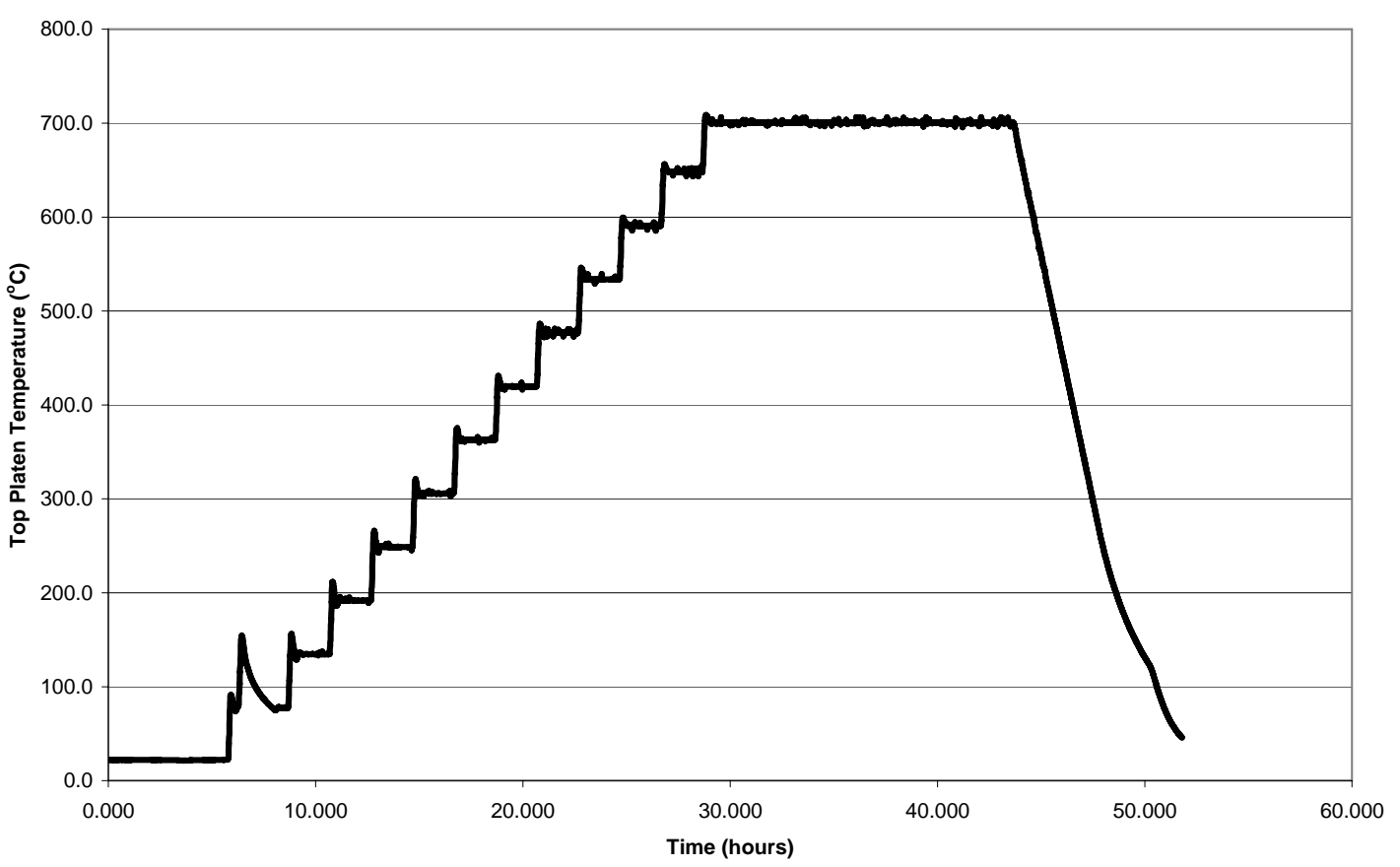

a)

Short-Term Loading Test

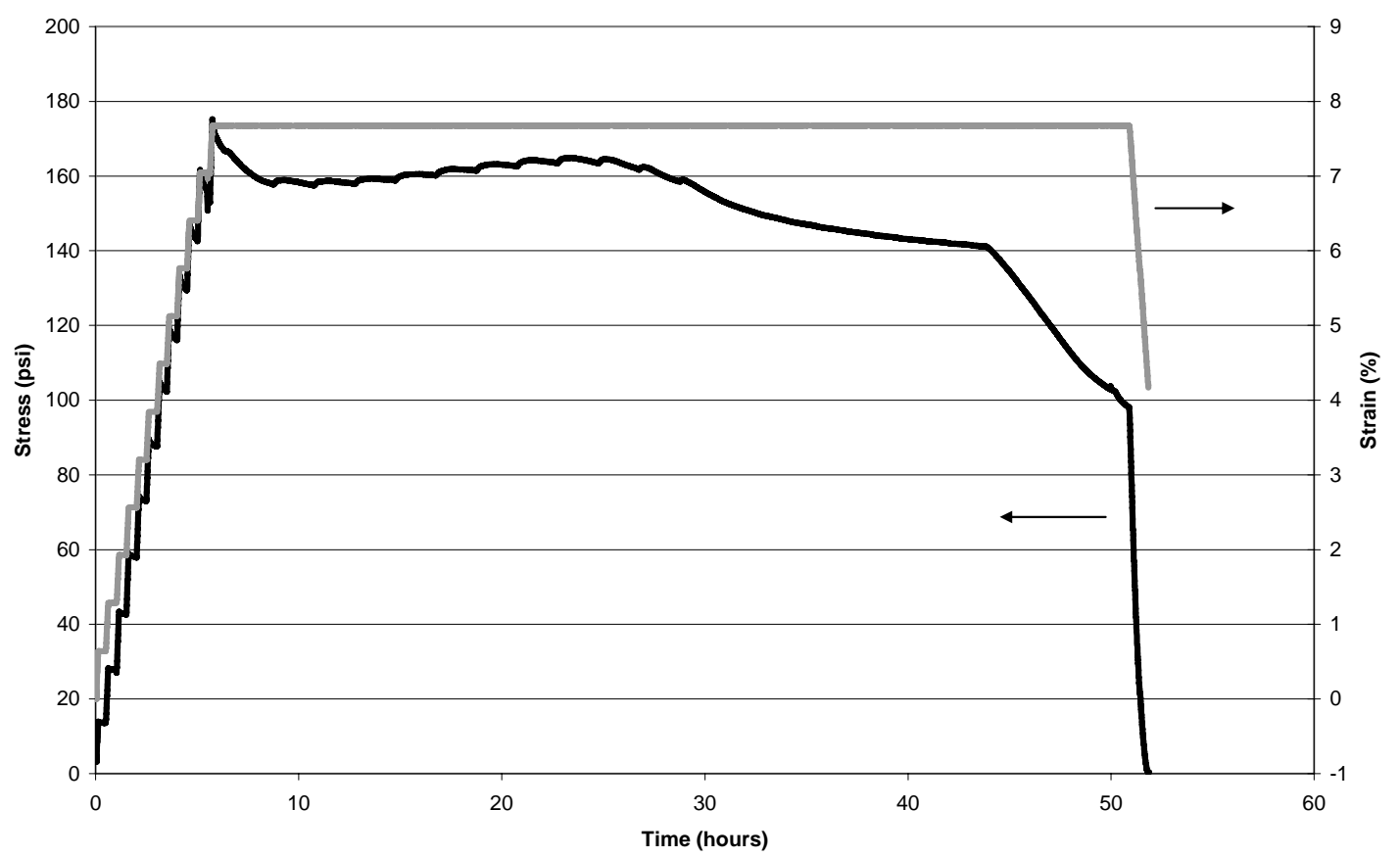

b)

Figure 5. Results from Short-Term Loading Test to Evaluate Min-K Performance Under Actual Expected Loading Conditions - (a) Temperature Cycle, (b) Stress and Strain Behavior. 
At the time of the writing of this report, the four current gradient stress relaxation tests (Gradient Test \#10,\#11,\#13, and \#15) were still on-going. Test \#10,\#11, and \#13 had testing attempted on them to simulate the EDL/MSL Transient Strain Events. Test \#15 has been running unaltered.

Test \#10 is currently the longest running gradient test to date. Due to a stuck crosshead, the EDL/MSL testing could not be run on this frame, but continued monitoring of the stress relaxation under a fixed displacement has been possible. At the end of the fiscal year, this test had been running for over 5525 hours and has relaxed to 127 psi. Results for this test are shown in Figure 6.

Gradient Test \#10

$\left(700 / 100^{\circ} \mathrm{C}, 200 \mathrm{psi}\right)$

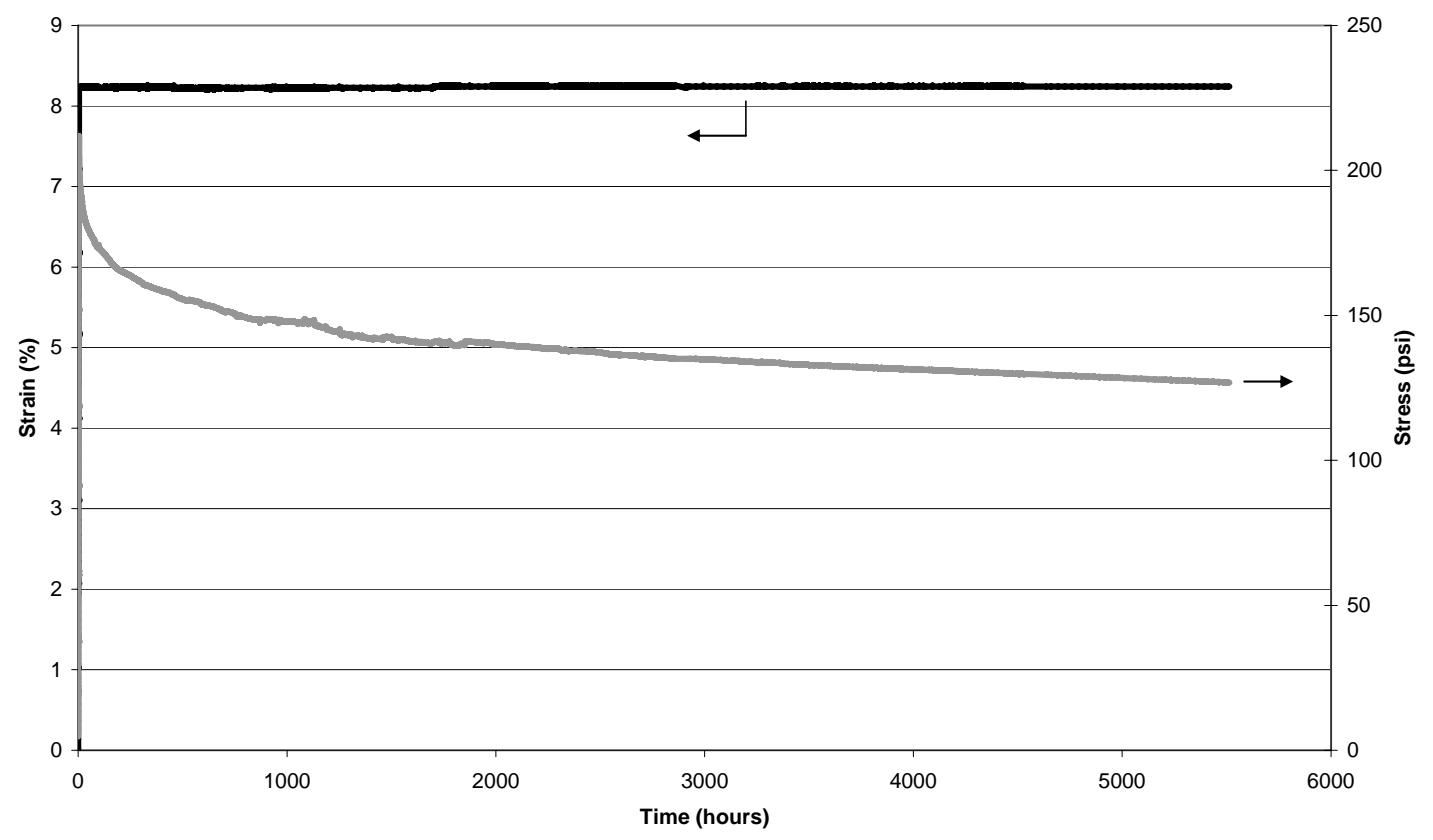

Figure 6. Results from Current $700 / 100^{\circ} \mathrm{C}$ Gradient Stress Relaxation Test (Test \#10)

EDL/MSL testing was also attempted on Test \#11. At the time of testing, this test had been running for over three months with over 3460 hours of data collected and had relaxed to 108 psi. This test was not successful and resulted in the sample being overloaded. After discussion with Rocketdyne, it was decided to attempt an unloading of the specimen back to the original strain level. During this unloading nearly the entire load was removed and the unloading was stopped with approximately 25 psi remaining on the specimen. The test was then allowed to sit under fixed displacement after these events. At the end of the fiscal year, this test had been running for over 4100 hours and was at a level of 59 psi. Results for this test are shown in Figure 7. 
Gradient Test \#11

$\left(700 / 100^{\circ} \mathrm{C}, 200 \mathrm{psi}\right)$

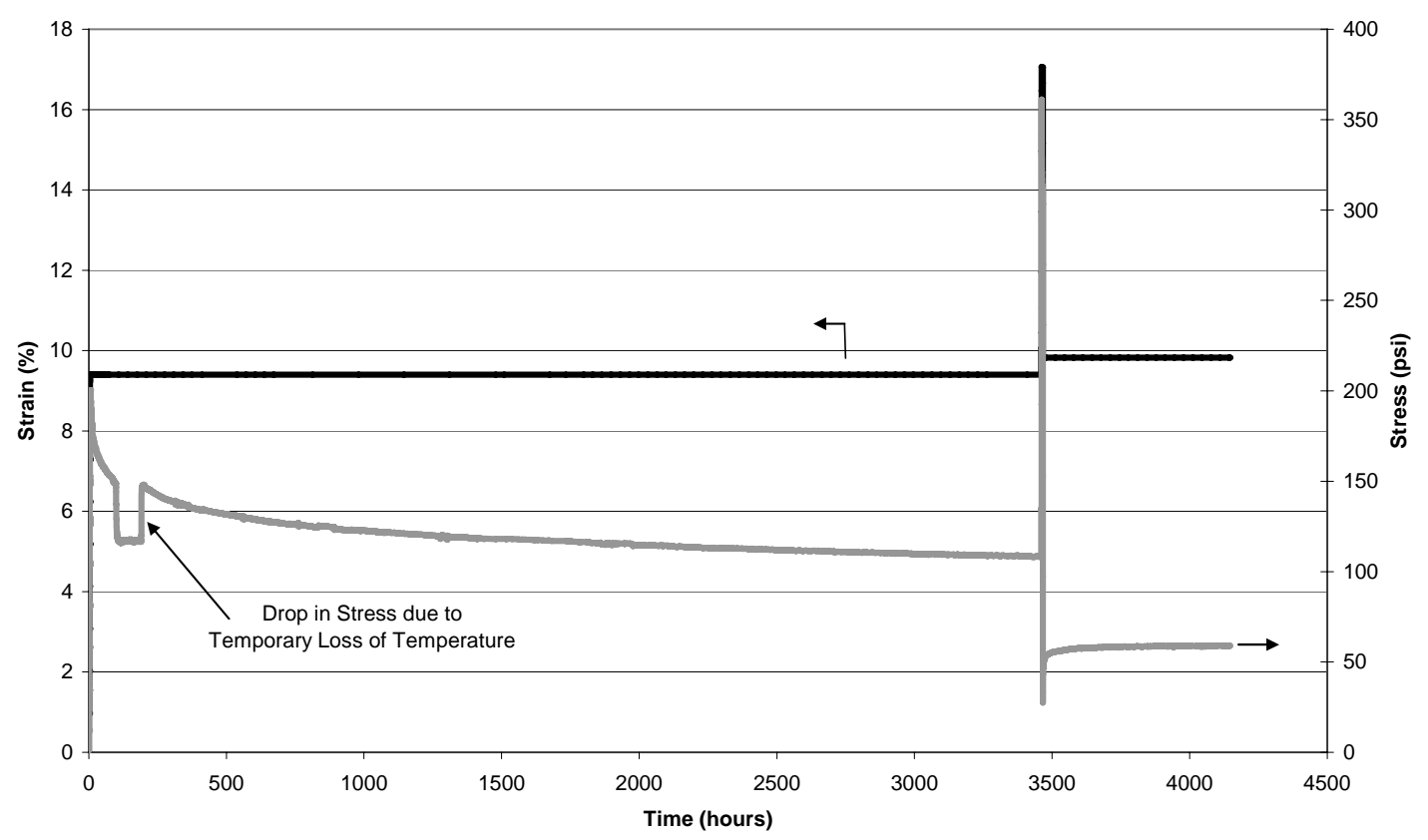

Figure 7. Results from Current $700 / 100^{\circ} \mathrm{C}$ Gradient Stress Relaxation Test (Test \#11)

EDL/MSL testing was also performed on Test \#13. At the time of testing, this test had been running for over 2945 hours and had relaxed to 119 psi. Phase I of the testing was successfully completed, raising the strain from $11.493 \%$ to $11.953 \%$ and the stress from 119 psi to 137 psi. The test was then allowed to sit for approximately four days under fixed displacement. After sitting, the sample had relaxed to a stress of 135 psi. Following this hold, Phase II was initiated by decreasing the strain from $11.953 \%$ to $11.320 \%$ at a rate of $1.52 \%$ /hour. This resulted in a loss of stress from approximately $135 \mathrm{psi}$ to roughly $110 \mathrm{psi}$. The sample was then held again under fixed displacement for thirty minutes. Phase III consisted of switching to load control and holding the existing stress level for one hour. During this time, no measurable change in the strain level was seen. Following the hold, the system was switched back to displacement control and Phase IV was started. For this phase, the strain was returned from $11.320 \%$ back to the original strain level of $11.493 \%$. This resulted in a change of stress from approximately 110 psi to 118 psi. Following Phase IV, the test was put back in hold under fixed displacement. At the end of the fiscal year, this test had been running for over 3025 hours and was at a level of 118 psi. Results for this test are shown in Figure 8. 
Gradient Test \#13

$\left(700 / 100^{\circ} \mathrm{C}, 200 \mathrm{psi}\right)$

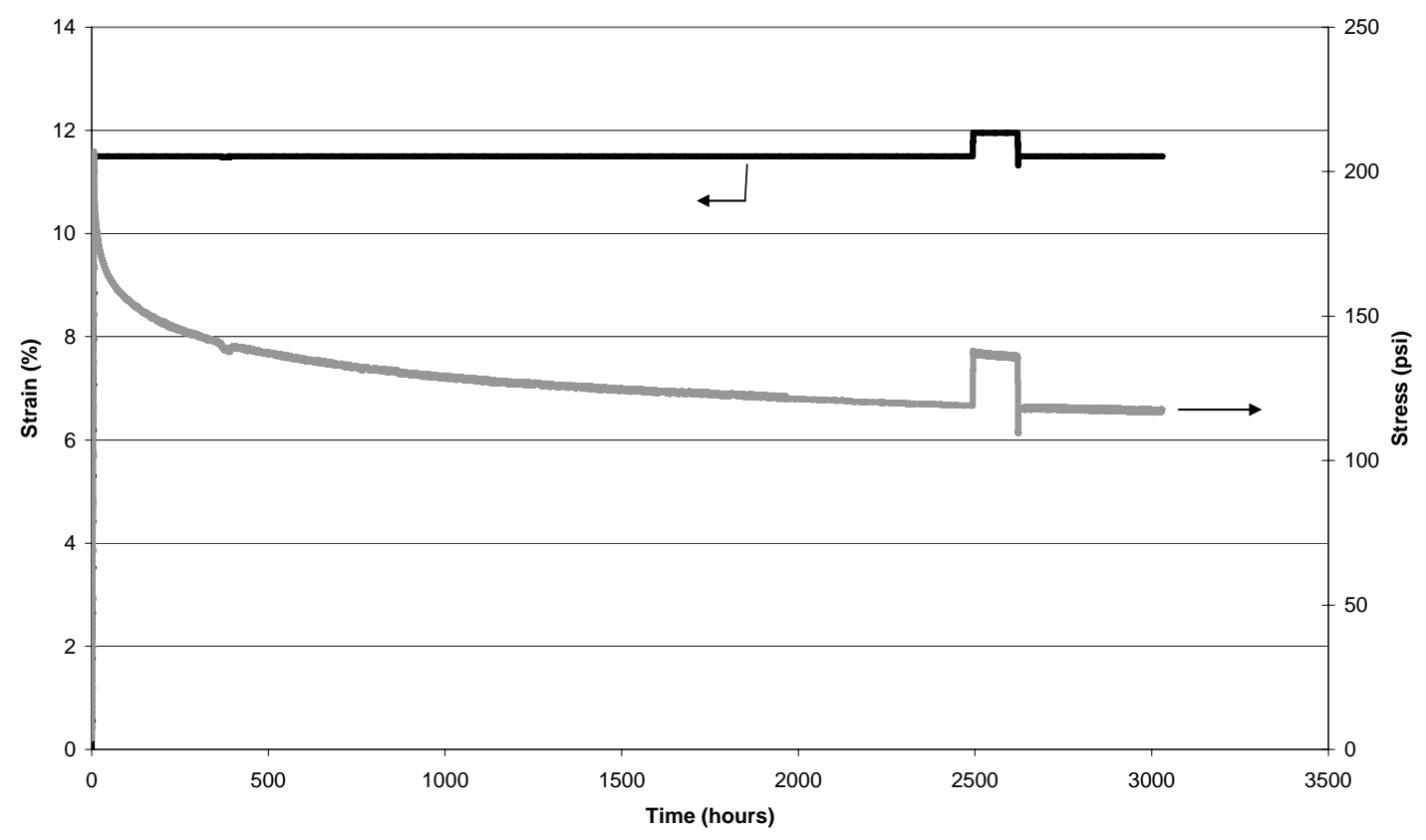

Figure 8. Results from Current $700 / 100^{\circ} \mathrm{C}$ Gradient Stress Relaxation Test (Test \#13)

Test\#15 has been running the least amount of time for almost 2700 hours and had relaxed to 134 psi as shown in Figure 9.

Gradient Test \#15

$\left(700 / 100^{\circ} \mathrm{C}, 200 \mathrm{psi}\right)$

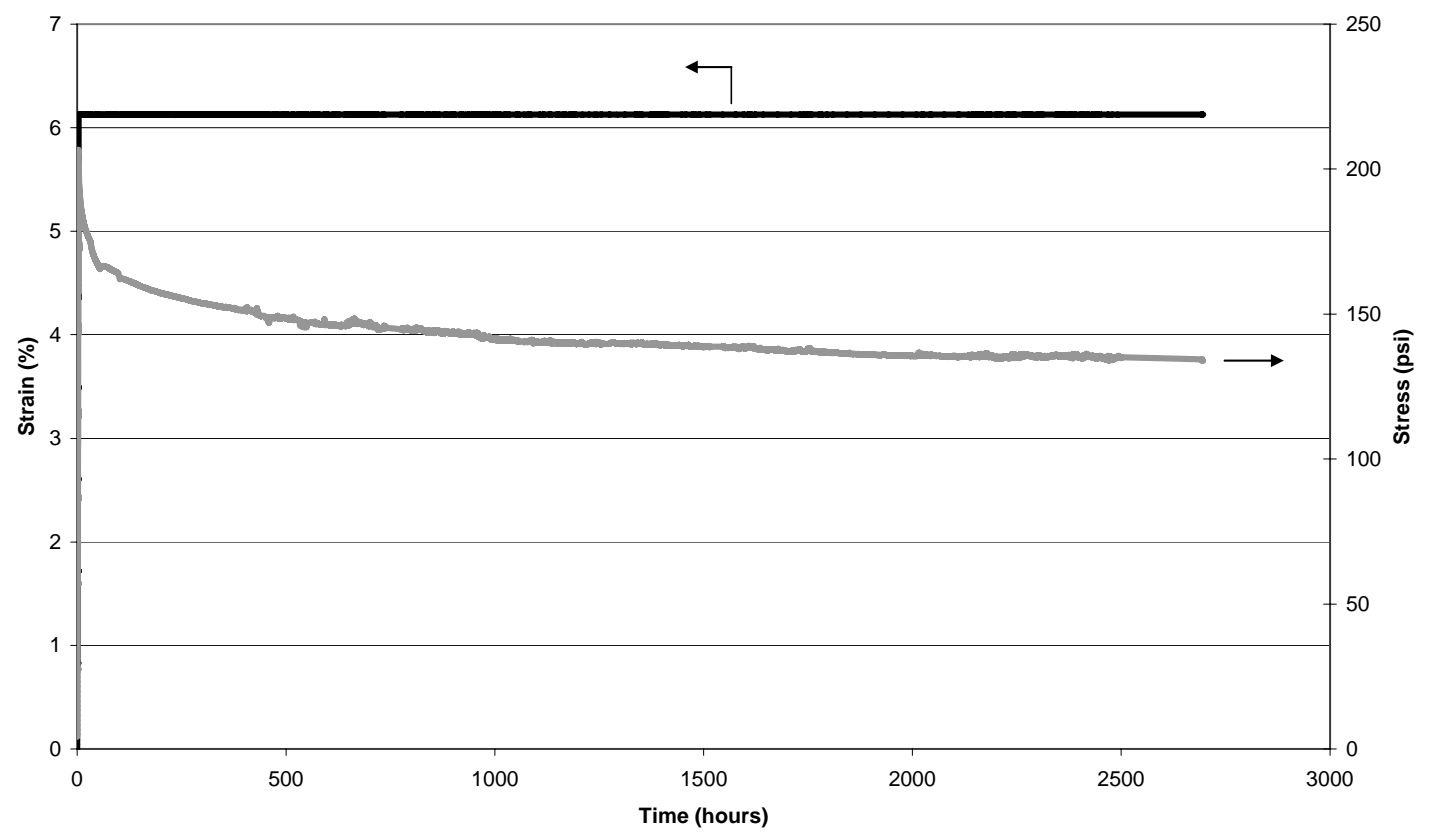

Figure 9. Results from Current $700 / 100^{\circ} \mathrm{C}$ Gradient Stress Relaxation Test (Test \#15) 
Gradient testing was initially scheduled to be completed by the end of June 2006, but due to delays in the initiation of testing, efforts will be continued to obtain long-term stress relaxation behavior in excess of six month duration for all current tests. Testing may then be extended for up to one year duration.

Gradient stress relaxation data was fit to a $\log -\log$ curve and to previous predictions made using isothermal stress relaxation data. Data was also fit to the previously derive ORNL mathematical model, a Maxwell model, and a KWW model. These fits were updated weekly as new data became available to evaluate convergence of each model. Examples for Gradient Stress Relaxation Tests \#10 and \#11 are shown in Figure 10.
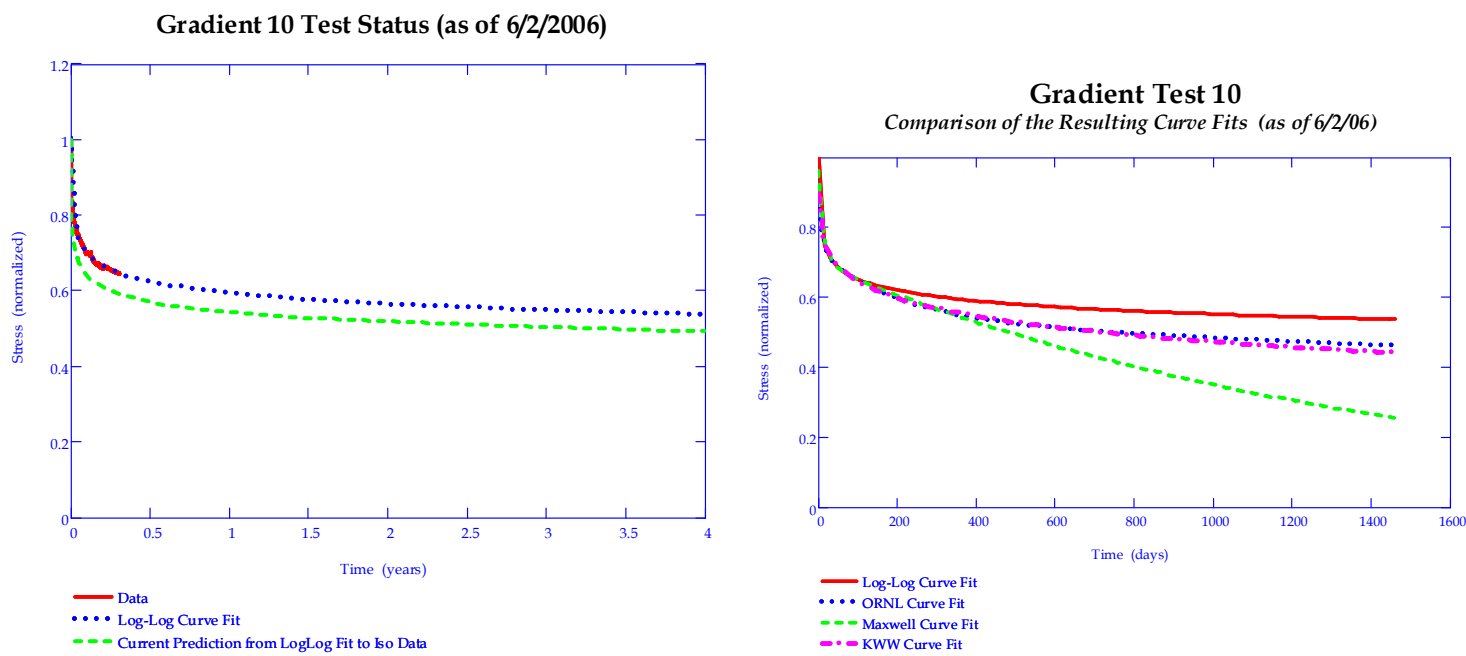

+.+ Log-Log Curve Fit
- - - Current Prediction from LogLog Fit to kso Da

Gradient 11 Test Status (as of 6/2/2006)
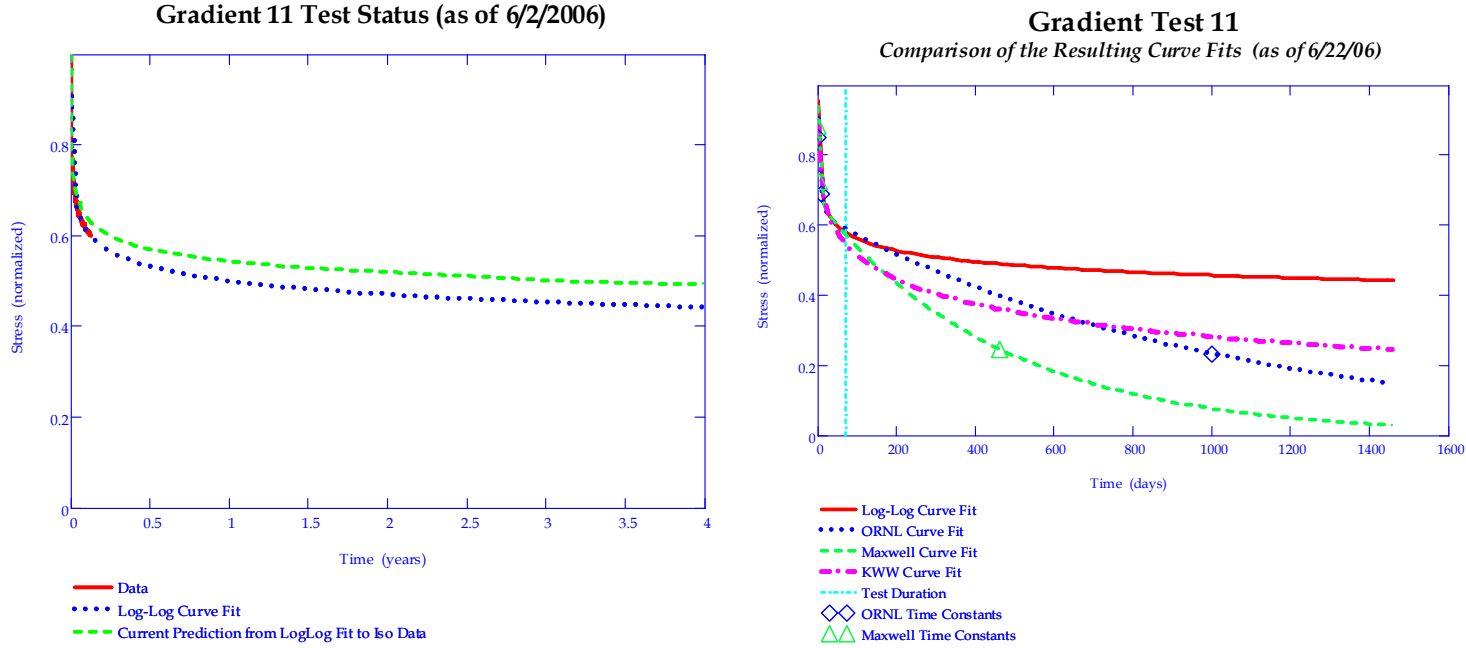

Figure 10. Examples of Curve Fit Convergence for Gradient Stress Relaxation Tests \#10 and \#11. 


\subsubsection{Appendix}

Table A1. Min-K Sample Densities w/ Respect to Batch Designations and Test Numbers

\begin{tabular}{|c|c|c|}
\hline Test & Batch & Density (g/in. $\left.{ }^{3}\right)$ \\
\hline \multicolumn{3}{|l|}{ Isothermal } \\
\hline Test \#1 & Batch \#1 & 5.42 \\
\hline Test \#2 & Batch \#1 & 5.06 \\
\hline Test \#3 & Batch \#1 & 5.29 \\
\hline Test \#4 & Batch \#1 & 5.46 \\
\hline Test \#5 & Batch \#1 & 5.36 \\
\hline Test \#6 & Batch \#1 & 5.23 \\
\hline Test \#7 & Batch \#1 & 5.14 \\
\hline Test \#8 & Batch \#1 & 5.14 \\
\hline Test \#9 & Batch \#1 & 5.19 \\
\hline Test \#10 & Batch \#1 & 5.21 \\
\hline Test \#11 & Batch \#1 & 5.19 \\
\hline Test \#12 & Batch \#1 & 5.09 \\
\hline Test \#13 & Batch \#1 & 5.23 \\
\hline Test \#14 & Batch \#1 & 5.31 \\
\hline Test \#15 & Batch \#1 & 5.31 \\
\hline Test \#16 & Batch \#1 & 5.45 \\
\hline Test \#17 & Batch \#1 & 5.42 \\
\hline Test \#18 & Batch \#2 & 5.20 \\
\hline Test \#19 & Batch \#1 & 5.19 \\
\hline Test \#20 & Batch \#2 & 5.24 \\
\hline \multicolumn{3}{|l|}{ Gradient } \\
\hline Test \#2 & Batch \#1 & - \\
\hline Test \#3 & Batch \#1 & 5.12 \\
\hline Test \#4 & Batch \#1 & 4.98 \\
\hline Test \#6 & Batch \#1 & 5.01 \\
\hline Test \#7 & Batch \#2 & 5.45 \\
\hline Test \#8 & Batch \#2 & 5.45 \\
\hline Test \#9 & Batch \#2 & 5.36 \\
\hline Test \#10 & Batch \#3 & 5.46 \\
\hline Test \#11 & Batch \#4 & 5.34 \\
\hline Test \#13 & Batch \#4 & 5.21 \\
\hline Test \#15 & Batch \#3 & 5.37 \\
\hline
\end{tabular}

